\author{
UNIVERSIDADE DE SÃO PAULO \\ ESCOLA DE ENFERMAGEM DE RIBEIRÃO PRETO
}

FERNANDA MARIA VIEIRA PEREIRA

Adaptação cultural e validação da Compliance with Standard Precautions Scale (CSPS) para enfermeiros brasileiros

Ribeirão Preto

2015 


\section{Adaptação cultural e validação da Compliance with Standard Precautions Scale (CSPS) para enfermeiros brasileiros}

Tese apresentada ao Programa Interunidades de Doutoramento em Enfermagem da Escola de Enfermagem da Universidade de São Paulo e Escola de Enfermagem de Ribeirão Preto da Universidade de São Paulo para obtenção do título de Doutor em Ciências.

Linha de pesquisa: Prática Social e Profissional em Saúde

Orientador: Elucir Gir

Ribeirão Preto

2015 
Autorizo a reprodução e divulgação total e parcial deste trabalho, por qualquer meio convencional ou eletrônico, para fins de pesquisa desde que citada a fonte.

Pereira, Fernanda Maria Vieira

Adaptação cultural e validação da Compliance with Standard Precautions Scale (CSPS) para enfermeiros brasileiros. Ribeirão Preto, 2015.

144 p.: il.; $30 \mathrm{~cm}$

Tese de Doutorado apresentada à Escola de Enfermagem de Ribeirão Preto/USP.

Orientadora: Gir, Elucir.

1. Precauções-Padrão. 2. Estudo de validação.

3. Enfermagem. 
PEREIRA, Fernanda Maria Vieira

Adaptação cultural e validação da Compliance with Standard Precautions Scale (CSPS) para enfermeiros brasileiros

Tese apresentada ao Programa Interunidades de Doutoramento em Enfermagem da Escola de Enfermagem da Universidade de São Paulo e Escola de Enfermagem de Ribeirão Preto da Universidade de São Paulo para obtenção do título de Doutor em Ciências.

Aprovado em:

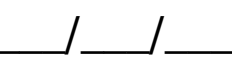

\section{Comissão Julgadora}

Prof. Dr.

Instituição: Assinatura:

Prof. Dr.

Instituição: Assinatura:

Prof. Dr.

Instituição:

Assinatura:

Prof. Dr.

Instituição:

Assinatura:

Prof. Dr.

Instituição:

Assinatura: 


\section{DEDICATÓRIA}

Dedico este trabalho ao meu pai e a minha mãe que destinaram suas vidas para a educação de suas filhas. Às minhas irmãs, pelo companheirismo e amizade. Ao Rafael, pelo apoio incondicional e por estar ao meu lado durante todos os momentos deste percurso. Ao meu tio Luís, pelo incentivo e pelo orgulho que tinha de mim. 


\section{AGRADECIMENTOS ESPECIAIS}

A Deus, pelo dom da vida. Por me conceder viver uma vida repleta de realizações e ao lado de pessoas especiais. Por estar ao meu lado em todos os momentos e por me amparar nas horas mais difíceis desta caminhada.

Aos meus pais, pois, sem eles, nada seria possível. Por terem me ensinado que a educação constitui o maior bem que se pode ter. Por terem me concedido a oportunidade de estudar e de realizar este ideal. Por abdicarem de suas próprias realizações para que eu pudesse idealizar as minhas. Por me ensinarem a ter fé e a acreditar em meus objetivos. Meu alicerce. Exemplos incondicionais. Amo vocês mais do que podem imaginar.

Às minhas irmãs, grandes exemplos de profissionais. Tassi, pela sensatez nos momentos mais difíceis; Taísa, por ajudar, acreditar e incentivar desde o início desta jornada. Dani, pelo espelho de garra e de determinação. Nath, pelo incentivo constante. Todas foram fundamentais para a construção deste trabalho. Não teria conseguido sem o apoio de vocês.

Ao Rafael, nem tenho palavras para agradecer. Paciência, abdicação, amor e cuidado resumem todo o meu agradecimento neste momento. Uma espera tão difícil e demorada que parecia não ter fim. Agradeço, meu amor, por estar comigo sempre, independentemente da distância e das dificuldades. Por acreditar no meu potencial a cada conquista. Por partilhar e por vibrar comigo a cada realização alcançada. Por ter paciência nos momentos de ausência e pelo carinho sem limites. Amo você!

À Professora Doutora Elucir Gir, pelo apoio incondicional. Seria difícil dimensionar a proporção de sua contribuição ao longo deste trabalho. Por me fazer compreender a importância da realização de uma pesquisa e por mostrar o quanto é indispensável a busca por conhecimentos. Agradeço por toda a confiança em mim depositada. Por me proporcionar viver por um período ao lado de uma pessoa tão especial, sua mãe. Por 
ter se tornado mais que uma orientadora, e, sim, uma grande amiga.

Ao meu tio Luiz, por ter acreditado na concretização deste ideal. Acredito que, de onde quer que esteja, estará orgulhoso de mim, como dizia sempre. Saudades eternas.

Aos meus cunhados, pelo incentivo e apoio.

Aos meus sobrinhos, Isabela, Ana Beatriz, João Pedro, Gabriel e Gabriela, por transmitirem imensas alegrias durante os momentos em que estivemos juntos.

Aos meus sogros por estarem sempre torcendo por mim.

Ao professor Simon Ching Lam, por ter me concedido permissão para a adaptação do instrumento de pesquisa e por todo o apoio durante a realização do estágio sanduíche na The Open University of Hong Kong, China.

À minha amiga Fernanda Souza e Silva, por ter sido uma luz no meu caminho nos momentos mais decisivos. Por todo o conhecimento partilhado e pela paciência em me ensinar.

À minha amiga Edilaine Assunção Caetano de Loyola, por ter me escutado em todos os momentos difíceis. Por ter sido minha grande companheira e por todas as palavras de incentivo e de apoio.

À minha amiga Lilian Andrea Fleck Reinato, por ter caminhado junto comigo rumo a esta realização. Por ter se tornado uma grande amiga. Por ter sempre uma palavra de descontração mesmo nos momentos mais complexos.

À minha amiga Maria Cristina Mendes de Almeida, por ter me auxiliado neste trabalho, sobretudo, pela ajuda na coleta de dados. 
À Fundação de Apoio à Pesquisa do Estado de São Paulo - FAPESP, pelo apoio financeiro destinado a esse projeto (Processo Fapesp 2012/12341/4) e ao estágio sanduíche (Processo Fapesp 2014/15695/7) vinculado a este trabalho. 


\section{AGRADECIMENTOS}

Ao Professor Doutor Luiz Pasquali, pelo auxílio no referencial teórico e na análise dos dados.

À Professora Doutora Rosana Aparecida Spadoti Dantas, por ter auxiliado nas questões metodológicas deste trabalho.

À Professora Doutora Silmara Elaine Malaguti-Toffano e a Professora Doutora Silvia Marin da Silva Canini, pelo incentivo e pela amizade.

À Professora Doutora Renata Karina Reis e a enfermeira Letícia Lopes Pimenta, por ter colaborado em uma das etapas desta pesquisa.

À Professora Jackie Hoi Man Chan, pelo apoio e amizade durante o estágio sanduíche realizado na Universidade de Hong Kong, China.

Às colegas do NAIDST, pela oportunidade de partilhar conhecimentos e experiências, especialmente à colega Carolina Castrighini, pela amizade.

Ao Jonas Bodini Alonso, pela ajuda na análise estatística dos dados.

Ao Programa Interunidades de Doutoramento de Enfermagem, em especial à secretaria Flávia pelo auxílio e pela presteza em resposta às solicitações.

À enfermeira Aparecida Helena Vicentin, por ter colaborado com a coleta de dados junto ao Setor de Educação Continuada Do Hospital do Servidor Público Estadual (HSPE), São Paulo.

Ao Enfermeiro Cláudio Luiz da Silveira, por ter autorizado a realização deste trabalho como coordenador da Divisão de Enfermagem do Hospital do Servidor Público Estadual (HSPE), São Paulo. 
À enfermeira Maraísa Souza Palatin Ciocca, pelo auxílio na coleta de dados no Hospital do Servidor Público Estadual (HSPE), São Paulo.

Aos enfermeiros do Hospital do Servidor Público Estadual (HSPE), por terem aceitado participar desta pesquisa.

A todos que, de alguma forma, me ajudaram e estiveram presentes nesta caminhada.

A todas as pessoas que, mesmo não citadas nominalmente, contribuíram para a conclusão deste trabalho.

Aos demais...

O meu muito obrigada! 
"Deus dá as batalhas mais difíceis aos seus melhores soldados." Papa Francisco 


\section{RESUMO}

PEREIRA, F.M.V. Adaptação Cultural e Validação da Compliance with Standard Precautions Scale (CSPS) para enfermeiros brasileiros. 2015. $144 \mathrm{f}$. Tese (Doutorado) - Escola de Enfermagem de Ribeirão Preto, Universidade de São Paulo, Ribeirão Preto, 2015.

Introdução: As precauções-padrão (PP) constituem um conjunto de medidas que têm como finalidade minimizar o risco de transmissão ocupacional de patógenos, sendo indispensável sua utilização por profissionais de saúde, sobretudo pelos enfermeiros. No entanto, a não adesão às PP constitui problemática amplamente discutida em todo o mundo. Embora haja diversos estudos brasileiros que visem avaliar a adesão às PP, ainda tem-se observado grande fragilidade no processo de construção e de validação dos instrumentos utilizados para avaliação deste construto. Objetivo: Realizar a adaptação cultural e validação da Compliance with Standard Precautions Scale (CSPS) para enfermeiros brasileiros. Metodologia: Trata-se de um estudo metodológico para a adaptação e validação da CSPS. Essa escala é composta por 20 itens com quatro opções de respostas, e destina-se a avaliar a adesão às PP. O processo de adaptação consistiu em Tradução, Consenso entre Juízes, Retrotradução e Validação Semântica. A primeira etapa foi a tradução do idioma original para o português do Brasil. Após foi realizado um comitê composto por sete juízes, a versão de consenso obtida na etapa anterior foi traduzida novamente para o idioma de origem. Foram avaliadas as propriedades psicométricas do instrumento, considerando-se as validades de face e de conteúdo, a validade de construto e a confiabilidade. A versão para o Português do Brasil da CSPS (CSPS-PB) foi aplicada em uma amostra de 300 enfermeiros que atuam na assistência a pacientes em um hospital localizado na cidade de São Paulo/SP. A confiabilidade foi avaliada por meio da consistência interna (alfa de Cronbach) e teste reteste (coeficiente de correlação intraclasse - ICC). Para a validação de construto, foi utilizada a comparação entre grupos diferentes, análise fatorial exploratória e análise fatorial confirmatória, segundo o Modelo de Equações Estruturais (SEM). Utilizou-se o software IBM ${ }^{\circledR}$ SPSS, 19.0. Para a análise fatorial confirmatória foi utilizado o módulo específico Analysis of Moment Structures (IBM ${ }^{\circledR}$ SPSS AMOS). Para a análise paralela utilizou-se o programa RanEigen Syntax. O nível de significância adotado foi $a=0,05$. Todos os aspectos éticos foram contemplados. Resultados: A tradução realizada por tradutores juramentados garantiu qualidade a esse processo. A validação de face e de conteúdo possibilitou a realização de modificações pertinentes e imperativas a fim de atender aos critérios de equivalências conceituais, idiomáticas, culturais e semânticas. Obteve-se $a=0,61$ na avaliação da consistência interna, indicando confiabilidade satisfatória. O ICC indicou uma correlação de 0,87 quase perfeita para o teste reteste duas semanas após a primeira abordagem, conferindo estabilidade satisfatória. A validade de construto mostrou que a CSPS-PB foi capaz de discriminar as médias de adesão às PP entre grupos distintos referente à idade $(F=5,15 p \leq 0,01)$, ao tempo de experiência clínica $(F=8,9 p \leq 0,000)$ e a ter recebido treinamento $(t=2,48 p \leq 0,01)$. Na análise fatorial confirmatória, 0 modelo foi subidentificado. A análise fatorial exploratória indicou que todos os itens 
apresentaram cargas fatoriais adequadas $(\geq 0,30)$, sendo identificados quatro fatores pela análise paralela. O total de variância explicada foi de $35,48 \%$. Conclusão: A CSPS-PB, trata-se de um instrumento adequado, confiável e válido para medir a adesão às PP entre enfermeiros brasileiros.

Palavras-chave: Precauções-Padrão, Estudo de Validação, Enfermeiros. 


\begin{abstract}
PEREIRA, F.M.V. Cultural Adaptation and Validation of the Compliance with Standard Precautions Scale (CSPS) for Brazilian nurses. 2015. 144p. Dissertation (Ph.D.) - Ribeirao Preto College of Nursing, University of São Paulo, Ribeirão Preto, 2015.
\end{abstract}

Introduction: Standard precautions (SP) are a set of measures that aim to minimize the risk of occupational transmission of pathogens, being essential their use by health professionals, especially nurses. However, the non-adhesion to SP is a widely discussed problem. Although there are several Brazilian studies aimed at evaluating adhesion to $\mathrm{SP}$, a great weakness in the construction and validation process of the instruments used to assess this construct was observed. Objective: To conduct the cultural adaptation and validation of the Compliance with Standard Precautions Scale (CSPS) for Brazilian nurses. Methodology: This is a methodological study to adapt and validate the CSPS. This scale consists of 20 items with four response options to evaluate adhesion to standard precautions. The adaptation process consisted of Translation, Consensus among Judges, Back-translation and Semantic Validation. The first step was the translation of the original language to Brazilian Portuguese. After that, a committee composed of seven judges analyzed the translation; the consensus version obtained in the previous step was translated back into the original language. The psychometric properties of the instrument were evaluated considering the validity of face and content, construct validity and reliability. The version for Brazilian Portuguese of CSPS (CSPS-PB) was applied to a sample of 300 nurses who work in the care of patients in a hospital located in city of São Paulo. Reliability was evaluated by internal consistency (Cronbach's alpha) and test retest (intraclass correlation coefficient-ICC). For construct validation, it was used comparisons among different groups, exploratory factor analysis and confirmatory factor analysis, according to the Structural Equation Model (SEM). IBM $®$ SPSS 19.0 was used. For the confirmatory factor analysis, it was used the

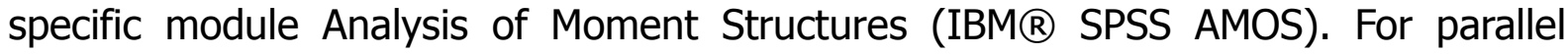
analysis, it was used the RanEigen Syntax program. The significance level was $a=0.05$. All ethical aspects were included. Results: The translation conducted by sworn translators assured quality to this process. Validation of face and content made possible the performance of relevant and imperative modifications in order to meet the criteria of conceptual, idiomatic, cultural and semantic equivalence. The evaluation of internal consistency obtained $a=0.61$, indicating satisfactory reliability. The ICC indicated a near-perfect correlation of 0.87 for the test-retest two weeks after the first approach, giving satisfactory stability. Construct validity showed that the CSPS-PB was able to discriminate the average of adhesion to PP among different groups related to age $(F=5.15 p \leq 0.01)$, to the time of clinical experience $(F=8.9 p \leq 0.000)$ and to have received training $(t=2.48 \mathrm{p} \leq 0.01)$. In confirmatory factor analysis, the model was under identified. Exploratory factor analysis indicated that all items had adequate factor loadings $(\geq 0.30)$, being identified four factors by parallel analysis. The total variance explained was $35.48 \%$. Conclusion: CSPS-PB is an appropriate instrument, reliable and valid to measure adhesion to PP among Brazilian nurses.

Keywords: Standard Precautions, Validation Studies, Nurse. 


\section{RESUMEN}

\section{PEREIRA, F.M.V. Adaptación cultural y validación de la Compliance with}

Standard Precautions Scale (CSPS) para los enfermeros brasileños. 2015. 144h. Tesis (Doctorado) - Escuela de Enfermería de Ribeirão Preto de la Universidad de São Paulo, Ribeirão Preto, 2015.

Introducción: Las precauciones estándar (PE) son un conjunto de medidas que tienen por objeto minimizar el riesgo de transmisión ocupacional de patógenos, siendo indispensable su uso por profesionales de salud, especialmente enfermeros. Sin embargo, el incumplimiento de las PE es ampliamente discutido mundialmente. Aunque existen varios estudios brasileños destinados a evaluar el cumplimiento de las $\mathrm{PE}$, se observó una gran debilidad en la construcción y validación de instrumentos utilizados para evaluar este construto. Objetivo: Realizar la adaptación cultural y validación de la Compliance with Standard Precautions Scale (CSPS) para los enfermeros brasileños. Metodología: Estudio metodológico para adaptación y validación de la CSPS. Esta escala consta de 20 ítems con cuatro opciones de respuestas para evaluar el cumplimiento de las PE. El proceso de adaptación consistió en Traducción, Consenso entre los Jueces, Back-traducción y Validación Semántica. El primer paso fue la traducción de la lengua original para el portugués de Brasil. Después se realizó un comité compuesto por siete jueces; la versión de consenso obtenida en la etapa anterior se tradujo nuevamente para el idioma de origen. Las propiedades psicométricas del instrumento fueron evaluadas teniendo en cuenta la validez de apariencia y de contenido, validez de construto y confiabilidad. Se aplicó la versión para el portugués de Brasil de la CSPS (CSPS-PB) a una muestra de 300 enfermeros que trabajan en el cuidado a los pacientes en un hospital ubicado en la ciudad de São Paulo/SP. La confiabilidad se evaluó por medio de consistencia interna (alfa de Cronbach) y test-retest (coeficiente de correlación intraclase-ICC). Para la validación de construto se utilizó la comparación entre diferentes grupos, análisis factorial exploratorio y análisis factorial confirmatorio, de acuerdo con el Modelo de Ecuaciones Estructurales (SEM). Se utilizó el software IBM® SPSS, 19.0. Para el análisis factorial confirmatorio se utilizó el módulo específico Analysis of Moment Structures (IBM®) SPSS AMOS). Para el análisis paralelo se utilizó el programa RanEigen Syntax. El nivel de significación fue $a=0,05$. Los aspectos éticos fueron incluidos. Resultados: La traducción realizada por traductores jurados aseguró la calidad de este proceso. La validación de cara y contenido hizo posible cambios pertinentes e imperativos a fin de cumplir los criterios de equivalencia conceptual, idiomática, cultural y semántica. Se obtuve $a=0,61$ en la evaluación de la consistencia interna, lo que indica confiabilidad satisfactoria. El ICC indicó una correlación casi perfecta de 0.87 para el test-retest dos semanas después de la primera aproximación, dando una estabilidad satisfactoria. La validez de construto mostró que el CSPS-PB fue capaz de discriminar los promedios de cumplimiento de las $P E$ entre los diferentes grupos referentes a edad $(F=5.15 p \leq 0,01)$, tiempo de experiencia clínica $(F=8,9 p \leq 0,000)$ y haber recibido entrenamiento $(t=2,48$ $\mathrm{p} \leq 0,01)$. En el análisis factorial confirmatorio, el modelo fue subidentificado. El análisis factorial exploratorio indicó que todos los ítems tenían cargas factoriales adecuadas $(\geq 0,30)$, siendo identificados cuatro factores para el análisis paralelo. El total de la varianza explicada fue $35,48 \%$. Conclusión: CSPS-PB es un instrumento adecuado, 
confiable y válido para medir el cumplimiento de las PE entre enfermeros brasileños. Descriptores: Precauciones-Padrón, Estudio de validación, Enfermería. 


\section{LISTA DE TABELAS}

Tabela 1 - Caracterização profissional e demográfica dos enfermeiros $(n=12)$ da fase de validação semântica da CSPS-PB. São PauloSP, 2013

Tabela 2 - Distribuição das respostas dos enfermeiros $(n=50)$ atribuídas na fase de pré-teste da CSPS-PB. São Paulo-SP, 2014.

Tabela 3 - $\quad$ Características demográficas e profissionais dos enfermeiros $(n=300)$. São Paulo-SP, 2014.

Tabela 4 - $\quad$ Frequência das respostas dos enfermeiros $(n=300)$ atribuídas aos itens segundo domínios da CSPS-PB. São Paulo-SP, 2014

Tabela 5 - $\quad$ Adesão e não adesão dos enfermeiros $(n=300)$ referente aos itens da CSPS-PB, segundo respostas agrupadas por domínios. São Paulo-SP, 2014.

Tabela 6 - Coeficiente de correlação item-total e Alfa de Cronbach $(n=300)$ da CSPS-PB. São Paulo-SP, 2014

Tabela 7 - Coeficiente de correlação de Pearson entre os domínios da CSPS-PB com o escore geral do instrumento. São Paulo-SP, 2014

Tabela 8 - $\quad$ Distribuição dos escores médios de adesão às PP, segundo grupos diferentes. São Paulo-SP, 2014.

Tabela 9 - $\quad$ Medidas de ajustes da análise fatorial confirmatória (20 itens) da CSPS-PB

Tabela 10 - Componente correlação matriz, autovalores empíricos e aleatórios da CSPS-PB

Tabela 11 - Correlação entre os fatores da CSPS-PB por rotação oblíqua.....

Tabela 12 - Matriz de rotação varimax dos fatores, da CSPS-PB.................. 85

Tabela 13 - Matriz de rotação varimax final dos fatores, da CSPS-PB........... 86

Tabela 14 - Distribuição final dos itens da CSPS-PB, segundo análise fatorial. 


\section{LISTA DE FIGURAS}

Figura 1 - Processo de Adaptação Cultural da Compliance with Standard Precautions Scale (CSPS)............................................. 47

Figura 2 - Gráfico do escore geral da CSPS-PB............................... 72

Figura 3 - Gráfico do escore de adesão às PP segundo idade (anos)..... 77

Figura 4 - Gráfico do escore de adesão às PP para ter recebido ou não treinamento............................................................ 78

Figura 5 - $\quad$ Modelo hipotético da CSPS-PB testado na análise fatorial confirmatória.............................................................. 79

Figura 6 - $\quad$ Análise fatorial confirmatória da CSPS-PB (16 itens).............. 81

Figura 7 - $\quad$ Scree Plot com os autovalores e número de fatores da matriz da CSPS-PB ............................................................... 82 


\section{LISTA DE QUADROS}

Quadro 1 - Modificações nos itens da CSPS-PB propostas pelos juízes.

Ribeirão Preto-SP, 2013............................................... 59 


\section{LISTA DE ABREVIATURAS E SIGLAS}

ANVISA Agencia Nacional de Vigilância Sanitária

CDC Centers for Disease Control and Prevention

CFI Índice de ajuste comparativo

CSPS Compliance with Standard Precautions Scale

CSPS-PB Versão para o Português do Brasil da CSPS

EUA Estados Unidos da América

EPI Equipamento de Proteção Individual

HIV Vírus da Imunodeficiência Humana

HM Higienização das mãos

ICC Coeficiente de Correlação Intraclasse

MS Ministério da Saúde

MTE Ministério do Trabalho e Emprego

NFI Índice de ajuste normalizado

NR32 Norma Regulamentadora 32

OMS Organização Mundial da Saúde

OPAS Organização Pan-Americana da Saúde

PP Precauções-Padrão

PU Precauções Universais

RMSEA Índice de ajuste parcimonioso

SPSS Social Package for the Social Sciences

VHB Vírus da Hepatite $B$

VHC Vírus da Hepatite C 


\section{SUMÁRIO}

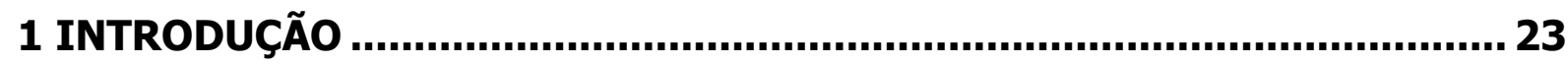

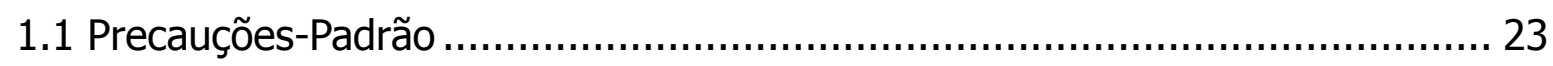

1.2 Instrumentos utilizados para avaliar a adesão às precauções-padrão ............ 28

2 REFERENCIAL TEÓRICO .................................................................... 33

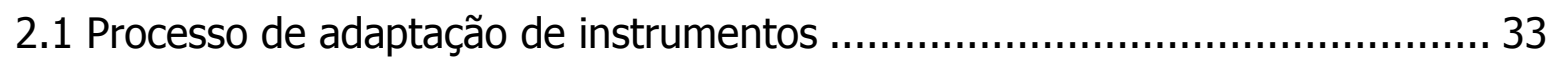

2.2 Avaliação das propriedades psicométricas de instrumentos ......................... 36

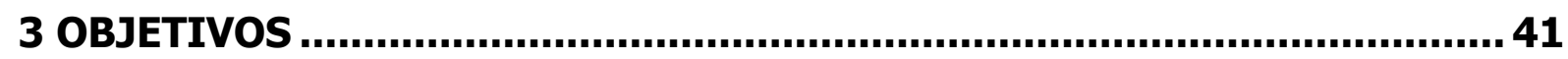

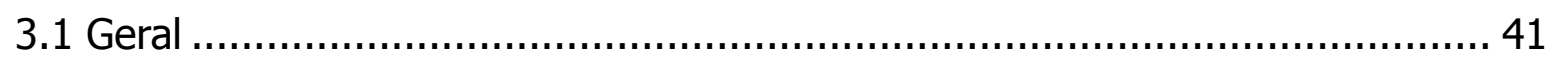

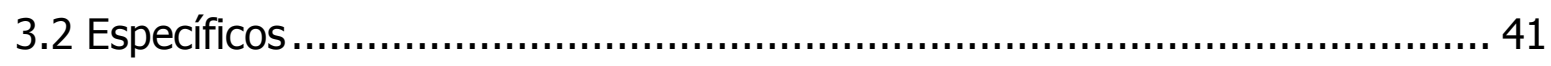

4 MÉTODOS ............................................................................................ 43

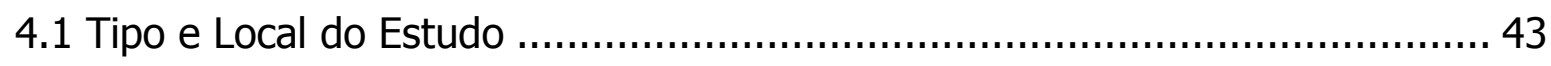

4.2 Compliance with Standard Precautions Scale (CSPS) ................................... 44

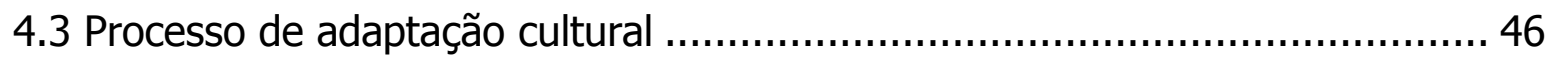

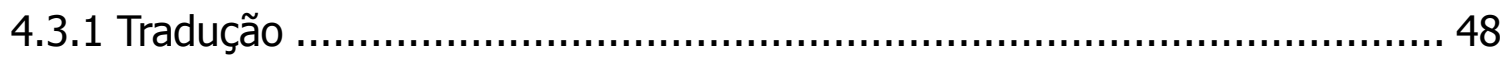

4.3.2 Consenso da versão em português .................................................... 48

4.3.3 Avaliação por Comitê de Juízes ......................................................... 48

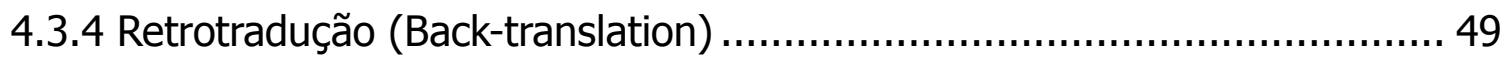

4.3.5 Consenso da versão em português e comparação com a original............ 49

4.3.6 Avaliação Semântica dos itens............................................................ 49

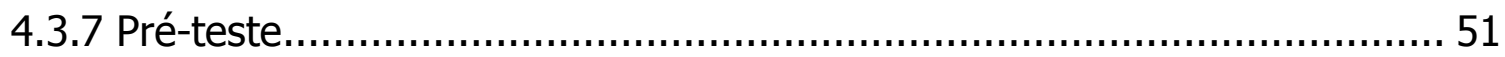

4.4 Avaliação das propriedades psicométricas do instrumento.......................... 51

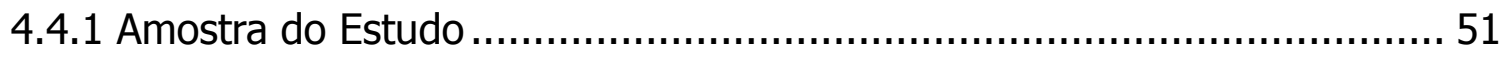

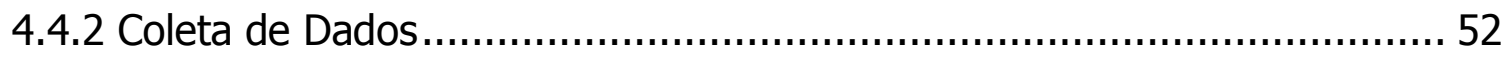

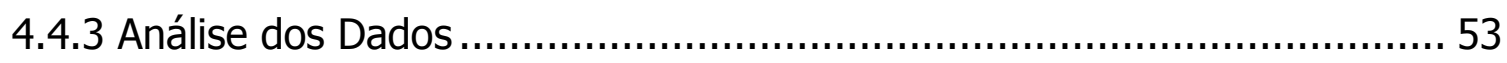

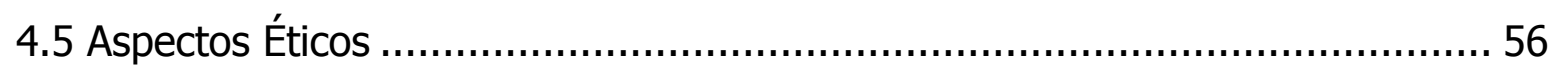

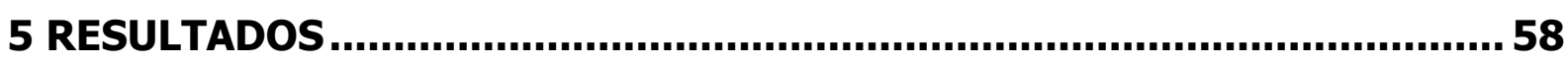

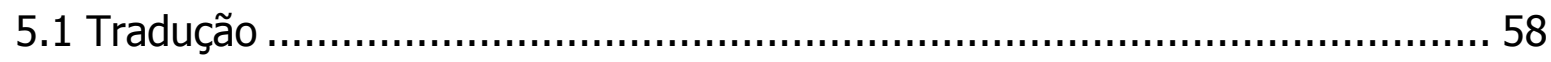

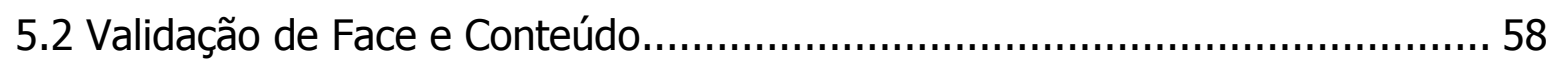

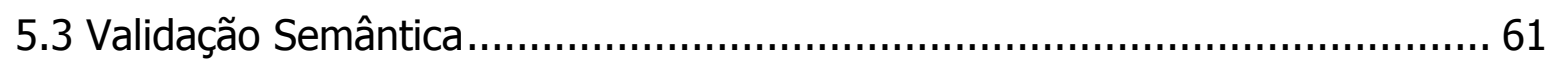

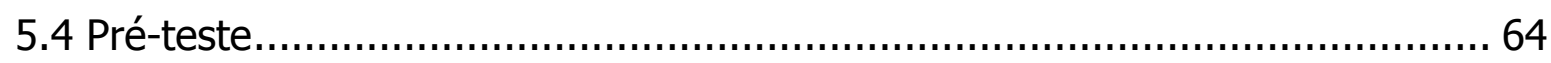

5.5 Avaliação das Propriedades Psicométricas da CSPS-PB ............................... 65

5.5.1 Caracterização demográfica e profissional da amostra ............................. 65

5.5.2 Análise das respostas da CSPS-PB segundo domínios ............................66 
5.5.3 Descrição dos escores da CSPS-PB .................................................. 71

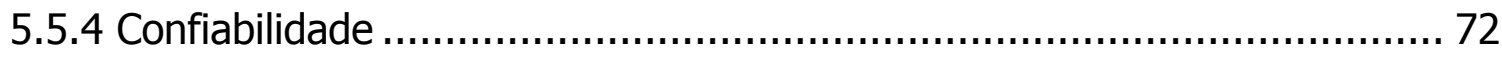

5.5.5 Análise de construto da CSPS-PB.................................................. 74

5.5.5.1 Comparação entre grupos distintos............................................... 74

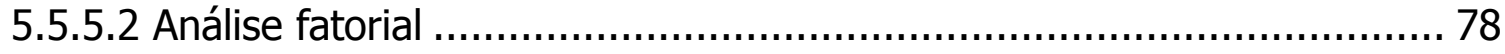

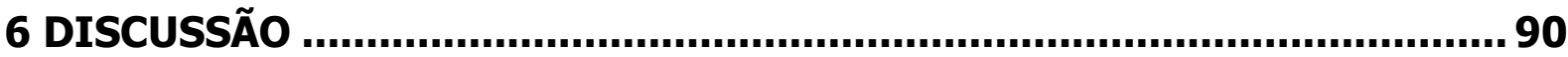

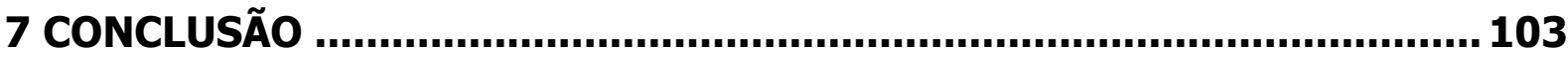

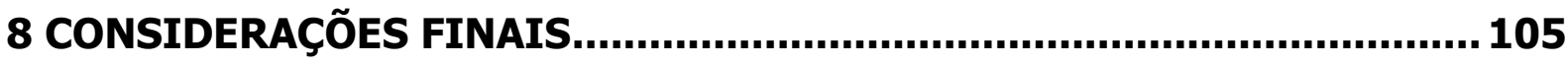

REFERÊNCIAS.................................................................................... 108

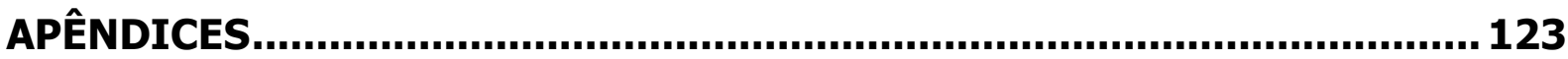

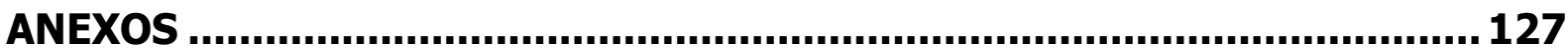




\section{INTRODUÇÃO}

\subsection{Precauções-Padrão}

A preocupação mundial com os riscos biológicos acentuou-se a partir da epidemia do vírus da imunodeficiência humana (HIV)/aids nos anos 1980, com a introdução de novas estratégias e normas estabelecidas para as questões de segurança no ambiente de trabalho (GARNER, 1996). Contudo, no Brasil, no final da década de 1970, já havia a preocupação em garantir a segurança dos trabalhadores com a criação de diretrizes (BRASIL,1978).

Todos os profissionais de saúde, ao prestar assistência a qualquer paciente, devem aderir a medidas preventivas, a fim de diminuir o risco de exposição ocupacional e garantir também a segurança do paciente (GARNER, 1996; SIEGEL et al., 2007).

Em 1987, nos Estados Unidos da América (EUA), foram criadas recomendações denominadas Precauções Universais (PU), pelo Centers for Diseases Control and Prevention $(C D C)$, o que resultou na publicação de um manual com a finalidade de minimizar o risco de transmissão do HIV e do vírus da hepatite B (VHB), entre os profissionais da área da saúde (CDC, 1987).

Em 1996, tais recomendações foram revisadas e passaram a ser chamadas de Precauções-Padrão (PP). Desse modo, as recomendações contidas nas PU permaneceram, ficando apenas o suor, como fluído desconsiderado de proteção de barreira. $O$ reencape de agulhas com apenas uma das mãos foi introduzido como medida segura de utilização (GARNER, 1996).

No Brasil, a Norma Regulamentadora 32 (NR32) foi criada a fim de estabelecer diretrizes básicas para proteção e para a segurança dos profissionais que atuam nos serviços de saúde, incluindo a utilização de medidas preventivas, como a adesão a equipamentos de proteção individual (EPI), a higienização das mãos e o cuidado no manuseio e no descarte de materiais perfurocortantes (BRASIL, 2005).

Em 2007, as PP foram novamente revisadas com o intuito de reforçar as recomendações para o controle de infecção, tendo como foco a segurança do paciente. 
Assim, as medidas preventivas devem orientar-se em função da ação a ser desenvolvida, considerando seu potencial para exposição a sangue e a fluidos orgânicos (SIEGEL et al., 2007).

As PP incluem a higienização das mãos, o uso de luvas, de óculos de proteção, de máscaras e de capotes no manuseio de equipamentos e de artigos contaminados ou sob suspeita de contaminação, nas situações em que houver riscos de contatos com sangue, com líquidos corpóreos, com secreções e com excreções, exceto com o suor, sem considerar ou não a presença de sangue visível e de pele com solução de continuidade e de mucosas. Além dessas medidas, recomenda-se que o material perfurocortante seja descartado em recipientes rígidos e que o ambiente em que o paciente se encontra deva estar livre de contaminação, bem como os materiais utilizados (GARNER, 1996; SIEGEL et al., 2007).

As PP também se destinam a proteger os pacientes, assegurando que os profissionais de saúde não sejam capazes de transmitir agentes infecciosos por meio de suas mãos ou de equipamentos utilizados na assistência a pacientes (SIEGEL et al., 2007).

Com isso, a utilização de medidas preventivas que visem à segurança do profissional e também do paciente constitui elemento imprescindível na assistência em saúde. Considerando-se que as PP consistem em um conjunto de medidas que têm como finalidade minimizar o risco de transmissão ocupacional a agentes biológicos, faz-se necessário que os profissionais, sobretudo, os da enfermagem, o utilizem em sua prática clínica diária.

A adesão às PP constitui problemática amplamente discutida em todo o mundo, de modo mais particular entre os profissionais que atuam na assistência direta ao paciente.

A equipe de enfermagem está sujeita à exposição a material biológico. 0 número elevado de exposições relaciona-se, sobretudo, ao tipo e à frequência de procedimentos realizados e ao fato de que esses profissionais têm contato direto com os pacientes (WARLEY et al., 2009). Embora seja imprescindível a adesão às PP pelos profissionais de enfermagem, ainda há resistência quanto a sua utilização (MALAGUTI et al., 2008; PEREIRA et al., 2015).

Dentre as precauções adotadas por profissionais da saúde, a higienização das 
mãos (HM) constitui ação indispensável para a proteção do profissional e do paciente. Contudo, estudos têm encontrado baixa adesão a essa medida (ERASMUS et al., 2010; LIU et al., 2014b; NADERI et al., 2012; PRIMO et al., 2010; REZENDE, et al., 2012).

A preocupação com a HM tem sido frequentemente reportada em nível mundial, sobretudo pela Organização Mundial da Saúde (OMS), com o objetivo de melhorar a adesão a esta prática e minimizar a transmissão de microorganismos entre os profissionais de saúde e pacientes (OMS, 2004; OMS; 2009).

O Desafio Global Mundial para a Segurança do Paciente, com enfoque em uma assistência limpa e segura para a prevenção de infecções relacionadas à assistência em saúde, destaca a HM como o principal componente para a redução significativa destas infecções (OMS, 2005, 2006).

A fim de multiplicar essas estratégias, a Agência Nacional de Vigilância Sanitária/Ministério da Saúde (Anvisa/MS), em parceria com a Organização PanAmericana da Saúde (OPAS), publicou no idioma português o "Guia para a implantação da estratégia multimodal da OMS para a melhoria da higienização das mãos", com a finalidade de embasar as ações direcionadas à prevenção e à redução da incidência de agravos e danos provocados pelas infecções relacionadas à assistência à saúde no país (BRASIL, 2008).

A estratégia multimodal para a melhoria da HM engloba cinco componentes indispensáveis: 1- Mudança do sistema (acesso à água, ao sabão, ao papel toalha e à solução alcoólica para HM); 2- Treinamento; 3- Observação e retorno; 4- Disposição de lembretes no local de trabalho; 5- Clima de segurança institucional (BRASIL, 2008).

Além disso, a estratégia denominada "Meus cinco momentos para a higienização das mãos" foicriada com a finalidade de promover a HM entre pacientes e profissionais de saúde e aumentar a sensação de autoeficácia entre os profissionais para integrar esta prática em seu plano de cuidados (OMS, 2009).

Os cinco momentos para a HM incluem sua realização: 1- Antes do contato com o paciente; 2- Antes da realização de procedimento asséptico; 3- Após risco de exposição a fluidos corporais; 4- Após contato com o paciente, e 5- Após contato com as áreas próximas ao paciente (OMS, 2009).

Apesar da instituição dessas práticas, alguns fatores como estrutura inadequada, deficiência de materiais, fatores individuais e falta de treinamento podem 
estar relacionados à adesão insuficiente à HM (PRADO; HARTMANN; TEIXEIRA FILHO, 2013).

Nesse sentido, faz-se necessário que os profissionais e as instituições estejam comprometidas com a segurança, sobretudo no que se refere à HM, pois esta medida constitui elemento essencial na assistência em saúde.

Além da importância da HM, as luvas compreendem um EPI indispensável quando houver a possibilidade de contato com sangue, com secreções e ou com excreções corporais. No entanto, investigações realizadas com profissionais de enfermagem que atuam na assistência a pacientes apontam que a adesão acontece parcialmente (LOVEDAY et al., 2014; MALAGUTI-TOFFANO et al., 2012; PEREIRA et al., 2013; PEREIRA et al., 2015).

Por outro lado, as luvas têm sido avaliadas como o EPI de maior facilidade de utilização entre os profissionais de enfermagem quando comparadas a outra medidas (BRAND; FONTANA, 2014; OLIVEIRA; CARDOSO; MASCARENHAS, 2010; REZENDE, et al., 2012).

Faz-se necessário enfatizar que as luvas devem ser removidas e descartadas imediatamente após sua utilização, e devem ser trocadas no contato entre pacientes. Além disso, o uso de luvas não substitui a HM (GARNER, 1996; OMS, 2005, 2006; SIEGEL et al., 2007).

O óculos de proteção e a máscara devem ser utilizados sempre que houver possibilidade de respingos de gotículas de sangue ou de outros fluidos corporais a fim de se evitar exposição das mucosas da boca, do nariz e dos olhos. Porém, é baixa a adesão ao uso de óculos pelos profissionais de enfermagem (MALAGUTI-TOFFANO et al., 2012; PEREIRA et al., 2013)

Pesquisa realizada em unidades de terapia intensiva em Mato Grosso do Sul encontrou baixa adesão aos EPI para proteção de olhos, de nariz e de boca, sendo que nenhum profissional utilizava óculos de proteção para o procedimento de aspiração endotraqueal (FROTA et al., 2012).

O avental deve ser utilizado durante os procedimentos em que houver possibilidade de gerar respingos de sangue ou de outros fluidos corporais. Ainda assim, tem sido referida adesão insuficiente a esse EPI (FROTA et al., 2012; FROTA, LOUREIRO; FERREIRA, 2014; RODRIGUES et al., 2014). 
O cuidado no manuseio de materiais perfurocortantes configura-se como elemento essencial das PP. Recomenda-se que sejam descartados em recipientes próprios, com paredes rígidas e alocados em local adequado (BRASIL, 2005; GARNER, 1996; SIEGEL et al., 2007). O descarte deve ocorrer imediatamente após sua utilização, ou seja, é vedado o reencape de agulhas após a aplicação de injeção (BRASIL, 2005). Ainda, o recipiente deve ser descartado assim que atingir três quartos de sua capacidade, cerca de cinco centímetros abaixo de sua abertura (BRASIL, 2005; BRASIL, 2011; SIEGEL et al., 2007).

Estudos têm reportado que o descarte inadequado desses materiais são a principal causa de ocorrência dos acidentes ocupacionais entre profissionais de saúde (ARAÚJO; COSTA; SILVA, 2014; JULIO; FILARDI; MARZIALE, 2014; SILVA et al., 2009; TIPLLE et al., 2013).

Segundo a NR32, as instituições devem implementar um Plano de Prevenção de Riscos de Acidentes com materiais perfurocortantes a fim de assegurar proteção à saúde dos profissionais que atuam nos serviços de saúde. Ainda, a adoção de materiais com dispositivos de segurança consiste em estratégia de controle para a prevenção de acidentes (BRASIL, 2011).

As inclusão de novas medidas de PP proposta por Siegel et al. (2007) englobam três componentes: etiqueta para tosse; práticas de injeção segura e uso de máscaras para inserção de cateteres ou de injeção espinhal ou epidural.

A etiqueta para tosse destina-se a pacientes e acompanhantes com infecções respiratórias transmissíveis (tosse; congestão nasal; rinorreia; ou aumento da produção de secreções respiratórias) ao entrar em uma unidade de saúde. Os profissionais de saúde que apresentarem tais infecções devem evitar o contato com pacientes considerados de alto risco. As principais medidas incluem: educação acerca da utilização de lenço de papel ao tossir e seu descarte imediato; uso de máscara cirúrgica; HM após o contato com secreções respiratórias e separação de pessoas com estas afecções, quando possível (SIEGEL et al., 2007).

Para as práticas de injeção segura, recomenda-se a utilização de agulhas e seringas estéreis e descartáveis, de uso único, para o preparo e para a administração de medicamentos. Deve-se optar preferencialmente por frascos de dose única, sobretudo quando o medicamento for administrado em mais de um paciente (SIEGEL 
et al., 2007).

Por fim, o uso de máscaras para a inserção de cateteres ou de injeção espinhal ou epidural para a proteção da mucosa nasal e oral (SIEGEL et al., 2007). Contudo, ainda não há evidências acerca da utilização dessa medida.

A gerência e a supervisão das instituições de saúde devem estimular a adesão às PP por profissionais, sobretudo os da enfermagem. Quanto ao uso do EPI, as instituições devem oferecer os equipamentos necessários a sua proteção no início da jornada de trabalho (BRASIL, 2005).

Ainda, cabe ao empregador adquirir o EPI adequado e aprovado pelo órgão nacional competente e que esteja de acordo com o tipo de atividade a ser realizada; exigir sua utilização; responsabilizar-se pela manutenção periódica; oferecer treinamentos e orientações sobre sua utilização e conservação; realizar a substituição imediata quando danificar ou extraviar; comunicar ao Ministério do Trabalho e Emprego (MTE) qualquer irregularidade; registrar seu fornecimento ao profissional (BRASIL, 2001; BRASIL, 2009; BRASIL, 2010).

Além disso, pesquisas têm constatado que a disponibilidade e o acesso facilitado às medidas de proteção favorecem sua utilização (EFSTATHIOU et al., 2011; LUO et al., 2010).

Para Beam et al. (2011), a falta de materiais bem como as crenças pessoais caracterizam-se como obstáculos para a adesão dos profissionais às PP.

Dessa forma, faz-se necessário compreender os fatores que influenciam a não adesão às $\mathrm{PP}$, para que se possa refletir sobre sua prática, na atuação da equipe de enfermagem, e direcionar estratégias que propiciem sua incorporação aos serviços de saúde (NEVES et al., 2011).

\subsection{Instrumentos utilizados para avaliar a adesão às precauções-padrão}

É importante que haja uma avaliação da adesão dos profissionais às medidas preventivas em sua prática. No entanto, essa necessidade aponta uma dificuldade 
expressiva, pois os instrumentos que visam mensurar a adesão às PP são, na maioria, de língua inglesa e não traduzidos nem validados para o português do Brasil.

Uma revisão integrativa da literatura realizada para identificar instrumentos já utilizados para avaliar conhecimentos e adesão às PP evidenciou que a maior parte dos estudos foram internacionais. Identificaram doze instrumentos, sendo que oito estavam publicados em inglês, três publicados em português e um, em espanhol. Ressaltaram também que dentre as pesquisas selecionadas, 66,6\% envolveram enfermeiras e detalharam o desenvolvimento, a origem e/ou a construção dos questionários e 58,3\% dos instrumentos tinham sido validados (DE CARVALHO NAGLIATE et al., 2013).

Revisão integrativa da literatura identificou 18 instrumentos para avaliação de práticas de controle de infecção, sendo que, dentre os temas mais abordados, destacaram-se o uso de EPI, a $\mathrm{HM}$ e as técnicas seguras no manuseio de perfurocortantes. A maioria desses estudos explorou a validade de conteúdo e análise de confiabilidade (VALIM et al., 2014).

Para Rattray e Jones (2007) é expressivo o aumento de pesquisas que objetivam a construção de instrumentos por enfermeiros. Esse cenário requer a avaliação da confiabilidade e da validade dos instrumentos para assegurar a qualidade e rigor metodológico.

Segundo Pilatti, Pedroso e Gutierrez (2010) a qualidade de instrumentos deve estar relacionada, sobretudo, com a avaliação das propriedades psicométricas. Nesse sentido, recomenda-se a utilização de instrumentos com validades e com confiabilidade conhecida.

A construção e a validação de escalas a fim de avaliar a adesão às PP constituem preocupação e objeto de estudo de diferentes pesquisadores (BREVIDELLI; CIANCIARULLO, 2009; CHAN et al., 2002; CHAN; HO; DAY, 2008; DEJOY; MURPHY; GERSHON, 1995; GERSHON et al., 1995; GREEN et al., 1980; LAM, 2011; VALIM; MARZIALE, 2013).

O modelo desenvolvido por Green et al. (1980) denominado PRECEDE, foi criado com o objetivo principal realizar a educação em saúde, por meio do diagnóstico educacional e organizacional e os fatores que podem influenciar o comportamento, sendo eles predisponentes, capacitadores e de reforço. 
Visando mensurar esses fatores, Gershon et al. (1995) construíram um modelo de adesão às PU englobando dimensões denominadas fatores individuais (variáveis sóciodemográficas); fatores psicossociais (percepções individuais em relação à contaminação no trabalho; aos traços de personalidade com tendência ao risco; a atitudes e medo com relação à aids), e fatores organizacionais (clima de segurança; apoio de colegas e treinamento).

Ainda com enfoque nas dimensões descritas por Gershon et al. (1995), os autores Dejoy, Murphy e Gershon (1995) desenvolveram o Modelo de Sistemas de Trabalho para avaliar a influência de fatores na adesão às PU em três níveis: individual, referente ao trabalho e organizacional.

Baseado nos modelos internacionais de Green et al. (1980), Gershon et al. (1995), Dejoy, Murphy e Gershon (1995) as pesquisadoras Brevidelli e Cianciarullo (2009) traduziram e validaram para o Brasil o Modelo Explicativo da Adesão às PP. Contendo dez escalas, totalizando 57 itens, o modelo avalia a intersecção entre fatores individuais, relativos ao trabalho e organizacionais. Apesar de ter apresentado validade e confiabilidade satisfatórias, os itens que formam a Escala de Adesão às PP não apresentaram afinidade teórica. Validado para médicos e enfermeiros que atuam na assistência a pacientes, tem sido utilizado por outros pesquisadores brasileiros na avaliação da adesão às PP por profissionais de enfermagem (MALAGUTI-TOFFANO et al., 2012; PEREIRA et al., 2013).

Com o objetivo de investigar a utilização de PU entre enfermeiros, Chan et al. (2002) desenvolveram um instrumento para avaliar o conhecimento das PU e seu cumprimento. A Escala de conhecimento é composta por 11 itens que discorrem sobre a transmissão de doenças infecciosas e PU. A Escala de Cumprimento das PU, composta por 15 itens, engloba práticas seguras na manipulação de perfurocortantes, na HM, nas medidas de desinfecção, entre outros. Validade e confiabilidade foram testadas e consideradas satisfatórias.

Askarian, McLaws e Meylan (2007), com o propósito de avaliar os níveis de conhecimentos, atitudes e prática com relação às PP entre profissionais médicos, construíram uma escala do tipo likert com nove itens acerca do uso de EPI, da HM e do manuseio de materiais perfurocortantes. A consistência interna foi avaliada por meio do alfa de Cronbach. 
Chan, Ho e Day (2008) desenvolveram uma escala com 25 itens para analisar a relação entre conhecimentos, atitudes e práticas e PP para profissionais que atuam em salas de cirurgia. $\mathrm{O}$ instrumento é dividido em três seções: conhecimento (04 itens); atitudes (11 itens), e práticas (10 itens). A confiabilidade foi mensurada por meio da consistência interna. A análise fatorial exploratória foi realizada para a validade de construto.

Utilizando-se outros instrumentos como o desenvolvido por Askarian, McLaws e Meylan (2007), os autores Luo et al. (2010) modificaram alguns itens e desenvolveram uma nova escala para avaliar a adesão de enfermeiros às PP e analisar os fatores que podem influenciar nessa adesão. As questões envolveram o conhecimento acerca das PP, a adesão e a auto eficácia. Esse instrumento foi adaptado para o português brasileiro (VALIM; MARZIALE, 2013). No entanto, suas propriedades psicométricas ainda não foram testadas.

A partir da escala de precauções universais, criada por Chan et al. (2002), desenvolveu-se a Compliance with Standard Precautions Scale (CSPS) por Lam (2011), na China, com o objetivo avaliar o cumprimento das PP entre enfermeiros.

Vale ressaltar que todas as escalas mencionadas anteriormente foram desenvolvidas em outros países. Embora haja diversos estudos que têm como objetivo avaliar a adesão às PP no Brasil, ainda tem-se observado grande fragilidade no processo de construção e de validação dos instrumentos utilizados.

Considerando-se a relevância do conteúdo da CSPS, e que o processo de adaptação e de construção de novos itens cumpriu os requisitos teóricos e metodológicos necessários, parece ser uma escala capaz de medir a adesão às PP por enfermeiros.

De acordo com Guillemin, Bombardier e Beaton (1993), quando não se têm instrumentos de medida especificamente elaborados para uma língua e cultura, devese realizar a adaptação cultural de um já existente.

Com base nesse processo, a adaptação da CSPS para o Brasil será de grande valia na mensuração da adesão às PP por enfermeiros. 


\section{REFERENCIAL TEÓRICO}

\subsection{Processo de adaptação de instrumentos}

O processo de adaptação de um instrumento de medida já existente tem sido amplamente utilizado em diversas áreas de conhecimento, pois apresenta vantagens a economia do tempo e de recursos e a realização de comparações (CUMMINGS; STUART; HULLEY, 2003; GUILLEMIN; BOMBARDIER; BEATON, 1993).

Para realizar a adaptação cultural de um instrumento para outro idioma, não há consenso sobre a melhor metodologia a ser seguida, com isso, autores têm utilizado sua própria metodologia (RAMOS DE CARVALHO et al., 1993).

Compendiando, o processo de adaptação cultural de um instrumento consiste basicamente em duas fases, a tradução e a adaptação. Dessa forma, o instrumento é traduzido do idioma original para o pretendido, considerando-se o contexto das palavras, os conceitos e os aspectos culturais. Em seguida, o instrumento é avaliado com relação à compreensibilidade, à validade de conteúdo e aparente, à replicabilidade e à adequação (GUILLEMIN, BOMBARDIER; BEATON, 1993).

A proposta sugerida por Guillemin, Bombardier e Beaton (1993) tem sido a mais utilizada. Esses autores sugerem as seguintes etapas: tradução, retrotradução; revisão da tradução por comitê (equivalência semântica; equivalência idiomática; equivalência experiencial; equivalência conceitual); pré-teste e ponderação dos escores.

Para Beaton et at. (2000), o processo de adaptação de um instrumento deve seguir cinco estágios: 1- Tradução; 2- Síntese das traduções; 3- Retrotradução (Backtranslation); 4- Revisão por comitê de especialistas; 5- Pré-teste.

No entanto, alguns pesquisadores apresentam outras propostas para realizar a adaptação cultural, como Ferrer et al. (1996) que sugerem alteração na sequência das etapas, sendo que a retrotradução ou back-translation deve acontecer após a avaliação pelo comitê de juízes, pois permite a deteç̧ão de questões que não foram compreendidas, possibilitando sua modificação.

De acordo com Ferrer et al. (1996), o processo de adaptação cultural deve ser realizado nas seguintes etapas: 1- Tradução; 2- Consenso das versões; 3- Avaliação 
por Comitê de Juízes; 4- Retrotradução (Back-translation); 5- Consenso das versões e comparação com a original; 6- Pré-teste; 7- Versão final do instrumento.

- Tradução - Consiste na primeira etapa importante a ser considerada no processo de adaptação de um instrumento. O processo de traduções é complexo e exige cautela para que a versão traduzida seja adequada ao construto avaliado (BORSA; DAMÁSIO; BANDEIRA, 2012). Nessa etapa, realiza-se a tradução do idioma original para o português do Brasil por duas pessoas com conhecimento profundo da língua de origem do instrumento. Dessa forma, as traduções podem ser comparadas e os erros que podem refletir inconsistências de redação no processo de tradução serem observados e corrigidos posteriormente (BEAM et al., 2011).

É aconselhável que apenas um dos tradutores conheça os objetivos do instrumento a fim de que possa fazer uma tradução com equivalência mais confiável, enquanto que o outro tradutor não deve ser informado do construto que está sendo medido (BEAM et al., 2011).

- Retrotradução (Back-translation) - A versão de consenso obtida na etapa anterior é traduzida novamente para a língua de origem, a fim de verificar a qualidade entre a versão original e a traduzida da escala. As retrotraduções devem ser realizadas por dois tradutores independentes com fluência no idioma e conhecedores da linguagem de origem. Esse processo consiste em se verificar se a versão traduzida está refletindo o conteúdo da versão original (BEATON et al., 2000).

Recomenda-se que os tradutores não estejam cientes dos objetivos do instrumento para que não haja expectativas acerca do significado do instrumento original (GUILLEMIN; BOMBARDIER; BEATON, 1993).

- Revisão da Tradução por Comitê - O objetivo desta fase é consolidar todas as versões do instrumento e desenvolver uma versão final. O comitê verifica as traduções e elabora uma versão consensual. Todos os juízes devem receber uma versão original do instrumento, as traduções e as orientações acerca do estudo (BEATON et al., 2000).

A composição mínima do comitê compreende especialistas no método, profissionais de saúde, profissionais da língua, e os tradutores envolvidos no processo de adaptação do instrumento (BEATON et al., 2000).

Para Ferreira et al. (2014), faz-se necessária a inclusão de um representante da população alvo nesse comitê, pois pode contribuir para o retorno imediato acerca da 
compreensão do itens.

De acordo com Guillemin, Bombardier e Beaton (1993) e Beaton et al. (2000), o comitê de especialistas avalia a equivalência semântica, a equivalência cultural, a equivalência idiomática e a equivalência conceitual entre o instrumento original e o instrumento traduzido.

1- Equivalência Semântica - Tem como objetivo verificar se os profissionais selecionados para o estudo serão capazes de entender as perguntas, responder e apresentar sugestões com relação às dificuldades encontradas;

2- Equivalência Idiomática - Tem como finalidade avaliar expressões coloquiais ou expressões difíceis de traduzir;

3- Equivalência Experiencial - O propósito é avaliar a existência de itens que reflitam experiências próprias de cada cultura;

4- Equivalência Conceitual - O objetivo é avaliar palavras que podem expressar conceitos ou significados de diferentes culturas.

- Validação semântica - A validação semântica do instrumento, para alguns autores, deve ser realizada antes de sua aplicação (BORSA; DAMÁSIO; BANDEIRA, 2012; DANTAS; ROSSI, 2004; PASQUALI, 1999). Tem como objetivo verificar a compreensibilidade dos itens para todos os componentes da população à qual o instrumento se destina. No entanto, é necessário considerar que os itens devem ser inteligíveis para o estrato mais baixo da população a ser estudada. Ainda, deverá ser realizada com uma amostra mais sofisticada da população a ser estudada, a fim de garantir a validade aparente (PASQUALI, 1998).

Segundo Borsa, Damásio e Bandeira (2012), nessa fase, nenhum procedimento estatístico é realizado, e sim a avaliação e adequação do instrumento com relação aos termos e à redação dos itens.

- Pré-teste - Tem como propósito verificar o campo de estudo. O instrumento traduzido deverá ser aplicado em indivíduos da população de profissionais de enfermagem. Considera-se 30 a 40 indivíduos como número ideal para esse teste (BEATON et al., 2000; GUILLEMIN; BOMBARDIER; BEATON, 1993).

Uma nova proposta, criada no Brasil por Borsa, Damásio e Bandeira (2012), sugere como sétima etapa do processo de adaptação a avaliação da estrutura fatorial 
do instrumento, que comumente não é incluída neste processo e, sim, na avaliação das propriedades psicométricas do instrumento.

\subsection{Avaliação das propriedades psicométricas de instrumentos}

Segundo Guillemin, Bombardier e Beaton (1993), é imprescindível avaliar as propriedades de medida de um instrumento que passou pelo processo de adaptação cultural.

Para Rattray e Jones (2007), a deficiência na avaliação das propriedades psicométricas de um instrumento é um dos fatores que podem dificultar a interpretação dos resultados em pesquisas.

O processo de testagem e de avaliação das propriedades psicométricas de um instrumento deve seguir um rigor metodológico. Nesse sentido, destaca-se a tríade confiabilidade-consistência interna-validação, como elementos indispensáveis para a fidedignidade de um instrumento (PILATTI; PEDROSO; GUTIERREZ, 2010).

Além da validade do instrumento, outras características psicométricas como a confiabilidade; a acurácia; a precisão; a fidedignidade; a consistência interna, a reprodutibilidade, a estabilidade, a equivalência e a homogeneidade devem ser avaliadas. O uso desses termos varia de acordo com o aspecto do teste que se quer investigar (FAYERS; MACHIN, 2007; PASQUALI, 1999).

Segundo Pasquali (1999), o parâmetro da precisão dos testes pode ser denominado por uma série de nomes distintos, podendo resultar do próprio conceito (precisão, fidedignidade e confiabilidade) ou do tipo da técnica estatística utilizada (estabilidade; constância; equivalência; consistência interna).

A precisão, a confiabilidade ou a fidedignidade de um teste está relacionada, sobretudo, à característica que ele deve possuir, a de mensurar sem erros. Medir os atributos dos mesmos sujeitos, em momentos diferentes, utilizando os mesmos testes e produzindo resultados idênticos (PASQUALI, 2009).

A correlação e a consistência interna consistem em duas grandes técnicas estatísticas para medir a confiabilidade de um teste (PASQUALI, 2009). Ainda, Peter 
(1979) e Chwalow (1995) listam três tipos básicos de testes para avaliar a confiabilidade de um instrumento de medida: teste reteste; formas alternativas (Coeficiente de KAPPA) e consistência interna.

$O$ teste reteste reflete a reprodutibilidade de se obter respostas semelhantes para o mesmo instrumento em um segundo momento, com os mesmos indivíduos, nas mesmas condições (COZBY, 2003; SHROUT; FLEISS, 1979; STREINER; NORMAN, 2008).

Segundo Urbina (2007), há muitos fatores que podem afetar os escores dos testes em dois momentos distintos; por isso não existe um intervalo fixo recomendado para a reaplicação, no entanto não pode ser nem muito curto, nem muito longo. Por outro lado, Peter (1979) e Terwee et al. (2007), recomendam que o intervalo seja de duas semanas após a primeira abordagem, assumindo que o seu construto medido permaneça estável.

Formas alternativas podem ser utilizadas para avaliar a confiabilidade. $O$ Coeficiente de KAPPA consiste em um teste estatístico que correlaciona duas diferentes observações, do mesmo sujeito, ao mesmo tempo (CHWALOW, 1995).

A consistência interna é verificada na administração única do instrumento e reflete a homogeneidade interna dos itens em se que medem as mesmas dimensões. As duas técnicas utilizadas com maior frequência para o cálculo da consistência interna consistem na formula de Kuder-Richardson 20 (K-R20) e no coeficiente alfa (a) (CHWALOW, 1995).

De acordo com Cummings, Stuart e Hulley (2003), o alfa de Cronbach é a medida mais utilizada para a verificação da consistência interna.

Embora as evidencias das medidas de confiabilidade sejam consideradas uma condição necessária na avaliação das propriedades psicométricas de um instrumento, não são suficientes para assegurar a validade (SAWILOWSKY, 2003).

Para evidenciar se o que está sendo medido é realmente o pretendido, avaliase a validade do instrumento que poderá ser por meio da validade de Face; da validade de conteúdo; da validade de construto ou de Conceito e da validade relacionada ao critério (PASQUALI, 1998; PASQUALI, 2009).

A validade de face consiste na percepção do que está sendo medido (PASQUALI, 2001). Incide na verificação dos itens do instrumento quanto à clareza, ao 
entendimento e à pertinência (CHWALOW, 1995). Esse tipo de validade está relacionada à validade de conteúdo, sendo, muitas vezes, considerada parte deste (FAYERS; MACHIN, 2007).

A validade de conteúdo caracteriza-se pela análise crítica da estrutura básica do instrumento e está relacionada com a capacidade dos itens de representar adequadamente todas as dimensões do conteúdo a que se propõem. Deve-se considerar a aplicabilidade do instrumento para a questão de pesquisa do estudo (FAYERS; MACHIN, 2007).

A validade de conteúdo deve ser realizada por um comitê de juízes que irá julgar a clareza, a compreensibilidade e a redundância dos itens e se estes representam os domínios ou os conceitos propostos. Esse é um passo inicial para se estabelecer a validade do instrumento, mas não é suficiente por si só (RATRAY; JONES, 2007).

A validade de construto ou de conceito é a principal medida de validade de instrumentos (PASQUALI, 2009). Para Fayers e Machin (2007), pode-se avaliar a validade de construto por grupos conhecidos (known-groups validity), por validade convergente, por validade discriminante e por análise multitraço-multimétodo.

A validade por grupos conhecidos constitui uma das formas mais simples para a validade de construto, pois parte do pressuposto de que grupos específicos podem apresentar resultados diferentes de outros, sendo que o instrumento deve ser sensível a estas diferenças (FAYERS; MACHIN, 2007). A falta de sensibilidade do instrumento pode ser um dos fatores para que o instrumento não apresente distinção entre os grupos.

A validade de construto convergente consiste na associação significativa da medida obtida pelo instrumento com outras variáveis com o qual o construto medido deveria estar relacionado (PASQUALI, 1999). Esse tipo de validade tem como objetivo comparar dois instrumentos que medem o mesmo construto, a fim de se obter correlações entre eles. Dessa forma, correlações altas entre duas escalas podem indicar que ambas estão medindo o mesmo fator (FAYERS; MACHIN, 2007).

A validade de construto discriminante ou divergente determina que 0 instrumento apresenta correlações baixas com medidas que avaliam construtos diferentes (PASQUALI, 2003; URBINA, 2007).

A análise fatorial consiste em uma das técnicas que podem ser utilizadas como 
demonstração da adequação da representação do construto, revelando parte fundamental e imprescindível no processo de validação de instrumentos psicológicos (PASQUALI, 2001; 2012).

A análise fatorial pode ser utilizada na construção, na revisão e na avaliação de instrumentos psicológicos. Dessa forma, pode ser classificada quanto ao método utilizado (exploratório e confirmatório) e o tipo de técnica (procedimentos exploratórios e procedimentos confirmatórios). A análise fatorial exploratória, também denominada de análise fatorial comum, está relacionada a redução de dados, ou seja, a identificação de dimensões que um instrumento está medindo. Já a analise fatorial confirmatória, irá confirmar uma teoria já estabelecida anteriormente (PASQUALI, 2012).

A validade de critério avalia se a escala tem associação com critérios externos relacionados às medidas de outros instrumentos com validade confirmada e que avaliam o mesmo construto (FAYERS; MACHIN, 2007).

Esse tipo de validade pode ser concorrente (capacidade da escala de medir outras variáveis) ou preditiva (capacidade da escala de correlacionar-se com alguma medida de critério externo obtido no mesmo momento) (CHWALOW, 1995).

A diferença entre os dois tipos de validade é um ponto do tempo em que se concretiza a coleta da informação pelo teste a ser validado e a coleta de informação acerca do critério. Quando a coleta é simultânea, caracteriza-se validade do tipo concorrente, e, quando os dados acerca do critério são coletados após a coleta de informações sobre o teste, caracteriza-se validade preditiva. O elemento mais importante nesse tipo de validade é a definição de um critério válido e adequado para estabelecer esta medida (PASQUALI, 2009).

Mediante a explanação da necessidade de avaliação das propriedades psicométricas, faz-se necessário avaliar a confiabilidade e a validade dos instrumentos, utilizando-se testes adequados e factíveis de serem realizados de acordo com os objetivos pretendidos. 


\section{OBJETIVOS}

\subsection{Geral}

$\checkmark$ Realizar a adaptação cultural e validação da Compliance with Standard Precautions Scale (CSPS) para enfermeiros brasileiros.

\subsection{Específicos}

$\checkmark$ Traduzir a Compliance with Standard Precautions Scale (CSPS) para o português do Brasil;

$\checkmark$ Avaliar a validade de face e de conteúdo da versão para o Português do Brasil da CSPS (CSPS-PB);

$\checkmark$ Avaliar a confiabilidade da versão para o Português do Brasil da CSPS (CSPS$\mathrm{PB})$ no que se refere à consistência interna dos itens, segundo a estatística alfa de Cronbach;

$\checkmark$ Avaliar a confiabilidade no que se refere à estabilidade da versão para o Português do Brasil da CSPS (CSPS-PB), segundo o Coeficiente de Correlação Intraclasse;

$\checkmark$ Avaliar a validade de construto da versão para o Português do Brasil da CSPS (CSPS-PB) entre grupos distintos;

$\checkmark$ Avaliar a validade de construto da versão para o Português do Brasil da CSPS (CSPS-PB) por meio da análise fatorial. 


\section{MÉTODOS}

\subsection{Tipo e Local do Estudo}

Trata-se de um estudo metodológico desenvolvido no Hospital do Servidor Público Estadual (HSPE) localizado na região centro-sul da cidade de São Paulo/SP.

O HSPE é um hospital de grande porte que presta atendimento em todos os níveis de atenção, executando procedimentos desde os mais simples até os de alta complexidade. Atende cerca de 50 especialidades médicas, e dispõe de diversos programas de saúde, incluindo Assistência Domiciliar, Planejamento Familiar e Atenção ao Idoso, Bancos de Sangue, de Olhos e de Leite Humano.

A instituição conta com 942 leitos de enfermaria dentre as especialidades cirúrgicas (geral; cardíaca; cabeça e pescoço; plástica; torácica; vascular; gástrica; ginecológica; neurológica; oftálmica; obstétrica; ortopédica; otorrino; queimados; bucomaxilofacial e urologia) e clínicas (geral; alergia; cardiologia; cuidados paliativos; dermatologia; aparelho respiratório; endocrinologia; gastrologia; geriatria; hematologia; moléstias infectocontagiosas; nefrologia; neurologia; oncologia e reumatologia).

Além desses serviços, o hospital oferece atendimento pediátrico clínico, cirúrgico e intensivo; unidades de tratamento a pacientes críticos, incluindo a unidade coronariana e unidades de terapia intensiva; pronto-socorro e psiquiatria.

O pronto-socorro atente em média 18.000 usuários mensais; possui 62 leitos, sendo 54 para observação e oito leitos, para emergência.

O hospital dia é um serviço oferecido pela instituição que tem como finalidade atender os pacientes para terapia medicamentosa assistida e assistência durante o dia. Assim, os acolhimentos se iniciam às 6 horas e encerram às 22 horas quando os pacientes são liberados após terem recebido o atendimento. É importante ressaltar que são destinados 45 leitos para essa finalidade.

O ambulatório da instituição, com 60.000 atendimentos por mês, dispõe de especialidades médicas e cirúrgicas e realiza procedimentos de menor complexidade. 
O Serviço de Atendimento Domiciliar consiste na assistência prestada por profissionais médicos e enfermeiros a 800 pacientes no domicílio.

Atualmente, a instituição encontra-se em ampla reforma após a liberação de $\mathrm{R} \$ 146,7$ milhões pelo governo de São Paulo para a modernização da unidade, que existe há 52 anos. A proposta dessas modificações e reformas inclui a construção de um centro de proteção à saúde do idoso, com estrutura de reabilitação física e social para a promoção do envelhecimento saudável; e a concepção de pronto-socorro adulto novo. Com isso, as unidades sofreram adaptações e foram fechados 205 leitos de enfermarias provisoriamente.

O hospital conta exclusivamente com 490 profissionais enfermeiros, sendo que, destes, 41 executam atividades administrativas.

\subsection{Compliance with Standard Precautions Scale (CSPS)}

A CSPS é uma escala desenvolvida na China por Lam (2011) a qual permite avaliar o cumprimento das PP de profissionais e de estudantes de enfermagem em sua prática clínica.

A CSPS foi construída utilizando-se o modelo proposto por Chan et al. (2002), composto por 15 itens, que tem como objetivo avaliar a adesão dos profissionais às PU. Com a modificação dos conceitos de PU para PP por Garner (1996) e com a inserção de novas medidas por Siegel et al. (2007), verificou-se a necessidade da construção e de adaptação de um instrumento que englobasse esta nova normatização.

Assim, a CSPS foi criada por meio da modificação da escala de PU, utilizandose o processo de adaptação de acordo com as etapas a seguir (LAM, 2011):

1- Análise das diretrizes de controle de infecção: Foi realizada uma análise acerca das diferenças entre PU e PP juntamente com o grupo de especialistas para comparar as semelhanças e as diferenças dos conceitos adotados.

2- Modificação dos itens da Escala de PU: Nesta etapa, os itens foram modificados e adicionados, obedecendo às diretrizes atualizadas de PP. 
3- Validade de conteúdo: Foram avaliadas a pertinência e a adequação de novos itens por um comitê de especialistas composto por dois enfermeiros especializados no controle de infecção dois acadêmicos que ensinam práticas de controle de infecção, e dois enfermeiros que atuam na assistência. As diretrizes de PP locais e internacionais foram fornecidas a eles como referência para a avaliação.

4- Verificação de questões linguísticas e erros gramaticais: Nesta etapa, verificaram-se os erros linguísticos e gramaticais por um especialista em tradução e em linguística.

5- Validade de face: A amostra foi composta por 72 indivíduos, sendo 24 estudantes de enfermagem e 48 enfermeiros que atuavam na assistência em um hospital de ensino e tinham mais de um mês de experiência profissional. Os participantes inspecionaram, revisaram e comentaram acerca de cada item de todo 0 instrumento e apontaram sugestões. Os participantes retornaram os questionários por correio interno, em envelope fechado.

6- Avaliação da consistência interna: A CSPS foi aplicada para 193 enfermeiros e a consistência interna foi aceitável, com alfa de Cronbach 0,73.

Assim, a CSPS é uma escala composta por 20 itens (anexo 1), alocados em cinco dimensões:

1 - Uso de EPI (seis itens);

2 - Descarte de material perfurocortante (três itens);

3 - Eliminação de resíduos (01 item);

4 - Descontaminação de artigos usados e derramamentos (três itens);

5 - Prevenção de infecção cruzada de pessoa para pessoa (oito itens).

Dentre os itens da CSPS, quatro apresentam-se invertidos, sendo o item 2, 0 item 4, o item 6 e o item 15. Desse modo, a interpretação das respostas para estes deve ocorrer inversamente aos demais.

A CSPS contém quatro opções de respostas que indicam a frequência do cumprimento com às PP, compreendendo "sempre", "muitas vezes", "raramente" ou "nunca". Tendo em vista que os profissionais devem aderir integralmente às PP, é esperado que a opção "sempre" totalize a maioria das respostas. Em contrapartida, para a opção "nunca" deve incidir a maior frequência entre os itens invertidos.

Dessa forma, Lam $(2011,2014)$ sugere que a análise do cumprimento das PP 
seja feita utilizando-se escores atribuídos às opções de respostas. Para a opção de resposta "sempre", é atribuído o escore de "um" e para as opções "muitas vezes", "raramente" ou "nunca" o escore atribuído é "zero". Já para as questões invertidas, a opção "nunca" confere o escore "um" e as demais, o escore "zero".

\subsection{Processo de adaptação cultural}

Para a realização do processo de adaptação cultural, adotou-se o método proposto Ferrer et al. (1996). A esquematização dessas etapas, está ilustrada na figura 1. 


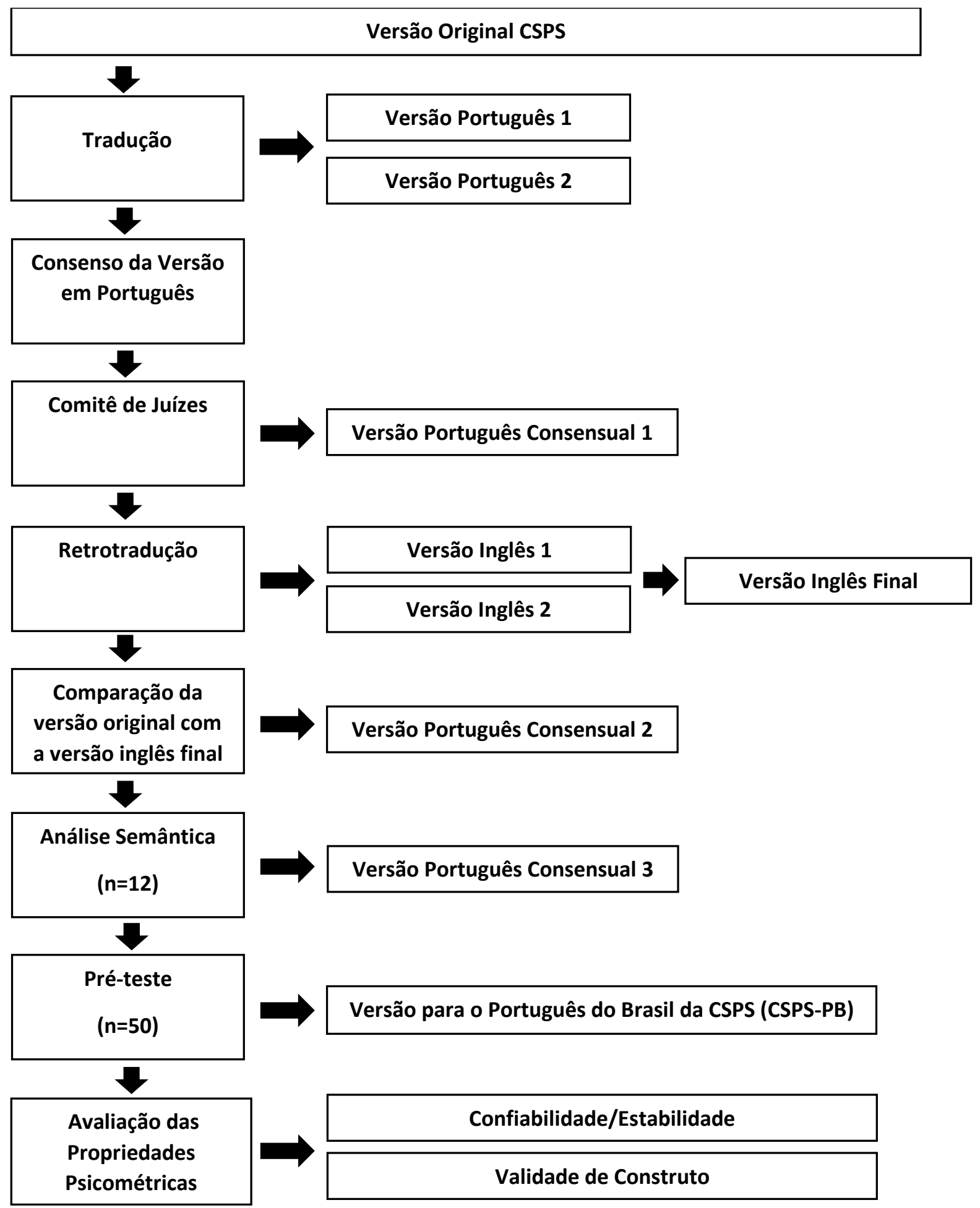

Figura 1 - Processo de Adaptação Cultural da Compliance with Standard Precautions Scale (CSPS) 


\subsubsection{Tradução}

Nesta etapa, foi realizada a tradução do idioma original para o português do Brasil por duas pessoas com conhecimento profundo da língua de origem do instrumento, tradutores juramentados e distintos. Para cada tradutor, obteve-se uma versão traduzida da escala, sendo denominadas: versão português 1 (anexo 2) e versão português 2 (anexo 3).

\subsubsection{Consenso da versão em português}

A partir das duas traduções versão português 1 e versão português 2 , obtevese uma versão consensual, a versão português consensual 1 (anexo 4). É importante ressaltar que essa etapa foi realizada juntamente com o comitê de juízes.

\subsubsection{Avaliação por Comitê de Juízes}

Foi realizada uma reunião consensual que contou com a presença de juízes para auxiliar na avaliação das equivalências do instrumento

Esse comitê foi composto por sete juízes, sendo: dois tradutores juramentados residentes na cidade de Ribeirão Preto/SP; uma enfermeira e docente do Programa de Pós-Graduação em Enfermagem Fundamental da Escola de Enfermagem da Universidade de São Paulo; uma enfermeira da Unidade de Moléstias Infectocontagiosas do Hospital das Clínicas da Faculdade de Medicina de Ribeirão Preto; uma enfermeira e doutoranda da Escola de Enfermagem da Universidade de São Paulo; a orientadora deste estudo e docente do Programa de Pós-Graduação de Enfermagem Fundamental da Escola de Enfermagem da Universidade de São Paulo; a pesquisadora responsável pelo estudo. Foram avaliadas a equivalência semântica, a 
equivalência cultural, a equivalência idiomática e a equivalência conceitual do instrumento e elaborada uma versão consensual do instrumento.

Cada juiz recebeu as duas versões traduzidas do instrumento. Optou-se por utilizar as duas versões, a fim de se obter uma versão consensual após a discussão dos itens com especialistas da temática e da metodologia proposta. Após a assinatura do Termo de Consentimento Livre e Esclarecido (apêndice 1), foi realizada a leitura de cada item do instrumento pelo pesquisador e a discussão em grupo. As modificações foram realizadas mediante concordância mínima de $80,0 \%$ entre os juízes.

\subsubsection{Retrotradução (Back-translation)}

A versão português consensual 1 obtida na etapa anterior foi traduzida novamente para a língua de origem, a fim de se verificar a qualidade entre a versão original e a versão traduzida da escala.

A retrotradução foi realizada por dois tradutores independentes, americanos residentes no Brasil, resultando em duas versões: versão inglês 1 (anexo 5) e versão inglês 2 (anexo 6). As duas versões foram comparadas em uma reunião com a pesquisadora e com a orientadora, resultando em uma versão inglês final (anexo 7), que foi enviada ao autor da escala, sendo aprovada.

\subsubsection{Consenso da versão em português e comparação com a original}

A versão original da CSPS foi comparada com a versão inglês final e foi obtida uma versão consensual, denominada versão português consensual 2 (anexo 8).

\subsubsection{Avaliação Semântica dos itens}


Esta etapa foi realizada para verificar se todos os itens são compreensíveis para os enfermeiros que constituirão a população do estudo.

Foram entrevistados 12 enfermeiros da instituição, sendo que 10 atuavam na assistência a pacientes. Todos os participantes avaliaram os 20 itens da escala. Não houveram recusas ou perdas.

Segundo Pasquali (1998), não há um consenso específico quanto ao número de participantes para a análise semântica. No entanto, deve-se garantir a validade aparente, selecionando participantes da população alvo com menor e com maior habilidade para o construto a ser medido.

Dessa forma, a seleção de dez participantes foi realizada por meio amostragem aleatória simples, utilizando-se a lista obtida junto ao Departamento de Recursos Humanos da Instituição. Ainda, foram convidadas para participar dessa etapa uma enfermeira da Serviço de Controle de Infecção Hospitalar (SCIH) e uma enfermeira da Educação Continuada.

Os instrumentos utilizados para a validação semântica foram:

1- Formulário com informações demográficas e profissionais (sexo, data de nascimento, tempo na função, setor e turno de trabalho; como tomou conhecimento das PP, recebeu treinamento acerca das PP) (Apêndice 2). Esse formulário foi elaborado pela pesquisadora e validado quanto à forma e conteúdo por especialistas da área;

2- Versão Português Consensual;

3-Formulário para avaliação dos itens da escala (As questões foram compreensíveis? As questões foram relevantes? Gostaria de modificar alguma? O que você entendeu desta questão? As opções de resposta estão de acordo com a questão?).

Os dados foram coletados pela pesquisadora no próprio local de trabalho dos participantes no momento oportuno e, após a assinatura do Termo de Consentimento Livre e esclarecido (Apêndice 3), as entrevistas foram realizadas. A duração foi cerca de 30 minutos. 


\subsubsection{Pré-teste}

Após a adaptação cultural, foi realizado um pré-teste com o propósito de verificar as características do campo de estudo. $\mathrm{O}$ instrumento traduzido foi aplicado para os enfermeiros da instituição. Considera-se 30 a 40 indivíduos como número ideal para esse teste (GUILLEMIN; BOMBARDIER; BEATON, 1993; BEATON et al., 2000).

A amostra foi constituída por 50 enfermeiros selecionados por meio de amostragem aleatória simples, utilizando-se o software IBM ${ }^{\circledR}$ SPSS versão 19.0.

Os enfermeiros receberam um envelope contendo:

1- Formulário com informações demográficas e profissionais (sexo, data de nascimento, tempo na função, setor e turno de trabalho; como tomou conhecimento das PP, recebeu treinamento acerca das PP);

2- Versão Português Consensual 3 (anexo 9);

3- Termo de Consentimento Livre e esclarecido.

A pesquisadora orientava os profissionais quanto ao preenchimento dos instrumentos e quanto ao fechamento do envelope e aguardava o término. Após, o envelope lacrado era recolhido com o termo de consentimento separadamente. Os dados foram coletados pela pesquisadora no próprio local de trabalho no momento oportuno. A duração foi cerca de 15 minutos.

\subsection{Avaliação das propriedades psicométricas do instrumento}

\subsubsection{Amostra do Estudo}

A amostra do estudo foi composta por enfermeiros que atuam na assistência ao paciente na instituição.

De acordo com lista obtida junto ao Departamento de Recursos Humanos da instituição, há 490 enfermeiros alocados em diferentes unidades. No entanto, adotou- 
se como critério de inclusão ser enfermeiro e atuar na assistência a pacientes. Como critérios de exclusão, ser enfermeiro e exercer funções exclusivamente administrativas. Considerando-se esses critérios, foram excluídos 41 profissionais que exerciam atividades exclusivamente administrativas, sendo elegíveis para a realização do estudo 440 enfermeiros.

Para as etapas do processo de validação, foram realizados três sorteios: 1Validação semântica (10 enfermeiros); 2- Pré-teste (50 enfermeiros) e 3- Avaliação das propriedades psicométricas da Versão para o Português do Brasil da CSPS (CSPSPB) (300 enfermeiros). Para todas as etapas, adotou-se o percentual de 20,0\% a mais na realização do sorteio, devido a possibilidade de perdas. Para as etapas de validação semântica e pré-teste, não houve perdas. Para a avaliação das propriedade psicométricas, houve duas recusas, quatro demissões e 11 profissionais de licença saúde. Assim, o percentual de perdas dessa fase foi de 5,6\%, sendo estes substituídos pelos números seguintes.

Foram considerados elegíveis para o estudo todos os setores do hospital onde havia enfermeiros que prestavam assistência a pacientes. Dessa forma, os setores foram agrupados considerando-se as especialidades, sendo clínica médica, clínica cirúrgica, urgência, terapia intensiva e ambulatórios.

O cálculo da amostra para a avaliação das propriedades psicométricas da CSPSPB partiu do pressuposto de que, para um instrumento contendo 20 questões, seriam necessários no mínimo dez profissionais para cada item a fim de se realizar a análise fatorial (CROCKER; ALGINA 1986). No entanto, segundo Comrey e Lee (1992), amostras de 200 sujeitos são razoáveis e de 300 são consideradas como boas. Com isso, a amostra foi composta por 300 enfermeiros, considerando-se 15 sujeitos para cada item do instrumento.

\subsubsection{Coleta de Dados}

A coleta de dados ocorreu por meio de abordagens individuais realizadas pela 
pesquisadora, no próprio local de trabalho durante todos os dias da semana, nos turnos manhã, tarde e noite.

Todos os enfermeiros foram convidados a participar da pesquisa e, após assinatura do termo de consentimento livre e esclarecido, foram aplicados os instrumentos.

A pesquisadora aguardava 0 momento em que 0 profissional tinha disponibilidade para responder à pesquisa.

Os enfermeiros receberam um envelope contendo:

- Formulário com informações demográficas e profissionais (sexo, data de nascimento, tempo na função, setor e turno de trabalho; como tomou conhecimento das PP, se recebeu treinamento acerca das PP);

2- CSPS-PB (anexo 10);

3- Termo de Consentimento Livre e esclarecido.

A pesquisadora orientava os profissionais quanto ao preenchimento dos instrumentos e quanto ao fechamento do envelope e aguardava o término. Após, o envelope lacrado era recolhido com o termo de consentimento separadamente. Os dados foram coletados pela pesquisadora e por duas enfermeiras que foram treinadas quanto ao procedimento de coleta de dados e acerca dos aspectos éticos. A coleta ocorreu no próprio local de trabalho no momento oportuno quando o enfermeiro tivesse disponibilidade.

\subsubsection{Análise dos Dados}

Caracterização dos sujeitos: Utilizou-se análise estatística descritiva (média, mediana e desvio padrão) para a caracterização dos sujeitos segundo variáveis sociodemográficas e profissionais.

Frequência das respostas e análise dos escores da CSPS-PB: Análise descritiva e percentuais foram utilizados para descrever a frequência das respostas de CSPS-PB. Para a análise dos escores, foram atribuídos valores às opções de respostas 
"nunca", "raramente", "às vezes", e "sempre". Considerando-se que os profissionais devem aderir integralmente às $\mathrm{PP}$, apenas à opção "sempre" nos itens positivos e à opção "nunca" nos itens formulados negativamente foram atribuídos um escore 1. Para as outras opções de respostas, o escore foi zero. Assim, o escore da CSPS-PB varia de 0 a 20, sendo que um maior escore indica maior adesão às PP (LAM, 2011; LAM, 2014).

Confiabilidade e Estabilidade: A confiabilidade foi avaliada por meio da consistência interna e do teste reteste. A consistência interna foi verificada pelo Coeficiente Alfa de Cronbach (a), cuja amplitude varia de 0 a 1, sendo considerados valores oportunos superiores a 0,60 (DEVELLIS, 1991; FREITAS; RODRIGUES, 2005).

Para o teste reteste, foi utilizado o Coeficiente de Correlação Intra-Classe, para verificar a correlação entre os escores resultantes da primeira aplicação do instrumento e a segunda. Os valores tomados como referência para tal análise são descritos como ICC $<0,40$, indicando correlação fraca; $0,41<$ ICC $<0,60$, correlação moderada; 0,61 $<$ ICC $<0,80$, correlação boa ou substancial, e ICC > 0,81, quase perfeita ou muito boa (FAYERS; MACHIN, 2007; MCDOWELL; NEWEEL, 1996; TERWEE et al., 2007). Essa forma de mensuração é indicada nesse caso, pois há a possibilidade de diferenças sistemáticas entre as respostas que não são levadas em consideração ao se utilizar o coeficiente de correlação de Pearson.

Validade de Construto: Para a validação de construto, foi utilizada a comparação entre grupos diferentes, a análise fatorial exploratória e a análise fatorial confirmatória, segundo Modelo de Equações Estruturais (SEM) (HO, 2006; YUAN; BENTLER, 2007).

Comparação entre grupos distintos. Testou-se a hipótese da diferença dos escores de adesão às PP, considerando-se o sexo, a idade, o setor, o tempo de experiência clínica, o número de horas trabalhadas na semana e ter recebido treinamento acerca das PP. Para a comparação das médias dos escores de adesão às PP entre os diferentes grupos mencionados utilizou-se o Teste T de Student para duas variáveis e análise de variância (ANOVA) para a comparação entre três ou mais grupos de variáveis contínuas, adotando-se $p \leq 0,05$. 


\section{Análise Fatorial}

\section{Confirmatória}

Foi realizada análise fatorial confirmatória para verificar a adequação do modelo ao original, considerando-se os ajustes:

1- Índice de ajuste normalizado (NFI) e índice de ajuste comparativo (CFI). Essas medidas devem variar de zero a um, sendo recomendados valores acima de 0,90 (HAIR JR et al., 2005).

2- Índice de ajuste parcimonioso (RMSEA), sendo adequados valores abaixo de 0,80 (HAIR JR et al., 2005).

\section{Exploratória}

Foi realizada análise fatorial exploratória para a identificação da estrutura do instrumento e dos construtos teóricos existentes (PASQUALI, 2012). Foram adotados os seguintes procedimentos:

1- Método dos Componentes Principais (PC) para a extração dos fatores;

2- Método de rotação ortogonal (Varimax) para a determinação dos fatores;

3- Teste de adequação da amostra de Kaiser-Meyer-Olkin (KMO) com valores acima de 0,60 (indica a proporção das variâncias; quanto mais próximo de 1, melhor o resultado e mais adequada é a amostra para a realização da análise fatorial) (KAISER, 1974).

4- Para o Teste de Esfericidade de Bartlett (AIC), considerou-se $p<0,001$ (BARTLETT, 1954);

5- Para a determinação do número de fatores a extrair, adotaram-se dois critérios: autovalores $>1$ e análise paralela. Para os autovalores, foram considerados os que apresentaram eigenvalue $\geq 1$ e a variância explicada por eles (GUTTMAN, 1954; KAISER, 1960; KAISER, 1974). A análise paralela foi realizada por meio do programa RanEigen Syntax (Enzmann, 1997), obtendo-se autovalores aleatórios que foram comparados aos autovalores empíricos, estimando-se, de fato, o número real de fatores (REISE; WALLER; COMREY, 2000).

6- Confirmação das dimensões teóricas previamente definidas, considerando os 
itens com carga fatorial $\geq 0,30$ (COMREY; LEE, 1992; PASQUALI, 2003).

Para as análises estatísticas, utilizou-se o software IBM ${ }^{\circledR}$ SPSS, versão 19.0. Para a análise fatorial confirmatória, foi utilizado seu módulo específico Analysis of Moment Structures (IBM ${ }^{\circledR}$ SPSS AMOS). Para a análise paralela, utilizou-se o programa RanEigen Syntax, versão 2.0. O nível de significância adotado foi $a=0,05$.

\subsection{Aspectos Éticos}

Foi solicitada autorização para a adaptação do instrumento junto ao autor original da CSPS, Simon Ching Lam. Dessa forma, foi autorizada a utilização do instrumento para a realização deste trabalho no Brasil, mediante assinatura de um termo de reprodução (Approval code: B500D36-201206) e apresentação do banco de dados, contendo os vinte itens da CSPS sem exclusões (anexo 11).

A autorização requerida junto à Diretoria de Enfermagem da Instituição foi concedida (anexo 12).

O projeto foi aprovado pelo Comitê de Ética e Pesquisa da Escola de Enfermagem de Ribeirão Preto ( $n^{\circ} 343.473 / 2013$ ) (anexo 13) e pelo Comitê de Ética e Pesquisa do IAMSPE (n0405.247/2013) (anexo 14). No entanto, um novo parecer (n0599.965/2014) foi reemitido no ano de 2014 devido a um erro no sistema em substituição ao parecer anterior, alterando, assim, o número CAAE de 13906813.6.0000.5393 para 13906813.6.3001.5463 (anexo 15).

A todos os participantes, foi assegurado o sigilo e o anonimato, segundo as recomendações da Resolução 466/12 do Conselho Nacional de Saúde. Os dados foram coletados mediante a concordância e a assinatura do Termo de Consentimento Livre e Esclarecido pelos profissionais. 


\section{RESULTADOS}

Os resultados serão apresentados de acordo com as etapas do processo de adaptação cultural e validação da CSPS-PB.

\subsection{Tradução}

A tradução realizada por tradutores juramentados independentes possibilitou a utilização de termos e expressões pertinentes aos objetivos do trabalho e gerou duas versões em português distintas do instrumento.

\subsection{Validação de Face e Conteúdo}

Um comitê composto por especialistas realizou a validação de face e conteúdo do instrumento. Mediante a leitura e discussão dos itens da escala entre os sete juízes, as modificações foram realizadas quando o percentual de concordância fosse $\geq 80,0 \%$, ou seja, quando cinco juízes ou mais aceitaram e ou atribuíram sugestões aos itens. Dessa forma, para 10 itens do instrumento, houve propostas para alterações, pela maioria dos juízes, sendo acatadas. Os dois tradutores juramentados participaram desse comitê, e foram utilizadas as duas versões por eles traduzidas para ampliar as discussões acerca dos itens (quadro 1). 
Quadro 1 - Modificações nos itens da CSPS-PB propostas pelos juízes. Ribeirão Preto-SP, 2013

\begin{tabular}{|c|c|}
\hline Item & Sugestão para modificação \\
\hline $\begin{array}{l}1^{1} \text { - Eu lavo minhas mãos entre contatos com } \\
\text { cada paciente. } \\
1^{2} \text { - Lavo as mãos após contato com cada } \\
\text { paciente. }\end{array}$ & $\begin{array}{l}\text { Considerou-se a expressão "entre contatos } \\
\text { com pacientes". }\end{array}$ \\
\hline $\begin{array}{l}\text { 2- Eu uso somente água para lavar as mãos. } \\
2^{2} \text { - Uso apenas água para lavar as mãos. }\end{array}$ & $\begin{array}{l}\text { A sugestão foi trocar a o verbo "lavar" por } \\
\text { "higienizar". }\end{array}$ \\
\hline $\begin{array}{l}3^{1} \text { - Uso desinfetante alcoólico } \\
\text { alternativamente, se minhas mãos não estão } \\
\text { visivelmente sujas. } \\
3^{2} \text { - Uso produto a base de álcool para } \\
\text { esfregar as mãos como alternativa se minhas } \\
\text { mãos não estiverem visivelmente sujas. }\end{array}$ & $\begin{array}{l}\text { Considerou-se "minhas mãos" apenas uma } \\
\text { vez na frase, para que não ficasse muito } \\
\text { extensa. }\end{array}$ \\
\hline $\begin{array}{l}\text { 41- Eu recubro as agulhas de injeção após o } \\
\text { uso. } \\
4^{2} \text { - Cubro as agulhas com uma tampa após } \\
\text { aplicar uma injeção. }\end{array}$ & $\begin{array}{l}\text { Utilizou-se a palavra "reencape", pois é mais } \\
\text { comumente conhecida pelos profissionais. }\end{array}$ \\
\hline $\begin{array}{l}7^{1} \text { - Eu removo Equipamento de Proteção } \\
\text { Pessoal (EPP) em um local especial. } \\
7^{2} \text { - Removo os EPI (Equipamento de } \\
\text { Proteção Individual) em uma área } \\
\text { apropriada. }\end{array}$ & $\begin{array}{l}\text { Optou-se por utilizar a palavra "retiro" em } \\
\text { vez de "removo". Com relação ao local } \\
\text { utilizou-se "local designado". }\end{array}$ \\
\hline $\begin{array}{l}10^{1} \text { - Eu uso luvas quando estou exposto a } \\
\text { secreções, sangue, ou qualquer excreção de } \\
\text { pacientes. } \\
10^{2} \text { - Uso luvas quando fico exposto a líquidos } \\
\text { corporais, produtos de sangue e qualquer } \\
\text { excreção de pacientes. }\end{array}$ & Acrescentou-se "sangue e derivados". \\
\hline $\begin{array}{l}\text { 13¹- Eu uso máscara cirúrgica somente, ou } \\
\text { em combinação com os óculos de proteção } \\
\text { de rosto, e avental, sempre que tem a } \\
\text { possibilidade de respingos ou espirros. }\end{array}$ & $\begin{array}{l}\text { Não foi considerado o EPI proteção de rosto, } \\
\text { pois não é um EPI comumente utilizado em } \\
\text { combinação com óculos de proteção pelos } \\
\text { profissionais de enfermagem em enfermarias }\end{array}$ \\
\hline
\end{tabular}




\begin{tabular}{|c|c|}
\hline $\begin{array}{l}13^{2} \text { - Uso apenas uma máscara cirúrgica ou } \\
\text { junto com óculos de proteção, máscara facial } \\
\text { e avental sempre que houver possibilidade } \\
\text { de respingos ou derramamentos. }\end{array}$ & o Brasil. \\
\hline $\begin{array}{l}\text { 16- Eu uso uma vestimenta ou avental } \\
\text { quando estou exposto a sangue, secreções } \\
\text { corporais, ou excreções de pacientes. } \\
16^{2} \text { - Uso uma bata ou avental quando estou } \\
\text { exposto a sangue, líquidos corporais ou } \\
\text { quaisquer excreções do paciente. }\end{array}$ & $\begin{array}{l}\text { Foram utilizadas as palavras } \\
\text { "avental/capote", pois alguns profissionais } \\
\text { conhecem este EPI com essas } \\
\text { denominações. }\end{array}$ \\
\hline $\begin{array}{l}\text { 17¹- Lixo contaminado com sangue, líquidos } \\
\text { do corpo, secreções e excreções são } \\
\text { colocados em sacolas plásticas vermelhas } \\
\text { independente do estado do paciente. } \\
17^{2} \text { - O lixo contaminado com sangue, } \\
\text { líquidos corporais, secreção e excreção é } \\
\text { colocado dentro de sacos plásticos } \\
\text { vermelhos, independente do estado de } \\
\text { infeção do paciente. }\end{array}$ & $\begin{array}{l}\text { Considerou-se como "material contaminado" } \\
\text { a expressão "lixo". A legislação vigente } \\
\text { determina que os materiais desse tipo sejam } \\
\text { descartados em "sacos plásticos brancos" } \\
\text { devidamente identificados. }\end{array}$ \\
\hline $\begin{array}{l}20^{1} \text { - Eu limpo imediatamente derramamento } \\
\text { de sangue ou outros líquidos corporais com } \\
\text { desinfetante. } \\
20^{2} \text { - Limpo os derramamentos de sangue ou } \\
\text { outros líquidos corporais imediatamente com } \\
\text { desinfetantes. }\end{array}$ & $\begin{array}{l}\text { O termo "líquidos corporais" foi substituído } \\
\text { por "fluidos corporais". }\end{array}$ \\
\hline
\end{tabular}

${ }^{1}$ Versão traduzida 1

${ }^{2}$ Versão traduzida 2

Alguns itens da escala geraram dúvidas com relação à forma com que se apresentavam. Para todos os itens, optou-se pela utilização do pronome "eu" no início das frases, a fim de que a adesão às PP seja a representação das ações individuais realizadas na prática clínica de cada profissional.

Na questão 1, a sugestão foi utilizar a expressão "entre contatos com pacientes", para que se pudesse expressar melhor o contato entre um paciente e outro. Para a questão 2, o termo "lavar" foi substituído por "higienizar", por ser mais comumente 
utilizado no Brasil segundo as legislações vigentes.

Quanto à questão 3, a expressão "minhas mãos" foi citada apenas uma vez na frase para que não ficasse muito extensa. Já no item 4, adotou-se a palavra "reencape" para exprimir a prática de "cobrir agulhas" após aplicação de uma injeção.

Optou-se por utilizar a palavra "retiro" e "local designado" na questão 7 com relação aos EPI. Assim, no item 13, não foi considerado o EPI proteção de rosto, pois no Brasil não é comumente utilizado em combinação com óculos de proteção.

Na questão 16, foi acrescentada a palavra "capote", pois somente a inferência ao avental poderia ser confundida com o jaleco quando o profissional fosse responder a esta questão, não sendo esta a finalidade deste EPI.

Para a questão 17, acerca do descarte de resíduos contaminados, considerouse como "material contaminado" a palavra "lixo", e "sacos plásticos vermelhos" não condizem com a legislação brasileira vigente, que determina que os materiais desse tipo sejam descartados em "sacos plásticos brancos", devidamente identificados.

Na questão 20, a expressão "líquidos corporais" foi substituída por fluídos corporais, obedecendo à legislação. Esse item foi amplamente discutido no que diz respeito à importância de se discriminar quais seriam estas superfícies e qual o tipo de "desinfetante" utilizado. Porém, como não atingiu o percentual de concordância exigido, não foram realizadas modificações nesse sentido.

\subsection{Validação Semântica}

Nesta etapa, a escala foi aplicada para 12 enfermeiros, sendo $10(83,3 \%)$ do sexo feminino. Com relação à idade, a mediana foi de $37,3(\mathrm{DP}=8,7)$, com mínima de 26 e máxima de 61 anos.

Sobre o tempo na função, 06 (50,0\%) atuavam há menos de 10 anos. Quanto ao setor de trabalho, houve diversificação, uma vez que os enfermeiros foram sorteados (tabela 1). 
Tabela 1 - Caracterização profissional e demográfica dos enfermeiros $(n=12)$ da fase de validação semântica da CSPS-PB. São Paulo-SP, 2013

\begin{tabular}{lll}
\hline Variáveis & $\mathbf{n}$ & $\mathbf{\%}$ \\
\hline Sexo & 10 & 83,3 \\
Feminino & 02 & 16,7 \\
Masculino & & \\
Idade & 02 & 16,7 \\
$25 \mid-30$ anos & 02 & 16,7 \\
$30 \mid-35$ anos & 05 & 41,6 \\
$35 \mid-40$ anos & 02 & 16,7 \\
$40 \mid-45$ anos & 01 & 8,3 \\
>=45 anos & & \\
Tempo na função & 03 & 25,0 \\
$<05$ anos & 03 & 25,0 \\
05|-10 anos & 04 & 33,4 \\
$10 \mid-15$ anos & 01 & 8,3 \\
$15 \mid-20$ anos & & \\
Setor de trabalho & 02 & 16,8 \\
Hemodiálise & 02 & 16,8 \\
Clínica Cirúrgica & 01 & 8,3 \\
Clínica Médica & 01 & 8,3 \\
Transplante de rim & 01 & 8,3 \\
Pediatria & 01 & 8,3 \\
Emergência & 01 & 8,3 \\
Unidade Coronariana & 01 & 8,3 \\
Unidades de Moléstias Infectocontagiosas & 01 & 8,3 \\
Serviço de Controle de Infecção & 01 & 8,3 \\
Educação Continuada & & \\
\hline
\end{tabular}

Na avaliação geral do instrumento, 07 (58,3\%) enfermeiros consideraram-no como muito bom e 05 (41,7\%), bom. A alternativa ruim não foi assinalada por nenhum participante. Com relação à compreensão das questões, 10 (83,3\%) afirmaram serem fáceis de entender e $02(16,7 \%)$ responderam que às vezes são difíceis. Para as categorias de respostas (sempre, às vezes, raramente, nunca) $11(91,7 \%)$ não tiveram nenhuma dificuldade em utilizá-las; 01 (8,3\%) relatou alguma dificuldade.

Na avaliação dos itens da escala, os enfermeiros responderam que as questões são relevantes para sua prática clínica, e não tiveram dificuldade para entendê-las. Além disso, apontaram que as opções de respostas estavam claras e compreensíveis.

Considerando-se a relevância das questões para sua prática diária, 11 (91,7\%) demarcaram ser muito relevante e 01 (8,3\%), às vezes relevante. Acerca do item "você 
gostaria de mudar alguma coisa no questionário?", 10 (83,3\%) referiram que não e 02 $(16,7 \%)$, sim. Dentre os que indicaram sim, uma sugestão foi referente a não ter conteúdo repetitivo. No entanto, essas sugestões não foram acatadas por ser conteúdo estrutural do item original.

Para a pergunta "Você não quis responder alguma questão", todos os enfermeiros $12(100,0 \%)$ responderam que não.

Para quatro questões, houveram sugestões de modificações, que foram acatadas.

Na questão 3 "Eu uso produto à base de álcool para esfregar as mãos como alternativa se não estiverem visivelmente sujas", o termo esfregar foi substituído por "higienizar".

Para o item 13 "Eu uso apenas máscara cirúrgica ou em combinação com óculos de proteção e avental sempre que houver a possibilidade de respingos ou derramamentos", a palavra "apenas" foi retirada.

A questão 17 "Material contaminado com sangue, fluídos corporais, secreções e excreções de pacientes é descartado em sacos plásticos brancos independentes do estado infeccioso do paciente", foi alterada, iniciando com a expressão: "Eu descarto" e excluindo "é descartado".

Algumas dúvidas foram apontadas para a questão 20. A primeira foi com relação ao tipo de desinfetante utilizado e a segunda no que diz respeito à limpeza das superfícies, tendo como justificativa que nem sempre os enfermeiros são responsáveis por essa tarefa. A sugestão apresentada foi citar o tipo de superfície a ser descontaminada e o tipo de produto empregado. Desta forma, após consulta ao autor da CSPS original, para o item 20 "Eu limpo imediatamente com desinfetante superfícies após derramamento de sangue ou outros fluídos corporais", foi acrescentada a palavra "álcool" para determinar o tipo de desinfetante utilizado. 


\subsection{Pré-teste}

Nesta fase, 50 enfermeiros que atuavam na assistência a pacientes na instituição responderam aos instrumentos, sendo que a maioria, $40(80,0 \%)$, eram mulheres. Com relação ao número de empregos, 37 (74,0\%) responderam ter um vínculo empregatício e 29 (58,0\%) informaram trabalhar 30 horas semanais.

Dentre os setores, a maior parte dos profissionais $34(68,0 \%)$ atuava em unidades de clínica médica e 16 (32,0\%) em unidades de clínica cirúrgica.

Todos os itens da escala foram respondidos. Não houve recusas quanto à participação nesta etapa do estudo. As frequências das respostas estão apresentadas na tabela 2.

Tabela 2 - Distribuição das respostas dos enfermeiros $(n=50)$ atribuídas na fase de pré-teste da CSPS-PB. São Paulo-SP, 2014

\begin{tabular}{lcccc}
\hline Item & Nunca & Ás vezes & Raramente & Sempre \\
\cline { 2 - 5 } & $\mathbf{n ~ ( \% )}$ & $\mathbf{n ~ ( \% )}$ & $\mathbf{n ~ ( \% )}$ & $\mathbf{n ~ ( \% )}$ \\
\hline Item 1 & - & - & $07(14,0)$ & $43(86,0)$ \\
Item 2 & $36(72,0)$ & $03(6,0)$ & $05(10,0)$ & $06(12,0)$ \\
Item 3 & $06(12,0)$ & $05(10,0)$ & $20(40,0)$ & $19(38,0)$ \\
Item 4 & $34(68,0)$ & $09(18,0)$ & $07(14,0)$ & - \\
Item 5 & - & - & - & $50(100,0)$ \\
Item 6 & $09(18,0)$ & $05(10,0)$ & $14(18,0)$ & $22(44,0)$ \\
Item 7 & $34(68,0)$ & $09(18,0)$ & $07(14,0)$ & - \\
Item 8 & $19(38,0)$ & $13(26,0)$ & $06(12,0)$ & $12(24,0)$ \\
Item 9 & $02(4,0)$ & $05(10,0)$ & $09(18,0)$ & $34(68,0)$ \\
Item 10 & - & - & - & $50(100,0)$ \\
Item 11 & - & - & $01(2,0)$ & $49(98,0)$ \\
Item 12 & - & $01(2,0)$ & $08(16,0)$ & $41(82,0)$ \\
Item 13 & $02(4,0)$ & $04(8,0)$ & $15(30,0)$ & $29(58,0)$ \\
Item 14 & - & $01(2,0)$ & - & $49(98,0)$ \\
Item 15 & $38(76,0)$ & $05(10,0)$ & $06(12,0)$ & $01(2,0)$ \\
Item 16 & $03(6,0)$ & $08(16,0)$ & $19(38,0)$ & $20(40,0)$ \\
Item 17 & $03(6,0)$ & $02(4,0)$ & $05(10,0)$ & $40(80,0)$ \\
Item 18 & - & $03(6,0)$ & $12(24,0)$ & $35(70,0)$ \\
Item 19 & $02(4,0)$ & - & $04(8,0)$ & $44(88,0)$ \\
Item 20 & - & - & $04(8,0)$ & $46(92,0)$ \\
\hline
\end{tabular}




\subsection{Avaliação das Propriedades Psicométricas da CSPS-PB}

\subsubsection{Caracterização demográfica e profissional da amostra}

A CSPS-PB foi aplicada para 300 enfermeiros que atuavam na assistência de enfermagem na instituição. A maior parte dos participantes eram do sexo feminino (tabela 3); a idade mínima foi de 25 anos e a máxima, de 75 anos.

Sobre vínculo empregatício, um total de 222 (74,0\%) enfermeiros responderam ter um vínculo; 72 (24,0\%), dois vínculos e 06 (1,9\%) informaram ter três ou mais. A média de horas trabalhadas na semana foi de 40,7 (DP=14,2), variando de 30 a 87 horas. Com relação ao turno de trabalho, 223 (74,3\%) trabalhavam no período diurno fixo (manhã/tarde); 66 (22,0\%) trabalhavam no período noturno fixo e 11 (3,7\%) responderam realizar rodízio nos turnos. Acerca da experiência clínica, 101 (33,7\%) profissionais alegaram atuar há menos de cinco anos na função; 65 (21,7\%), de 5 a 10 anos; 77 (25,7\%), entre 10 a 15 anos; 16 (5,3\%), de 15 a 20 anos, e 41 (13,7\%), há 20 anos ou mais.

Quanto à aquisição de conhecimento acerca das PP, 123 (41,0\%) dos participantes referiram ter sido no hospital; $17(5,7 \%)$, na escola ou universidade, e $160(53,3 \%)$ demarcaram as duas opções.

A maioria dos enfermeiros respondeu ter recebido treinamento sobre PP (tabela 3). 
Tabela 3 - Características demográficas e profissionais dos enfermeiros $(n=300)$. São Paulo-SP, 2014

\begin{tabular}{lc}
\hline Características & Estatísticas \\
\hline Idade & $\mathrm{X}^{2}=39,0(\mathrm{DP}=9,7)$ \\
$\quad$ Mexo & $42(14,0 \%)$ \\
$\quad$ Feminino & $258(86,0 \%)$ \\
Treinamento sobre precauções-padrão & \\
$\quad$ Não & $106(35,3 \%)$ \\
Sim & $194(64,7 \%)$ \\
Experiência clínica (anos) & $\mathrm{X}^{2}=10,0(\mathrm{DP}=8,6)$ \\
Horas trabalhadas (semana) & $\mathrm{X}^{2}=40,7(\mathrm{DP}=14,8)$ \\
Setor de trabalho & \\
Clínica Médica & $92(30,7 \%)$ \\
Clínica Cirúrgica & $77(25,7 \%)$ \\
Ambulatórios & $76(25,3 \%)$ \\
UTI & $32(10,6 \%)$ \\
Urgência & $23(7,7 \%)$ \\
\hline
\end{tabular}

Com relação ao setor de trabalho, a maior parte dos enfermeiros (30,7\%) estavam alocados em unidade de clínica médica.

\subsubsection{Análise das respostas da CSPS-PB segundo domínios}

Os 300 enfermeiros responderam aos 20 itens da CSPS-PB, selecionando uma das quatro alternativas "sempre", "muitas vezes", "às vezes" ou "nunca". Não houve perdas para nenhum item. A tabela 4 evidencia as frequências obtidas nos vinte itens da CSPS-PB alocadas nos cinco domínios: Uso de EPI; Descarte de materiais perfurocortantes; Descarte de resíduos; Descontaminação de artigos e superfícies e Prevenção de infecção de pessoa para pessoa. 
Tabela 4 - Frequência das respostas dos enfermeiros $(n=300)$ atribuídas aos itens segundo os domínios da CSPS-PB. São Paulo-SP, 2014

\begin{tabular}{|c|c|c|c|c|}
\hline Itens & $\begin{array}{c}\text { Nunca } \\
n(\%)\end{array}$ & $\frac{\text { Às vezes }}{\mathrm{n}(\%)}$ & $\begin{array}{c}\text { Raramente } \\
\mathbf{n}(\%)\end{array}$ & $\begin{array}{c}\text { Sempre } \\
\mathrm{n}(\%)\end{array}$ \\
\hline Uso de EPI & & & & \\
\hline $\begin{array}{l}\text { 7. Eu retiro os Equipamentos de } \\
\text { Proteção Individual (EPI) em um local } \\
\text { designado. }\end{array}$ & $14(4,7)$ & $15(5,0)$ & $52(17,3)$ & $219(73,0)$ \\
\hline 10. Eu uso luvas quando estou exposto & $02(0,7)$ & - & $12(4,0)$ & $286(95,3)$ \\
\hline $\begin{array}{l}\text { a fluidos corporais, sangue ou } \\
\text { derivados e qualquer excreção de } \\
\text { pacientes. }\end{array}$ & & & & \\
\hline $\begin{array}{l}\text { 13. Eu uso máscara cirúrgica ou em } \\
\text { combinação com óculos de proteção e }\end{array}$ & $08(2,7)$ & $32(10,7)$ & $99(33,0)$ & $161(53,7)$ \\
\hline avental sempre que houver a & & & & \\
\hline $\begin{array}{l}\text { possibilidade de respingos ou } \\
\text { derramamentos. }\end{array}$ & & & & \\
\hline $\begin{array}{l}\text { 14. Minha boca e meu nariz ficam } \\
\text { cobertos quando uso máscara. }\end{array}$ & $06(2,0)$ & $02(0,7)$ & $09(3,0)$ & $283(94,3)$ \\
\hline $\begin{array}{l}\text { 15. Eu reutilizo uma máscara cirúrgica } \\
\text { ou EPI descartável. }\end{array}$ & $225(75,0)$ & $31(10,3)$ & $27(9,0)$ & $17(5,7)$ \\
\hline $\begin{array}{l}\text { 16. Eu uso avental/capote quando } \\
\text { estou exposto a sangue, fluídos } \\
\text { corporais ou qualquer excreção de } \\
\text { pacientes. }\end{array}$ & $15(5,0)$ & $33(11,0)$ & $103(34,3)$ & $149(49,7)$ \\
\hline Descarte de material perfurocortante & & & & \\
\hline $\begin{array}{l}\text { 4. Eu reencapo agulhas usadas após } \\
\text { aplicar uma injeção. }\end{array}$ & $201(67,0)$ & $43(14,3)$ & $48(16,0)$ & $08(2,7)$ \\
\hline $\begin{array}{l}\text { 5. Eu descarto materiais } \\
\text { perfurocortantes em caixas próprias. }\end{array}$ & $04(1,3)$ & $02(0,7)$ & $03(1,0)$ & $291(97,0)$ \\
\hline $\begin{array}{l}\text { 6. A caixa de materiais } \\
\text { perfurocortantes é descartada } \\
\text { somente quando está cheia. } \\
\text { Descarte de resíduos }\end{array}$ & $48(16,0)$ & $35(11,7)$ & $94(31,3)$ & $123(41,0)$ \\
\hline $\begin{array}{l}\text { 17. Eu descarto material contaminado } \\
\text { com sangue, fluidos corporais, } \\
\text { secreções e excreções de pacientes em }\end{array}$ & $19(6,3)$ & $15(5,0)$ & $38(12,7)$ & $228(76,0)$ \\
\hline $\begin{array}{l}\text { sacos plásticos } \\
\begin{array}{l}\text { independentemente } \\
\text { infeccioso do paciente. }\end{array}\end{array}$ do $\begin{array}{r}\text { brancos } \\
\text { estado }\end{array}$ & & & & \\
\hline $\begin{array}{l}\text { Descontaminação de artigos } e \\
\text { superfícies }\end{array}$ & & & & \\
\hline $\begin{array}{l}\text { 18. Eu descontamino superfícies e } \\
\text { equipamentos após o uso. }\end{array}$ & $03(1,0)$ & $14(4,7)$ & $72(24,0)$ & $211(70,3)$ \\
\hline $\begin{array}{l}\text { 19. Eu uso luvas para descontaminar } \\
\text { equipamentos que apresentam sujeira } \\
\text { visível). }\end{array}$ & - & $08(2,7)$ & $28(9,3)$ & $264(88,0)$ \\
\hline $\begin{array}{l}\text { 20. Eu limpo imediatamente com } \\
\text { desinfetante (álcool) superfícies após } \\
\text { derramamento de sangue ou outros } \\
\text { fluidos corporais. }\end{array}$ & $07(2,3)$ & $07(2,3)$ & $23(7,7)$ & $263(87,7)$ \\
\hline
\end{tabular}


Prevenção de infecção de pessoa para pessoa

1. Eu lavo minhas mãos entre contatos com pacientes.

$02(0,7) \quad 01(0,3) \quad 37(12,3) \quad 260(86,7)$

2. Eu uso somente água para lavar as mãos.

3. Eu uso produto à base de álcool para higienizar as mãos como alternativa se não estiverem visivelmente sujas.

8. Eu tomo banho em caso de respingos extensos mesmo que eu tenha usado EPI.

9. Eu cubro meus ferimentos ou lesões com curativos a prova d'água antes do contato com pacientes.

11. Eu troco de luvas entre contato com pacientes.

12. Eu higienizo as minhas mãos imediatamente após remover as luvas.

$179(59,7) \quad 54(18,0) \quad 33(11,0) \quad 34(11,3)$

$29(9,7) \quad 32(10,7) \quad 145(48,3) \quad 94(31,3)$

$104(34,7) \quad 67(22,3) \quad 65(21,7) \quad 64(21,3)$

$25(8,3) \quad 22(7,3) \quad 60(20,0) \quad 193(64,3)$

$01(0,3) \quad 01(0,3) \quad 04(1,3) \quad 294(98,0)$

$02(0,7) \quad 02(0,7) \quad 48(16,0) \quad 248(82,7)$

Alguns itens merecem ser destacados, considerando-se que a adesão não aconteceu em sua totalidade.

No domínio Uso de EPI, no item 13 "Eu uso máscara cirúrgica ou em combinação com óculos de proteção e avental sempre que houver a possibilidade de respingos ou derramamentos", 53,7\% das respostas foram alocadas na alternativa "sempre". Para o item 16 "Eu uso avental/capote quando estou exposto a sangue, fluídos corporais ou qualquer excreção de pacientes", a adesão a este EPI foi de 49,7\%.

Referente ao domínio Descarte de materiais perfurocortantes, no item 4 "Eu reencapo agulhas usadas após aplicar uma injeção", os enfermeiros responderam realizar essa prática com alguma frequência, sendo que a alternativa "sempre" correspondeu a 14,3\%; a alternativa "raramente", a 16,0\% e a alternativa "sempre", a $2,7 \%$.

Com relação ao domínio Descarte de resíduos, para o item 17 "Eu descarto material contaminado com sangue, fluídos corporais, secreções e excreções de pacientes em sacos plásticos brancos independentemente do estado infeccioso do paciente", 76,0\% dos enfermeiros responderam a alternativa "sempre".

Para o domínio Descontaminação de artigos e superfícies, o item 18 "Eu descontamino superfícies e equipamentos após o uso", 70,3\% dos enfermeiros responderam realizar "sempre" essa prática. 
No domínio Prevenção de infecção de pessoa para pessoa, no item 1 "Eu lavo minhas mãos entre contatos com pacientes", 86,7\% dos enfermeiros demarcaram a alternativa "sempre". Considerando o mesmo domínio, o item 2 "Eu uso somente água para lavar as mãos", 59,7\% dos profissionais assinalaram a alternativa "nunca".

$\mathrm{Na}$ tabela 5, estão apresentadas as taxas de adesão referentes aos itens. As opções de respostas "nunca", "às vezes" e "raramente" foram agrupadas, indicando não adesão à prática avaliada, e a opção de resposta "sempre" correspondeu à adesão ao item avaliado. Para os itens invertidos, a classificação ocorreu inversamente à descrita.

Tabela 5 - Adesão e não adesão dos enfermeiros $(n=300)$ referente aos itens da CSPSPB segundo respostas agrupadas por domínios. São Paulo-SP, 2014

\section{Itens}

\begin{tabular}{cc}
$\begin{array}{c}\text { Não } \\
\text { Adesão }\end{array}$ & Adesão \\
\hline$\%$ & $\%$
\end{tabular}

Uso de EPI

7. Eu retiro os Equipamentos de Proteção Individual (EPI) em um local designado.

10. Eu uso luvas quando estou exposto a fluidos corporais, sangue ou derivados e qualquer excreção de pacientes.

13. Eu uso máscara cirúrgica ou em combinação com óculos de proteção e avental sempre que houver a possibilidade de respingos ou derramamentos.

14. Minha boca e meu nariz ficam cobertos quando uso mascara.

$4,7 \quad 93,3$

15. Eu reutilizo uma máscara cirúrgica ou EPI descartável.*

46,3

16. Eu uso avental/capote quando estou exposto a sangue, fluidos corporais ou qualquer excreção de pacientes.

$\begin{array}{cc}5,7 & 94,3 \\ 25,0 & 75,0 \\ 50,3 & 49,7\end{array}$

Descarte de material perfurocortante

4. Eu reencapo agulhas usadas após aplicar uma injeção.*

5. Eu descarto materiais perfurocortantes em caixas próprias.

$3,0 \quad 97,0$

6. A caixa de materiais perfurocortantes é descartada somente quando está cheia.*

$84,0 \quad 16,0$

Descarte de resíduos

17. Eu descarto material contaminado com sangue, fluidos corporais, secreções e excreções de pacientes em sacos plásticos brancos independentemente do estado infeccioso do paciente. 
18. Eu descontamino superfícies e equipamentos após o uso.

19. Eu uso luvas para descontaminar equipamentos que apresentam sujeira visível.

20. Eu limpo imediatamente com desinfetante (álcool) superfícies após derramamento de sangue ou outros fluídos corporais.

Prevenção de infecção de pessoa para pessoa

1. Eu lavo minhas mãos entre contatos com pacientes.

2. Eu uso somente água para lavar as mãos.*

3. Eu uso produto a base de álcool para higienizar as mãos como alternativa se não estiverem visivelmente sujas.

8. Eu tomo banho em caso de respingos extensos mesmo que eu tenha usado EPI.

9. Eu cubro meus ferimentos ou lesões com curativos a prova d'água antes do contato com pacientes.

11. Eu troco de luvas entre contato com pacientes.

12. Eu higienizo as minhas mãos imediatamente após remover as luvas.

*Itens Invertidos

O uso de máscara e avental foram os EPI que apresentaram menores taxas de cumprimento, sendo 53,7\% e 49,7\%, respectivamente. Já para a utilização de luvas, o percentual de adesão mostrou-se mais elevado (95,3\%), no entanto não atingiu sua totalidade.

Para a HM após contato com pacientes, a taxa de cumprimento foi de $86,7 \%$ e após a remoção de luvas, foi de $82,7 \%$. Para a utilização de produto a base de álcool na ausência de sujeira visível obteve-se percentual de apenas 31,3\% de adesão.

Quanto ao reencape de agulhas, observou-se que 67,0\% dos profissionais responderam não realizar esta prática, no entanto 33,0\% a realizam com alguma frequência. Com relação à caixa de materiais perfurocortantes, somente $16,0 \%$ dos enfermeiros responderam que não se deve descartá-la somente quando estiver cheia.

A prática de tomar banho em caso de respingos extensos apresentou taxa de adesão de $31,3 \%$ entre os enfermeiros.

A taxa global média de adesão às PP foi de 69,3\% (DP=0,78). Considerando-se os domínios, obteve-se, para Uso de EPI adesão média de 73,5\%; para Descarte de material perfurocortante, média de 60,0\%; para Descarte de resíduos, 76,0\%; para Descontaminação de artigos e superfícies, $82,0 \%$, e para Prevenção de infecção de 
pessoa para pessoa adesão média de 60,6\%.

\subsubsection{Descrição dos escores da CSPS-PB}

Para a análise dos escores da CSPS-PB, e de acordo com a sintaxe definida por Lam (2011), foram atribuídos o valor 1 para a alternativa "sempre" que indicou adesão às PP e, para as demais opções de respostas, foram atribuídos o valor "zero". Dessa forma, o escore da escala variou de 0 a 20, ou seja, quanto maior o escore, melhor a adesão às PP.

O escore médio dos enfermeiros para a CSPS-PB foi de $13,9(\mathrm{DP}=2,7)$, sendo que o escore mínimo apresentado foi 5,0 e o escore máximo foi 19,0 (figura 2). 


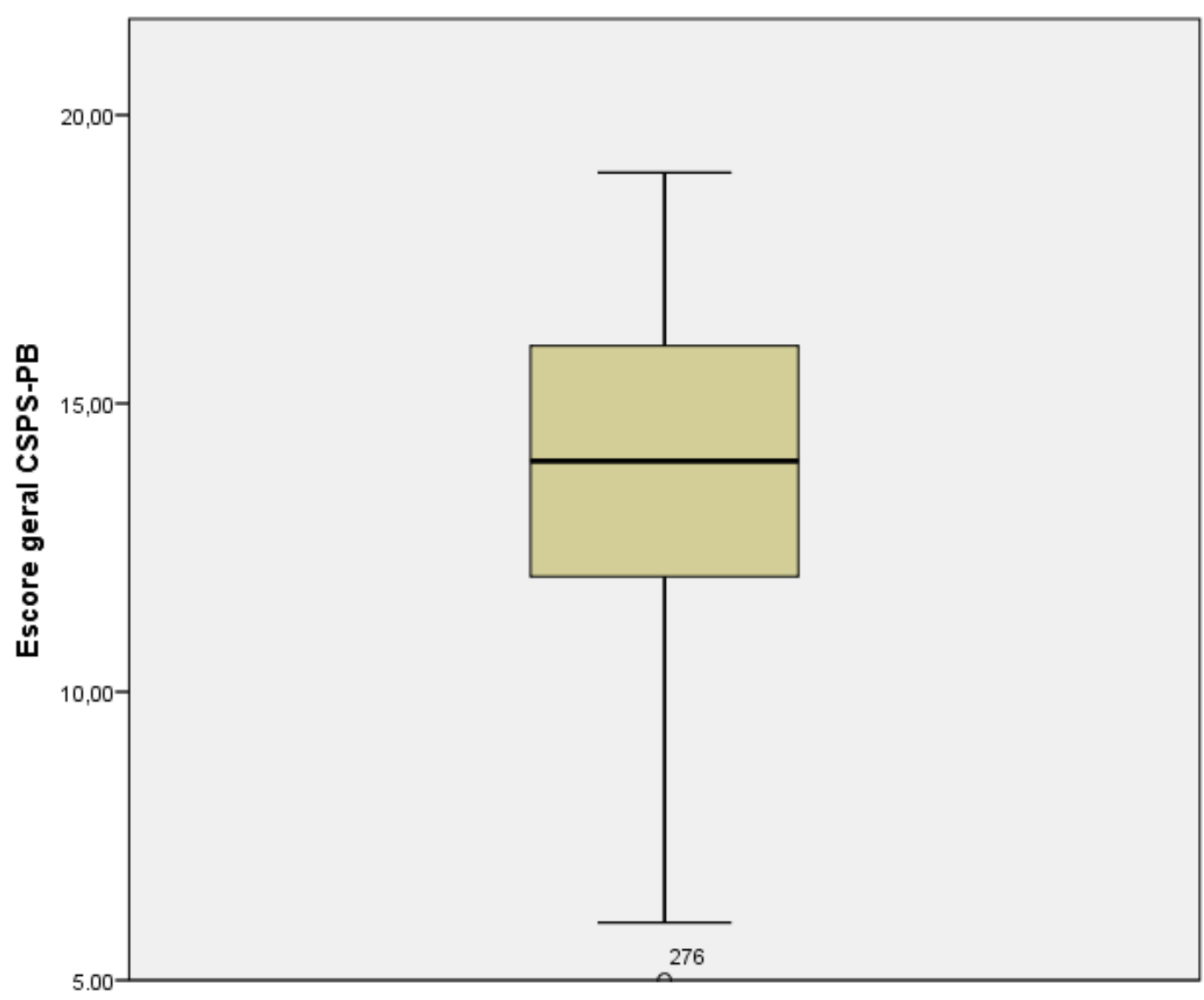

Figura 2 - Gráfico do escore geral da CSPS-PB

\subsubsection{Confiabilidade}

A confiabilidade da CSPS-PB foi avaliada, utilizando-se dois métodos. O primeiro foi pela análise da consistência interna, adotando-se o coeficiente alfa de Cronbach. 0 segundo método foi pela avaliação da confiabilidade/estabilidade por meio do teste reteste, utilizando-se o ICC.

$\mathrm{Na}$ análise da consistência interna geral da CSPS-PB, o coeficiente alfa de Cronbach foi 0.61 . Na tabela 6 encontram-se os valores de cada item. 
Tabela 6 - Coeficiente de correlação item-total e Alfa de Cronbach $(n=300)$ da CSPSPB, São Paulo-SP, 2014

\begin{tabular}{|c|c|c|}
\hline Itens & $\begin{array}{l}\text { Coeficiente } \\
\text { correlação } \\
\text { item-total }\end{array}$ & $\begin{array}{l}\text { Alfa de } \\
\text { Cronbach }\end{array}$ \\
\hline Eu lavo minhas mãos entre contatos com pacientes. & 0,24 & 0,59 \\
\hline Eu uso somente água para lavar as mãos. & 0,11 & 0,61 \\
\hline $\begin{array}{l}\text { Eu uso produto a base de álcool para higienizar as mãos } \\
\text { como alternativa se não estiverem visivelmente sujas. }\end{array}$ & 0,02 & 0,63 \\
\hline Eu reencapo agulhas usadas após aplicar uma injeção. & 0,17 & 0,60 \\
\hline Eu descarto materiais perfurocortantes em caixas próprias. & 0,11 & 0,60 \\
\hline $\begin{array}{l}\text { A caixa de materiais perfurocortantes é descartada somente } \\
\text { quando está cheia. }\end{array}$ & 0,07 & 0,61 \\
\hline $\begin{array}{l}\text { Eu retiro os Equipamentos de Proteção Individual (EPI) em } \\
\text { um local designado. }\end{array}$ & 0,31 & 0,60 \\
\hline $\begin{array}{l}\text { Eu tomo banho em caso de respingos extensos mesmo que } \\
\text { eu tenha usado EPI. }\end{array}$ & 0,18 & 0,60 \\
\hline $\begin{array}{l}\text { Eu cubro meus ferimentos ou lesões com curativos a prova } \\
\text { d'água antes do contato com pacientes. }\end{array}$ & 0,31 & 0,60 \\
\hline $\begin{array}{l}\text { Eu uso luvas quando estou exposto a fluidos corporais, } \\
\text { sangue ou derivados e qualquer excreção de pacientes. }\end{array}$ & 0,18 & 0,60 \\
\hline Eu troco de luvas entre contato com pacientes. & 0,18 & 0,60 \\
\hline $\begin{array}{l}\text { Eu higienizo as minhas mãos imediatamente após remover } \\
\text { as luvas. }\end{array}$ & 0,26 & 0,58 \\
\hline $\begin{array}{l}\text { Eu uso máscara cirúrgica ou em combinação com óculos de } \\
\text { proteção e avental sempre que houver a possibilidade de } \\
\text { respingos ou derramamentos. }\end{array}$ & 0,44 & 0,55 \\
\hline $\begin{array}{l}\text { Minha boca e meu nariz ficam cobertos quando uso } \\
\text { máscara. }\end{array}$ & 0,01 & 0,61 \\
\hline Eu reutilizo uma máscara cirúrgica ou EPI descartável. & 0,12 & 0,60 \\
\hline $\begin{array}{l}\text { Eu uso avental/capote quando estou exposto a sangue, } \\
\text { fluidos corporais ou qualquer excreção de pacientes. }\end{array}$ & 0,30 & 0,58 \\
\hline $\begin{array}{l}\text { Eu descarto material contaminado com sangue, fluídos } \\
\text { corporais, secreções e excreções de pacientes em sacos } \\
\text { plásticos brancos independentemente do estado infeccioso } \\
\text { do paciente. }\end{array}$ & 0,20 & 0,60 \\
\hline Eu descontamino superfícies e equipamentos após o uso. & 0,44 & 0,55 \\
\hline $\begin{array}{l}\text { Eu uso luvas para descontaminar equipamentos que } \\
\text { apresentam sujeira visível. }\end{array}$ & 0,37 & 0,57 \\
\hline $\begin{array}{l}\text { Eu limpo imediatamente com desinfetante (álcool) } \\
\text { superfícies após derramamento de sangue ou outros fluídos } \\
\text { corporais. }\end{array}$ & 0,18 & 0,60 \\
\hline
\end{tabular}

De acordo com os dados apresentados na tabela 6, os itens apresentaram correlações fracas e moderadas que variaram entre 0,55 e 0,61. Na tabela 7, estão 
apresentados os resultados da correlação entre os domínios da CSPS-PB com o escore geral do instrumento, utilizando-se o coeficiente de correlação de Pearson.

Tabela 7 - Coeficiente de correlação de Pearson entre os domínios da CSPS-PB com o escore geral do instrumento. São Paulo-SP, 2014

\begin{tabular}{|c|c|c|c|c|c|c|}
\hline Domínios & $\begin{array}{c}\text { CSPS-PB } \\
\text { Geral }\end{array}$ & $\begin{array}{l}\text { Uso de } \\
\text { EPI }\end{array}$ & $\begin{array}{l}\text { Descarte } \\
\text { perfuro }\end{array}$ & $\begin{array}{l}\text { Descarte } \\
\text { resíduos }\end{array}$ & $\begin{array}{l}\text { Descontaminação } \\
\text { superfícies }\end{array}$ & $\begin{array}{l}\text { Prevenção } \\
\text { infecção }\end{array}$ \\
\hline CSPS-PB Geral & 1 & $0,76^{* *}$ & $0,40^{* *}$ & $0,35^{* *}$ & $0,64^{* *}$ & $0,78^{* *}$ \\
\hline Uso de EPI & $0,76^{* *}$ & 1 & $0,20^{* *}$ & $0,12^{*}$ & $0,34^{* *}$ & $0,36^{* *}$ \\
\hline $\begin{array}{l}\text { Descarte } \\
\text { perfurocortante }\end{array}$ & $0,40^{* *}$ & $0,20^{* *}$ & 1 & 0,09 & 0,08 & $0,36^{* *}$ \\
\hline Descarte resíduos & $0,35^{* *}$ & $0,12^{*}$ & 0,09 & 1 & $0,20^{* *}$ & $0,14^{*}$ \\
\hline $\begin{array}{l}\text { Descontaminação } \\
\text { superfícies }\end{array}$ & $0,64^{* *}$ & $0,34^{* *}$ & 0,08 & $0,20^{* *}$ & 1 & $0,30^{* *}$ \\
\hline $\begin{array}{l}\text { Prevenção } \\
\text { infecção }\end{array}$ & $0,78^{* *}$ & $0,36^{* *}$ & $0,36^{* *}$ & $0,14^{*}$ & $0,30^{* *}$ & 1 \\
\hline
\end{tabular}

Todos os domínios apresentaram correlação com o escore geral do instrumento, sendo que, para o Uso de EPI, a descontaminação de superfícies e a prevenção de infecção apresentaram correlações mais fortes. Apenas os domínios descontaminação de superfícies e descarte de perfurocortantes não apresentaram correlação entre si.

$\mathrm{Na}$ avaliação da estabilidade, o teste reteste foi realizado por meio da reaplicação da CSPS-PB para trinta enfermeiros duas semanas após a primeira coleta. O ICC obtido foi de 0,876 o que indica correlação quase perfeita ou muito boa.

\subsubsection{Análise de construto da CSPS-PB}

\subsubsection{Comparação entre grupos distintos}


A comparação entre grupos diferentes testou a hipótese da diferença dos escores de adesão às PP, considerando-se o sexo; a idade; o setor de trabalho; o tempo de experiência clínica; o número de horas trabalhadas na semana e ter recebido treinamento acerca das PP.

É importante ressaltar que o escore de adesão da CSPS-PB varia entre 0 e 20, sendo que, quanto maior o escore, maior a adesão.

Para as variáveis sexo, setor e número de horas trabalhadas na semana, não houve diferença entre os escores de adesão. No entanto, para as variáveis idade, tempo de experiência clínica e ter recebido treinamento acerca das PP, houve diferenças entre as médias de adesão (tabela 8). 
Tabela 8 - Distribuição dos escores médios de adesão às PP segundo grupos diferentes. São Paulo-SP, 2014

\begin{tabular}{|c|c|c|c|c|}
\hline Variáveis & $\mathbf{n}$ & Escore & DP & Estatísticas \\
\hline \multicolumn{5}{|l|}{ Sexo } \\
\hline Feminino & 258 & 13,8 & 2,7 & $t=0,27 p=0,78$ \\
\hline Masculino & 42 & 13,7 & 2,9 & \\
\hline \multicolumn{5}{|l|}{ Idade (anos) } \\
\hline 20 a 29 & 50 & 13,0 & 2,5 & $F=5,15 p \leq 0,01$ \\
\hline 30 a 39 & 134 & 13,6 & 2,9 & \\
\hline 40 a 49 & 65 & 14,3 & 2,6 & \\
\hline $\begin{array}{l}50 \text { ou mais } \\
\text { Setor }\end{array}$ & 51 & 14,9 & 2,0 & \\
\hline Clínica médica & 92 & 13,7 & 2,9 & $F=0,41 p=0,74$ \\
\hline Clínica cirúrgica & 77 & 13,8 & 2,5 & \\
\hline UTI/Urgência & 55 & 13,7 & 2,6 & \\
\hline Ambulatório & 76 & 14,1 & 2,6 & \\
\hline \multicolumn{5}{|l|}{$\begin{array}{l}\text { Tempo de experiência clínica } \\
\text { (anos) }\end{array}$} \\
\hline$<5$ anos & 101 & 13,5 & 2,7 & $F=8,9 p \leq 0,000$ \\
\hline 5 a 10 anos & 65 & 12,7 & 2,9 & \\
\hline 10 a 15 anos & 77 & 14,4 & 2,3 & \\
\hline $\begin{array}{l}15 \text { anos ou mais } \\
\text { Horas trabalhadas na semana }\end{array}$ & 57 & 14,9 & 2,2 & \\
\hline 30 a 39 horas & 183 & 14,0 & 2,6 & $t=1,03 p=0,30$ \\
\hline 40 ou mais & 117 & 13,6 & 2,7 & \\
\hline \multicolumn{5}{|l|}{$\begin{array}{l}\text { Recebeu treinamento acerca } \\
\text { das PP }\end{array}$} \\
\hline $\operatorname{Sim}$ & 194 & 14,1 & 2,5 & $t=2,48 p \leq 0,01$ \\
\hline Não & 106 & 13,3 & 2,8 & \\
\hline
\end{tabular}

O escore médio de adesão às PP apresentou diferença estatisticamente significante quando comparado com a idade dos enfermeiros, sendo que, quanto maior a idade, maior a adesão às PP (figura 3). 


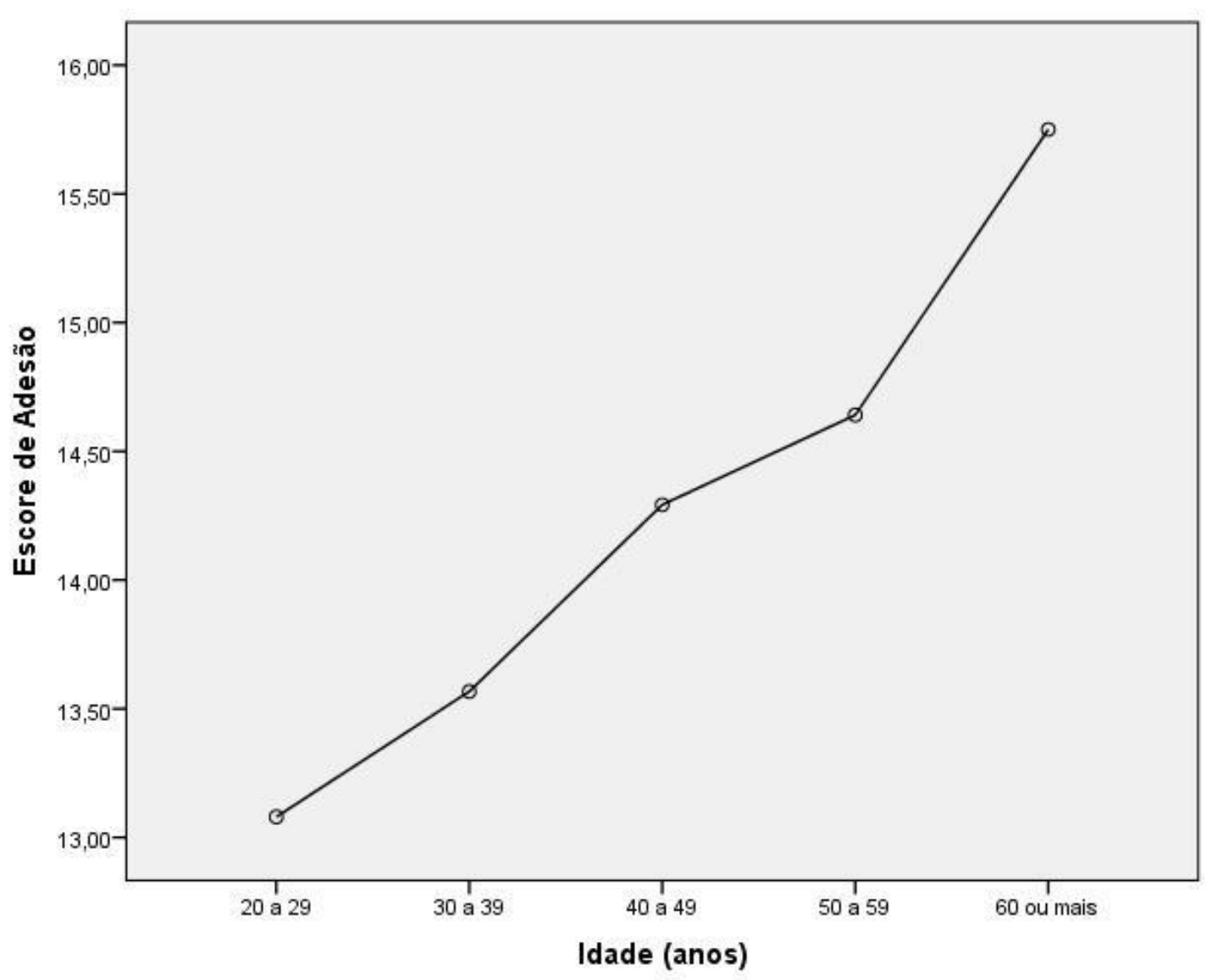

Figura 3 - Gráfico do escore de adesão às PP segundo idade (anos)

O escore médio de adesão PP apresentou diferença estatisticamente significante com a variável treinamento, ou seja, os enfermeiros que receberam treinamento apresentaram maior escore de adesão às PP (figura 4). 


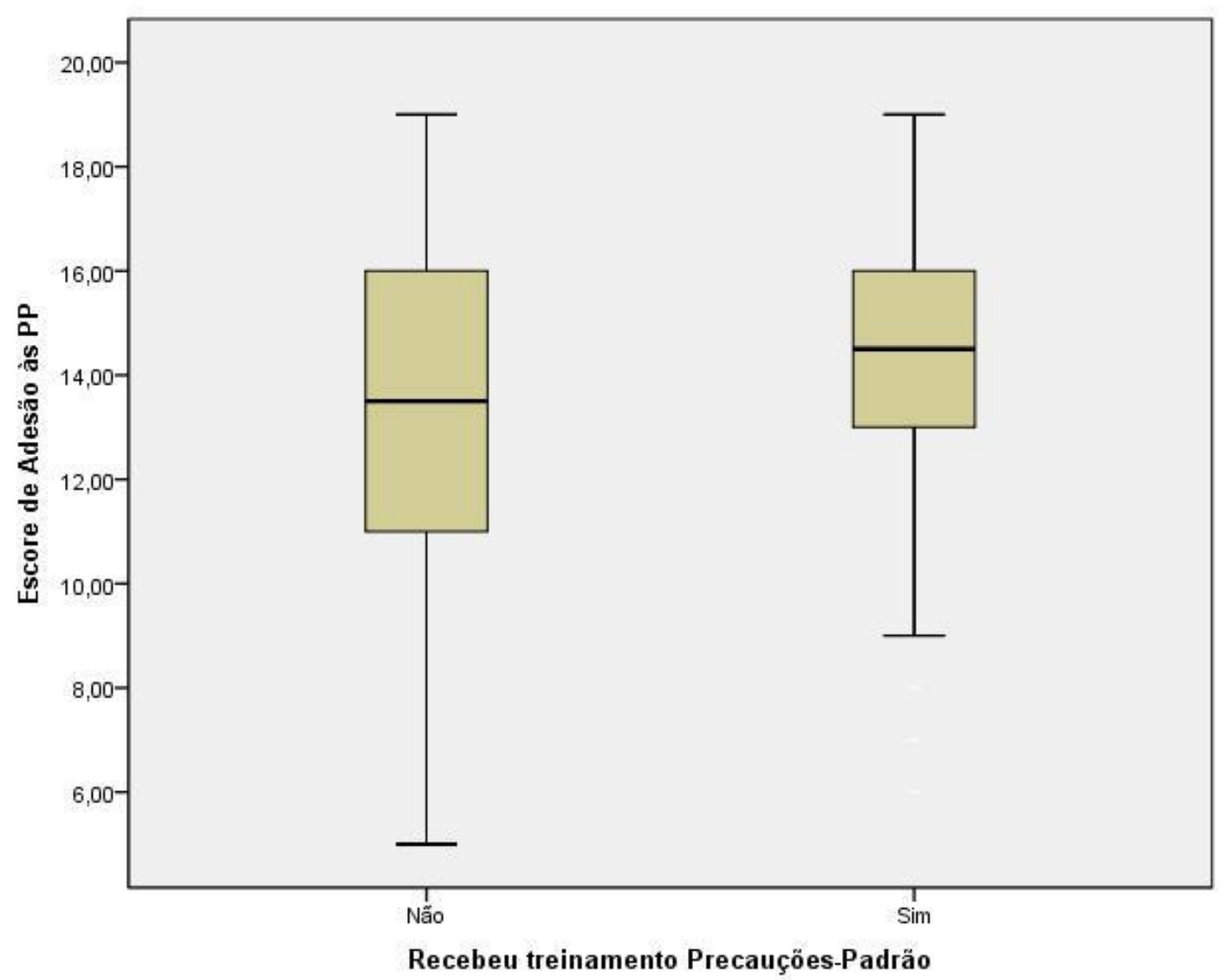

Figura 4-Gráfico do escore de adesão às PP para ter recebido ou não treinamento

\subsubsection{Análise fatorial}

A análise fatorial confirmatória da CSPS-PB foi realizada utilizando-se do modelo original da CSPS proposto por Lam (2011), que compreende os 20 itens alocados nos cinco fatores (prevenção de infecção; descarte de materiais perfurocortantes; descontaminação de artigos e superfícies; uso de EPI e descarte de resíduos) (figura $5)$. 

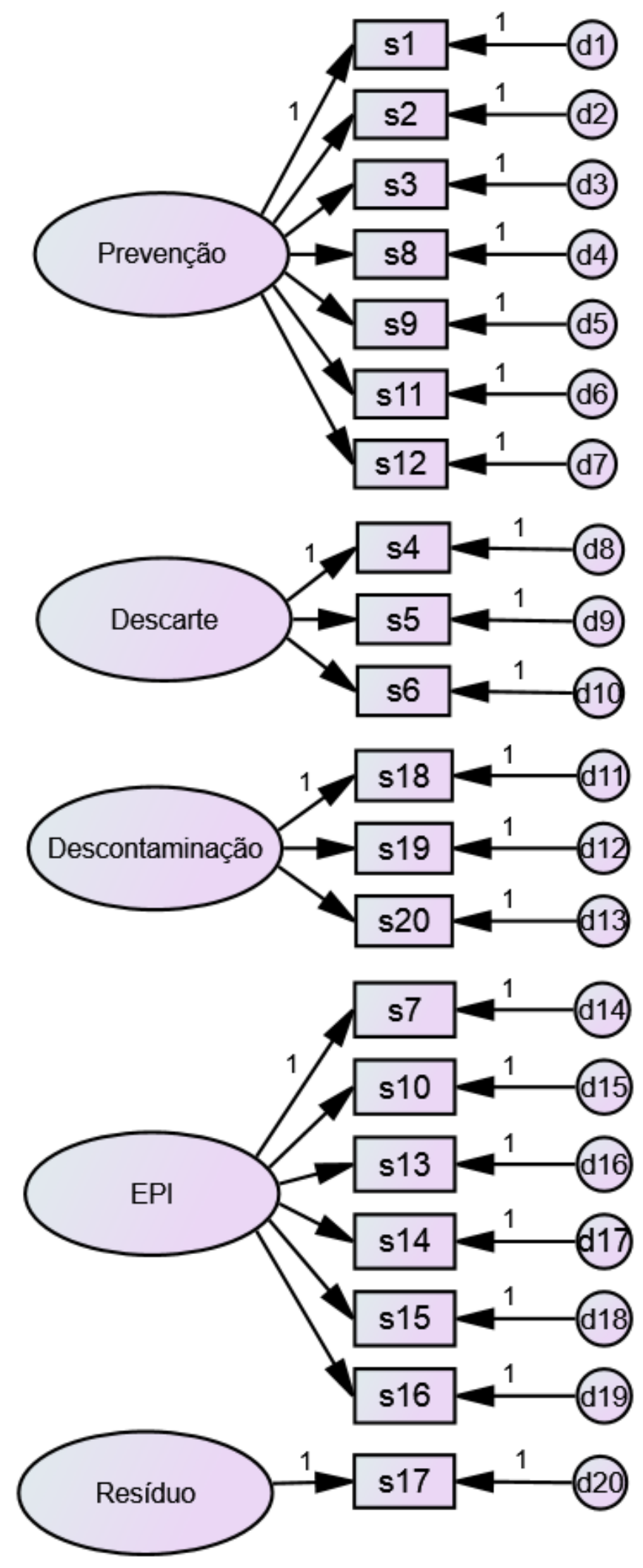

Figura 5 - Modelo hipotético da CSPS-PB testado na análise fatorial confirmatória 
Conforme ilustrado na tabela 9, as duas medidas de ajuste aproximado NFI e CFI foram iguais a 1,000. Essas medidas devem variar de zero a um, sendo recomendados valores acima de 0,90 (HAIR JR et al., 2005).

Para o RMSEA, o valor obtido foi de 0,087 , sendo considerados adequados valores abaixo de 0,80 (HAIR JR et al., 2005). O valor de LO 90 e HI 90 contêm o limite inferior e um limite superior de um intervalo de confiança de $90 \%$ para o valor de RMSEA. Embora os índices apresentem valores razoáveis, os dados não se adequaram ao modelo original proposto. Os itens 4, 5 e 6 pertencentes ao domínio descarte de materiais perfurocortantes e o item 20 do domínio descarte de resíduos não foram identificados no modelo.

Tabela 9 - Medidas de ajustes da análise fatorial confirmatória (20 itens) da CSPSPB

\begin{tabular}{ll}
\hline Teste realizado & Estatística \\
\hline CFI & 1,000 \\
NFI & 1,000 \\
RMSEA & 0,087 \\
LO 90 & 0,080 \\
HI 90 & 0,095 \\
\hline
\end{tabular}

Assim, a figura 6 apresenta os resultados da análise fatorial confirmatória para os domínios Prevenção de infecção de pessoa para pessoa, Descontaminação de materiais e superfícies e Uso de EPI. 

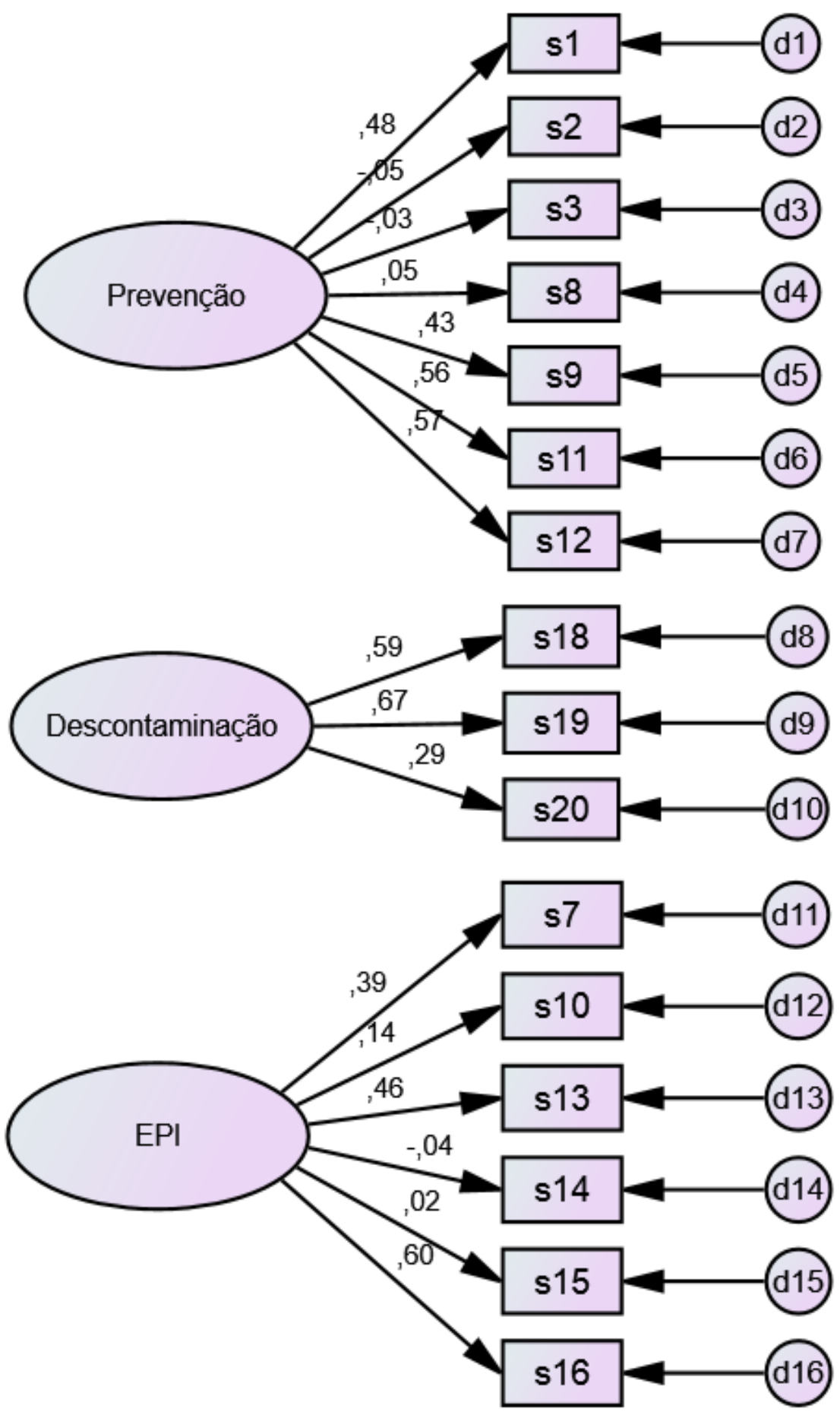

Figura 6 - Análise fatorial confirmatória CSPS-PB (16 itens)

As medidas de ajustes deste modelo também foram razoáveis ( $\mathrm{CFI}=0,531$; RMSEA $=0,075 ; \quad L O 90=0,065 ; H I 90=0,086)$. No entanto, considerando-se a não 
adequação do modelo original completo, optou-se pela realização da análise fatorial exploratória.

Utilizou-se o método de componentes principais com os 20 itens do instrumento para a amostra de 300 enfermeiros. Adotou-se, inicialmente, a rotação oblíqua para verificar se os fatores são independentes.

O teste Kaiser-Meyer-Olkin (KMO) foi igual a 0,630 e o teste de esfericidade de Bartlett igual a 606,096 rejeitou a hipótese nula de que a matriz de correlação dos dados fosse uma matriz identidade $(p<0,001)$. Esses resultados indicam que as correlações entre os itens foram suficientes para a realização da análise fatorial.

A análise fatorial inicial mostrou que oito fatores obedeceram ao critério de Kaiser, eigenvalue maior que 1, explicando 58,18\% da variância. Para a determinação do número de fatores, foram comparados dois testes: scree plot (autovalor $>1$ ) e análise paralela. O scree plot (figura 7) mostrou que os oito fatores postulados apresentam alto valor maior que um.

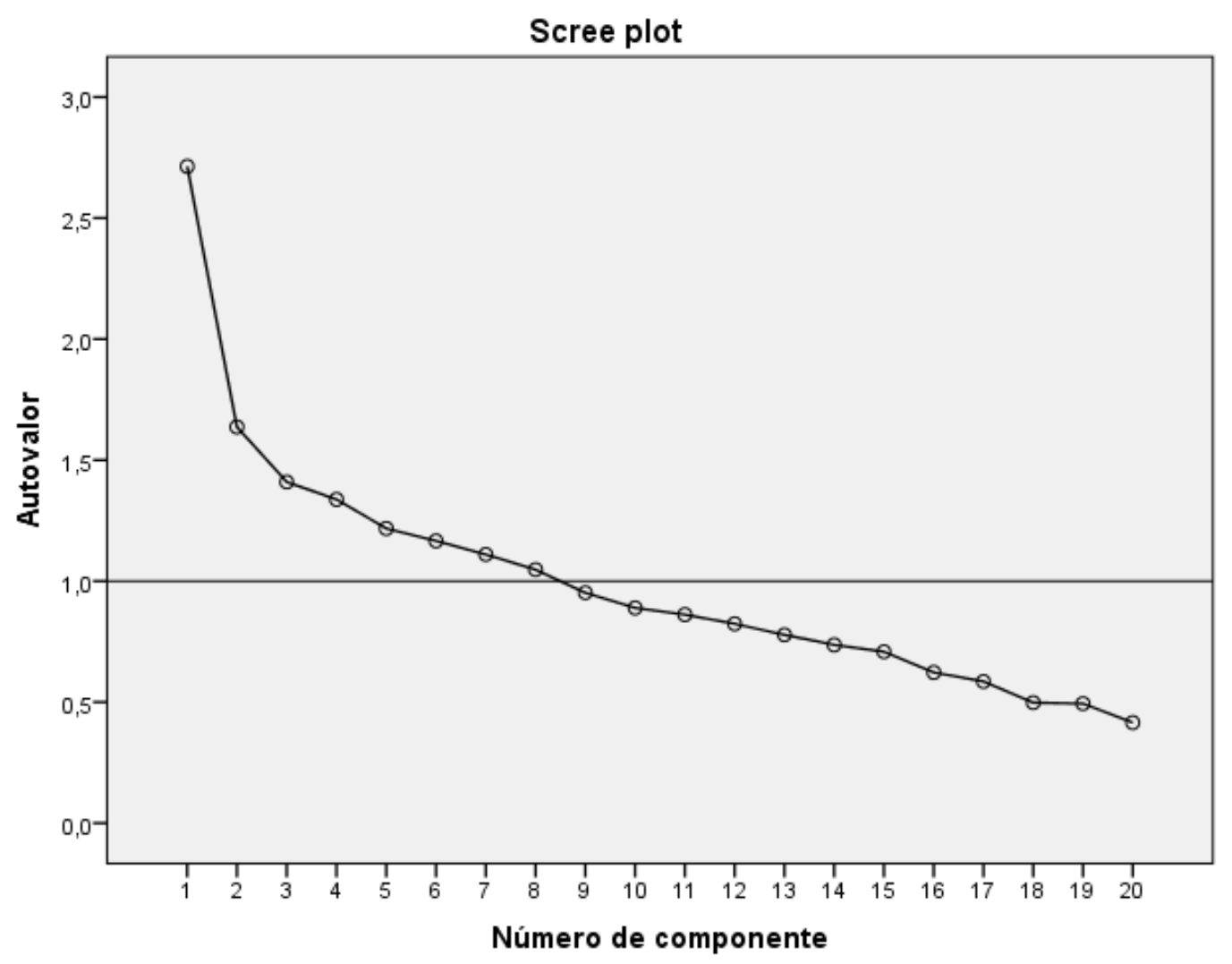

Figura 7 - Scree Plot com os autovalores e número de fatores da matriz 
No entanto, considerando que o critério de Kaiser (eigenvalue) maior que 1 pode sugerir mais componentes do que de fato existem, optou-se pela utilização da análise paralela realizada pelo programa RanEigen Syntax, para avaliar o número de fatores verdadeiros que o instrumento apresenta. A tabela 10 mostra os componentes, os autovalores empíricos obtidos na análise fatorial exploratória e os autovalores aleatórios resultantes da análise paralela.

Tabela 10 - Componente correlação matriz, autovalores empíricos e aleatórios da CSPS-PB

\begin{tabular}{ccccc}
\hline & \multicolumn{3}{c}{ Autovalores empíricos } & \multirow{2}{*}{$\begin{array}{c}\text { Autovalores } \\
\text { Componente }\end{array}$} \\
\cline { 2 - 4 } & Total & \% Variância & $\begin{array}{c}\% \\
\text { Cumulativo }\end{array}$ & \\
\hline 1 & 2,714 & 13,568 & 13,568 & 1,488 \\
2 & 1,637 & 8,183 & 21,750 & 1,398 \\
3 & 1,409 & 7,047 & 28,797 & 1,330 \\
4 & 1,337 & 6,687 & 35,484 & 1,271 \\
5 & 1,217 & 6,086 & 41,570 & 1,219 \\
6 & 1,166 & 5,830 & 47,400 & 1,170 \\
7 & 1,110 & 5,549 & 52,949 & 1,125 \\
8 & 1,047 & 5,237 & 58,186 & 1,082 \\
9 &, 952 & 4,759 & 62,945 & 1,040 \\
10 &, 889 & 4,446 & 67,391 & 1,000 \\
$\ldots$ & $\ldots$ & $\ldots$ & $\ldots$ & $\ldots$ \\
20 &, 415 & 2,076 & 100,000 & 0,597 \\
\hline
\end{tabular}

O modelo original da CSPS, consiste em cinco componentes, no entanto, na realização da análise paralela, o autovalor aleatório para o quinto componente, apresentou similaridade com o autovalor empírico, ou seja, traduz uma informação não verdadeira. Contudo, o resultado para quatro vetores traz informações verdadeiras do construto, pois o autovalor apresentado de 1,27 foi menor do que o autovalor empírico de 1,33, resultando em quatro componentes com variância explicada de $35,48 \%$.

A tabela 11 mostra que os quatro fatores são independentes (não apresentaram correlações mínimas de 0,30 ). Dessa forma, sugere-se utilizar rotação varimax para a análise fatorial exploratória. 
Tabela 11 - Correlação entre os fatores da CSPS-PB por rotação oblíqua

\begin{tabular}{ccccc}
\hline Componente & 1 & 2 & 3 & 4 \\
\hline 1 & 1,000 &, 007 &,- 071 &,- 116 \\
2 &, 007 & 1,000 &, 037 &,- 039 \\
3 &,- 071 &, 037 & 1,000 &, 016 \\
4 &,- 116 &,- 039 &, 016 & 1,000 \\
\hline
\end{tabular}

Método de extração: Componentes principais

Rotação: Oblíqua

Portanto, foi realizada a análise fatorial exploratória, considerando-se quatro componentes, utilizando-se rotação varimax.

A tabela 12 mostra a matriz de rotação dos quatro fatores com seus respectivos autovalores após a rotação, o percentual de variância explicada da matriz R e o número de itens alocados em cada fator. 
Tabela 12 - Matriz de rotação varimax dos fatores da CSPS-PB

\begin{tabular}{l|cccc}
\hline \multirow{2}{*}{ Item } & \multicolumn{4}{|c}{ Fator } \\
\cline { 2 - 5 } & $\mathbf{1}$ & $\mathbf{2}$ & $\mathbf{3}$ & $\mathbf{4}$ \\
\hline Item 11 &, 784 &,- 107 &,- 011 &,- 153 \\
Item 12 &, 644 &, 228 &,- 147 &, 282 \\
Item 10 &, 531 &,- 068 &, 142 &,- 136 \\
Item 1 &, 495 &, 286 &,- 022 &,- 029 \\
Item 9 &, 482 &, 172 &, 270 &, 192 \\
Item 7 &,- 027 &, 602 &, 177 &, 120 \\
Item 16 &, 175 &, 594 &, 038 &, 157 \\
Item 13 &, 256 &, 468 &, 339 &,- 261 \\
Item 8 &,- 109 &, 442 &, 259 &,- 014 \\
Item 5 &, 043 &, 372 &,- 221 &, 098 \\
Item 4 &,- 144 &,- 370 &, 006 &, 110 \\
Item 14 &, 049 &,- 305 &, 193 &, 081 \\
Item 19 &, 063 &, 201 &, 697 &, 037 \\
Item 18 &, 216 &, 120 &, 628 &, 193 \\
Item 15 &,- 045 &, 157 &,- 409 &, 073 \\
Item 3 &,- 096 &, 025 &, 352 &,- 069 \\
Item 2 &,- 069 &, 154 &, 012 &,- 607 \\
Item 17 &, 019 &, 216 &, 000 &, 599 \\
Item 20 &,- 040 &,- 113 &, 406 &, 541 \\
Item 6 &,- 226 &, 078 &,- 211 &, 385 \\
\hline Autovalor & 2,043 & 1,847 & 1,696 & 1,511 \\
\% variância & 10,215 & 9,236 & 8,479 & 7,554 \\
N. itens & 5 & 7 & 6 & 4 \\
\hline Nemy & 509 &
\end{tabular}

Método de Extração: Análise de Componente Principal Método de Rotação: Varimax com Normalização de Kaiser

Rotação convergida em 8 iterações

De acordo com a análise fatorial apresentada na tabela 12, o fator 1 englobou os itens 11,12 , 10, 1 e 9; o fator 2 , os itens $7,16,13,8,5$, 4, 14; o fator 3 englobou os itens 19, 18, 15 e 3; o fator 4, os itens 2, 17, 20 e 06. Dois itens se agruparam em mais de um fator. 0 item 13 foi agrupado aos fatores 2 e 3; o item 20 agrupou-se ao fator 3 e 4 . 0 fator 1 , composto por cinco itens, explicou a maior parte da variância com $10,21 \%$, seguido pelos demais fatores. 
A tabela 13 apresenta a matriz de rotação varimax final e a alocação dos itens nos seus respectivos fatores.

Tabela 13 - Matriz de rotação varimax final dos fatores, da CSPS-PB

\begin{tabular}{l|cccc}
\hline \multirow{2}{*}{ Item } & \multicolumn{3}{|c}{ Fator } \\
\cline { 2 - 5 } & $\mathbf{1}$ & $\mathbf{2}$ & $\mathbf{3}$ & $\mathbf{4}$ \\
\hline Item 11 &, 784 & & & \\
Item 12 &, 644 & & & \\
Item 10 &, 531 & & & \\
Item 1 &, 495 & & & \\
Item 9 &, 482 & & & \\
Item 7 & &, 602 & \\
Item 16 & &, 594 & & \\
Item 13 & &, 468 & & \\
Item 8 & &, 442 & & \\
Item 5 & &, 372 & & \\
Item 4 & &,- 370 & & \\
Item 14 & &,- 305 & & \\
Item 19 & & & & \\
Item 18 & & & & \\
Item 15 & & & & \\
Item 3 & & & \\
Item 2 & & & \\
Item 20 & & & & \\
Item 17 & & & & \\
Item 6 & & & & \\
\hline
\end{tabular}

Método de Extração: Análise de Componente Principal

Método de Rotação: Varimax com Normalização de Kaiser

As cargas fatoriais variaram entre os fatores, sendo considerados válidos os itens que apresentaram valores maiores que 0,30. 0 item 11 do fator 1 apresentou a maior carga fatorial de 0,78.

Considerando a adequação dos itens em quatro fatores, de acordo com a análise fatorial, os domínios foram renomeados e agrupados (tabela 14). 
Tabela 14 - Distribuição final dos itens da CSPS-PB segundo análise fatorial exploratória

Itens

Prevenção de infecção de pessoa para pessoa

11- Eu troco de luvas entre contato com pacientes.

12- Eu higienizo as minhas mãos imediatamente após remover as luvas.

10- Eu uso luvas quando estou exposto a fluidos corporais, sangue ou derivados e qualquer excreção de pacientes.

1- Eu lavo minhas mãos entre contatos com pacientes.

9- Eu cubro meus ferimentos ou lesões com curativos à prova d'água antes do contato com pacientes.

\section{Uso de EPI e descarte de materiais perfurocortantes}

7- Eu retiro os Equipamentos de Proteção Individual (EPI) em um local designado.

16- Eu uso avental/capote quando estou exposto a sangue, fluídos corporais ou qualquer excreção de pacientes.

13- Eu uso máscara cirúrgica ou em combinação com óculos de proteção e avental sempre que houver a possibilidade de respingos ou derramamentos.

8- Eu tomo banho em caso de respingos extensos mesmo que eu tenha usado EPI.

5- Eu descarto materiais perfurocortantes em caixas próprias.

4- Eu reencapo agulhas usadas após aplicar uma injeção.

14- Minha boca e meu nariz ficam cobertos quando uso máscara.

\section{Limpeza e descontaminação da pele e equipamentos}

19- Eu uso luvas para descontaminar equipamentos que apresentam sujeira visível.

18- Eu descontamino superfícies e equipamentos após o uso.

15- Eu reutilizo uma máscara cirúrgica ou EPI descartável.

3- Eu uso produto à base de álcool para higienizar as mãos como alternativa se não estiverem visivelmente sujas.

2- Eu uso somente água para lavar as mãos.

\section{Descarte e limpeza de materiais contaminados}

17- Eu descarto material contaminado com sangue, fluidos corporais, secreções e excreções de pacientes em sacos plásticos brancos independentemente do estado infeccioso do paciente.

20- Eu limpo imediatamente com desinfetante (álcool) superfícies após derramamento de sangue ou outros fluidos corporais.

6- A caixa de materiais perfurocortantes é descartada somente quando está cheia. 
O domínio prevenção de infecção de pessoa para pessoa englobou 05 itens (01, 09 ,10, 11 e 12); o domínio uso de EPI e descarte de materiais perfurocortantes, 07 itens $(04,05,07,08,13,14$ e 16); o domínio Limpeza e descontaminação da pele e equipamentos juntou 05 itens (02, 03, 15, 18 e 19), e o domínio descarte e limpeza de materiais contaminados englobou 03 itens (06, 17 e 20). Dessa forma, todos os itens apresentaram cargas fatoriais maior que 0,30 , ou seja, não foi excluído nenhum item na adaptação da versão original da CSPS para CSPS-PB. 


\section{DISCUSSÃO}

A discussão dos resultados do presente estudo contemplará os seguintes aspectos: processo de adaptação da CSPS-PB; domínios da CSPS-PB; amostra do estudo; escores de adesão às PP e avaliação das propriedades psicométricas da CSPSPB.

O processo de adaptação utilizado neste estudo foi desenvolvido respeitandose os critérios metodológicos recomendados na literatura. No entanto, é importante ressaltar o apoio do autor CSPS original em todas as etapas, destacando-se que as adaptações e alterações concretizadas foram por ele apreciadas e aprovadas.

É crescente o número de estudos de tradução, de adaptação e de validação de instrumentos realizados por enfermeiros, entretanto faz-se necessária a adoção de técnicas e de métodos apropriados, bem como a avaliação da confiabilidade e da validade para se assegurar a qualidade e o rigor metodológico da pesquisa (RATTRAY; JONES, 2007).

A qualidade no processo de adaptação faz com que o instrumento seja confiável para medir o construto a que se propõe, minimizando erros e dificuldades na aplicação.

Conforme descrito previamente, há vários métodos e avaliações para se realizar a validação de um instrumento de pesquisa, no entanto o pesquisador deve fundamentar o método escolhido de acordo com as estruturas testadas anteriormente no instrumento original, para que haja a possibilidade de se compararem os resultados obtidos.

Dessa forma, é importante que o instrumento escolhido para ser adaptado apresente arcabouço teórico e definições claras acerca da construção e da avaliação de suas propriedades psicométricas, sobretudo, com resultados satisfatórios.

Nesse sentido, a escolha da CSPS para a tradução e a adaptação para enfermeiros brasileiros atendeu a esses critérios, pois a escala foi construída e validada com base em critérios metodológicos bem definidos (LAM, 2011; LAM, 2014).

A tradução de um instrumento para o idioma pretendido constitui-se em um processo complexo que exige cautela, de modo que a versão obtida seja adequada ao construto e equivalente à versão original (BORSA; DAMÁSIO; BANDERIA, 2012). Dessa 
forma, a existência de dois tradutores independentes e que apresentem proficiência fluente no idioma alvo, se justifica para se obter um alto nível de qualidade nas traduções (BEATON et al., 2000).

Nesse sentido, visando atender a esses critérios, a tradução da CSPS foi realizada por dois tradutores independentes juramentados, que são profissionais habilitados a emitir traduções públicas oficiais em todo o território nacional de documentos redigidos em língua estrangeira.

Segundo Guillemin, Bombardier e Beaton (1993), os tradutores também devem integrar o comitê de especialistas, pois isso poderá possibilitar a modificação de expressões e de palavras equivalentes ao idioma de origem do instrumento. Ainda, segundo Ferreira et al. (2014), deve-se incluir um representante da população alvo, para minimizar a ocorrência de dúvidas e favorecer o retorno imediato acerca da compreensão dos itens.

No processo de adaptação da CSPS-PB o comitê de juízes avaliou a validade de conteúdo, incluindo as equivalências semântica, cultural, idiomática e conceitual dos itens. Essa etapa é considerada imprescindível no processo de adaptação de um instrumento, pois irá possibilitar a análise rigorosa dos itens bem como seus aspectos culturais a serem adaptados. Para Beaton et al. (2002, 2007), trata-se de em uma fase essencial para a obtenção de uma escala com características psicométricas satisfatórias.

A validade de conteúdo da versão original da CSPS foi avaliada por dois comitês de especialistas, sendo um local e outro internacional. O comitê de especialistas local constituiu-se por 02 enfermeiras especialistas em controle de infecção, dois acadêmicos, e dois enfermeiros assistenciais. Foram fornecidos os guidelines locais e internacionais de PP para consulta e uma escala likert de quatro pontos (1- não relevante, 2- pouco relevante, 3-bastante relevante, e 4- muito relevante) foi disponibilizada para a avaliação da relevância dos itens. O índice de validade de conteúdo geral obtido foi de 0,90 (LAM, 2011).

O comitê internacional composto por 19 especialistas de 16 países (Argentina; Austrália; Camboja; Colômbia; Alemanha; Índia; Irã; Iraque; Israel; Japão; Coréia; Malásia; Rússia; Singapura; Sri Lanka e EUA) analisou que a maior parte dos itens da CSPS foram interpretáveis e globalmente aplicáveis (LAM, 2014). 
Para a validação semântica da CSPS-PB, foram entrevistados enfermeiros que atuam na assistência a pacientes em um hospital. A fim de se garantir a validade aparente, conforme recomendado por Pasquali (1998), foram entrevistados um enfermeiro chefe do setor de educação continuada e um enfermeiro do serviço de controle de infecção. O instrumento foi considerado de fácil entendimento e as questões foram consideradas relevantes para se avaliar a adesão às PP.

No mesmo contexto, a versão original da CSPS foi apreciada por enfermeiros e por estudantes de enfermagem. Foram avaliadas as expressões apresentadas nos itens com relação ao entendimento, ao estilo do instrumento e à aceitação para ser utilizado na avaliação de sua prática clínica, sendo considerado satisfatório (LAM, 2011).

Conforme já descrito anteriormente, a CSPS é composta por 20 itens divididos em cinco domínios. O domínio uso de EPI compreende itens acerca da utilização destes equipamentos por enfermeiros em sua prática clínica diária, tais como luvas, óculos de proteção, máscara e avental. O uso adequado desses equipamentos contribui para reduzir o risco de exposição ocupacional a material biológico (SIEGEL et al., 2007).

Dentre os EPI, as luvas consistem em importante medida para se evitar o contato com os fluidos corporais (MOHAMMADI; ALLAMI; MOHAMADI, 2011). Além disso, contribuem para a diminuição da quantidade de sangue em situações de exposições percutâneas com agulhas ocas (BENETT; HOWARD, 1994).

O item acerca da utilização de EPI para proteção facial precisou ser adaptado, considerando-se somente óculos e máscara, tendo em vista que o EPI específico para proteção facial não é comumente utilizado no Brasil na prática clínica do enfermeiro.

Para os itens que compõem esse domínio, foram realizadas adaptações mínimas, uma vez que as informações contidas no instrumento original condizem com as ações realizadas na prática clínica dos enfermeiros brasileiros.

O domínio descarte de resíduos com apenas um item discorre acerca do descarte de material contaminado de maneira correta.

No processo de adaptação da CSPS-PB, o item acerca do descarte de resíduos precisou ser modificado, pois, no instrumento original recomendava que estes materiais fossem descartados em sacos vermelhos. Assim, foram considerados sacos plásticos brancos para o descarte de resíduos, considerando-se que a legislação sanitária vigente no Brasil recomenda que materiais contaminados com sangue e com 
fluidos de pacientes sejam descartados em sacos plásticos brancos, devidamente identificados, independentemente do estado infecioso do paciente (BRASIL, 2005).

O domínio Descarte de materiais perfurocortantes é composto por itens que discorrem sua manipulação e descarte. Sabe-se que esses materiais devem ser descartados em recipientes próprios, rígidos e dispostos em locais de fácil acesso (BRASIL, 2005; GARNER, 1996; SIEGEL et al., 2007).

Com relação ao descarte de materiais perfurocortantes, um aspecto importante está na manipulação de agulhas pelos profissionais. No item acerca dessa prática, a palavra reencape foi utilizada como termo para designar o ato de "cobrir as agulhas após aplicação de injeção".

O domínio Descontaminação de artigos e superfícies após o uso discorre sobre a limpeza e a descontaminação destes locais. Considerando-se aspectos culturais referentes à denominação do tipo de produto e da superfície a ser descontaminada, o item 20 gerou algumas dúvidas. Nesse sentido, adaptações foram realizadas mediante consentimento do autor original da CSPS, sendo inserida a palavra "álcool" para identificação do produto a ser utilizado.

O cuidado com materiais e com o ambiente de trabalho constituem elementos importantes das PP (GARNER, 1996). Vale ressaltar que o enfermeiro é responsável pela promoção de um ambiente seguro para o paciente e para outros profissionais, sendo fundamentais o conhecimento e a aplicação de princípios na manipulação e na manutenção de materiais e de equipamentos (MALAGUTI-TOFFANO et al., 2012).

O domínio prevenção de infecção de pessoa para pessoa inclui itens sobre HM e ações para a minimização da transmissão de infecções. Essas medidas constituem uma preocupação iminente, uma vez que seu cumprimento, muitas vezes, está aquém do recomendado (BATHKE et al., 2013; FROTA; LOUREIRO; PEREIRA, 2014; PEREIRA et al., 2013; PEREIRA et al., 2015; SAKIHAMA et al., 2014). A adaptação realizada para os itens desse domínio foi a utilização da expressão "higienizar" indicando a HM.

A amostra utilizada para a avaliação das propriedades psicométricas da CSPS$\mathrm{PB}$, foi composta de profissionais enfermeiros que atuam na assistência a pacientes em um hospital de grande porte. Com relação às características deste grupo, a maior parte pertenceu ao sexo feminino na faixa etária entre 25 e 75 anos. A literatura tem reportado que as mulheres são predominantes nessa categoria profissional 
(GARBACCIO et al., 2015; MALAGUTI-TOFFANO et al., 2012; PEREIRA et al., 2013; SILVA et al., 2012).

Segundo informações do setor de educação continuada da instituição, são realizados treinamentos contínuos acerca da importância da adesão às PP entre os profissionais, sobretudo da enfermagem. No entanto, o percentual de 64,7\% respondeu ter recebido treinamento sobre PP.

A NR32, norma vigente no Brasil, estabelece que as instituições de saúde ofereçam treinamento aos profissionais no momento de sua admissão e permanentemente ao longo de suas atividades laborais (BRASIL, 2005). No entanto, estudos têm reportado que parte dos profissionais não tem recebido treinamento acerca das PP nos estabelecimentos de saúde (BRAND; FONTANA, 2014; MALAGUTITOFFANO et al., 2012).

Considerando-se as respostas dos enfermeiros aos itens da CSPS-PB, a taxa de adesão às PP foi de 69,3\% e o escore médio de adesão apresentado pelos enfermeiros brasileiros ficou aquém do esperado $(13,9)$. Segundo classificação sugerida por Lam (2011, 2014), o escore máximo de 20 configura perfeita adesão. Esses resultados podem indicar que ainda há subestimação do risco e negligência na utilização das medidas de PP, corroborando com outros estudos realizados para avaliar este construto (CHAN et al., 2002; CHAN et al., 2008; GAMMON; MORGAN-SAMUEL; GOULD, 2008; LIU et al., 2014a; LUO et al., 2010; PEREIRA et al., 2013; PEREIRA et al., 2015).

Nesse contexto, algumas ações, merecem ser destacadas, como a utilização de EPI, a HM, a manipulação e descarte de perfurocortantes e práticas de prevenção de infecção.

A adesão ao uso de máscara e avental apresentou percentuais baixos quando comparado à utilização de luvas. Numerosos estudos têm encontrado adesão insuficiente aos EPI para boca, nariz e mucosa ocular entre os profissionais de saúde, sobretudo com relação ao uso de óculos de proteção (CUTTER; JORDAN, 2012; FROTA et al., 2012; KOTWAL; TANEJA, 2010; LUO et al., 2010; PEREIRA et al., 2013).

Segundo dados de estudos brasileiros os profissionais de enfermagem apresentaram maior adesão ao uso de luvas do que a outros EPI (BREVIDELLI; CIANCIARULLO, 2009; MALAGUTI-TOFFANO et al., 2012; PEREIRA et al., 2015). Por outro lado, investigações que avaliaram a ocorrência de exposições ocupacionais 
envolvendo profissionais da equipe de enfermagem apontaram que no momento do acidente houve situações em que não se utilizaram os EPI, como a punção venosa (CARDOSO; FIGUEREDO, 2010; CIRELLI; FIGUEIREDO; ZEM-MASCARENHAS, 2007; OLIVEIRA; PAIVA, 2013).

Em pesquisa realizada nos EUA (Virginia), com 311 profissionais que atuam em atendimento pré-hospitalar, $83,0 \%$ dos entrevistados relataram que sempre usavam luvas; no entanto motivos como esquecimento e baixo risco de transmissão foram citados para o não uso durante procedimentos (HARRIS; NICOLAI, 2010).

Sobre a HM após o contato com pacientes, a taxa de cumprimento foi semelhante após a remoção de luvas. No entanto, a HM com produto a base de álcool foi baixa.

Para a HM, pode-se utilizar água e sabão, preparação alcoólica e soluções antissépticas. No entanto, vale ressaltar que as preparações alcoólicas são indicadas somente quando as mãos não apresentarem sujeira visível (BRASIL, 2007).

Investigação realizada em um hospital no Estado de São Paulo, reportou que $33,3 \%$ dos profissionais de enfermagem sempre utilizavam solução alcoólica para realizar a HM, contudo o produto foi apontado como insuficiente (SANTOS et al., 2014).

Quanto à manipulação e ao descarte de materiais perfurocortantes, a prática de reencape de agulhas foi apontada por parte dos profissionais. De acordo com as legislação vigente, é desaconselhado o reencape de agulhas após o uso (BRASIL, 2005; GARNER, 1996; SIEGEL et al., 2007). Diversos estudos no Brasil (CHIOIDI et al., 2010; RAPPARINI et al., 2007; TIPPLE et al., 2013) e no mundo (AMIRA; AWOBUSUYI, 2014; PARK et al., 2008; ZANG et al., 2014; ZANG et al., 2009) enfatizam que o reencape de agulhas é o preditor para a ocorrência de acidentes com material biológico.

Com relação ao coletor de materiais perfurocortantes, segundo respostas dos enfermeiros, o descarte é realizado de maneira inadequada na maioria das vezes. Sabe-se que esses recipientes devem ser descartados assim que atingem o limite de dois terços de sua capacidade ou quando alcançarem o nível de preenchimento de cinco centímetros de distância da abertura do recipiente. Ainda, é vedado seu esvaziamento ou reaproveitamento (BRASIL, 2006).

Os coletores de materiais perfurocortantes constituem elemento fundamental para a prevenção e para a redução do riscos de acidentes ocupacionais com material 
biológico (RAPPARINI, 2010).

Outro item que merece destaque por ter apresentado baixa adesão é com relação à prática de tomar banho em caso de respingos extensos. A legislação vigente no Brasil não torna obrigatória a realização dessa prática, justificando, assim, o resultado apresentado. Além disso, é importante ressaltar que a maior parte das instituições brasileiras não oferecem infraestrutura ao profissional para essa finalidade.

Para avaliação das propriedades psicométricas da CSPS-PB, foram avaliadas a consistência interna, a estabilidade e a validade de construto. Aspectos semelhantes foram analisados na versão original da CSPS demostrando resultados satisfatórios (LAM, 2011; LAM, 2014).

A confiabilidade da CSPS-PB foi avaliada por meio da consistência interna e estabilidade. O resultado obtido para a análise da consistência interna mensurada pelo alfa de Cronbach foi considerado aceitável $(0,61)$. Para a análise da consistência interna da versão original da CSPS, o alfa obtido foi de 0,73 (LAM, 2014).

A avaliação da confiabilidade de um instrumento irá determinar a consistência e a reprodutibilidade/estabilidade dos resultados (FAYERS; MACHIN, 2007).

A análise da consistência interna de um instrumento consiste na correlação dos itens de um mesmo construto, obtida por meio da variância da soma dos componentes avaliados, ou seja, o alfa estima o quanto os itens contribuem para o instrumento. 0 coeficiente alfa varia de zero a um, sendo que, quanto mais o valor se aproxima de um, evidencia maior consistência, ou seja, maior confiabilidade terá o instrumento avaliado (CRONBACH, 1951).

Segundo Pasquali (2003), a consistência interna estima a fiabilidade dos instrumentos de pesquisa, sendo que, quanto menor a variabilidade do item para a mesma população, menor será o erro de medida atribuído. Ainda, a variabilidade da amostra e a quantidade de itens do instrumento podem comprometer a fidedignidade do teste (PASQUALI, 2009).

Para Terwee et al. (2011), a análise da consistência interna como parâmetro para mensuração da confiabilidade de questionários constitui um critério importante para a qualidade de estudos de adaptação.

Nesse sentido, diversos autores determinaram valores para o alfa de Cronbach na avaliação da consistência interna de instrumentos (DEVELLIS, 1991; FREITAS; 
RODRIGUES, 2005; NUNNALLY, 1978; NUNNALLY, 1979; PETERSON, 1994; TERWEE et al., 2007). Para DeVellis (1991), o alfa de 0,60 é considerado aceitável, desde que os resultados sejam bem interpretados e, para Freitas e Rodrigues (2005), este valor é considerado moderado. Segundo Nunnally (1978) e Terwee et al. (2007), o alfa deve ser de 0,70 a 0,95 .

A utilização de somente uma estimativa de fiabilidade para análise de um instrumento está sujeita a erros (MAROCO; GARCIA-MARQUES, 2006). Como qualquer estimativa de medida estatística, o alfa de Cronbach pode apresentar estimativas inferiores à verdadeira fiabilidade do instrumento, sendo indicada, a utilização de testes complementares, incluindo a análise do ICC (CRONBACH; RAJARATNAM; GLESER, 1963).

Os resultados do teste reteste obtidos para análise da estabilidade/ reprodutividade realizados duas semanas após a primeira aplicação do instrumento indicou uma correlação quase perfeita ou muito boa (ICC=0,87). Recomenda-se que o ICC seja no mínimo 0,70, para indicar reprodutibilidade satisfatória (TERWEE et al., 2007). O ICC da versão original da CSPS realizado no mesmo intervalo de tempo foi de 0,79 (LAM, 2014).

O ICC é o método mais utilizado para a avaliação da confiabilidade com dados contínuos ou categóricos quando houver quatro ou cinco opções de respostas (FAYERS; MACHIN, 2007; TERWEE et al., 2007). Uma revisão de literatura realizada por Terwee et al. (2011), com o objetivo de investigar a qualidade metodológica empregada em estudos de adaptação de instrumentos, apontou que o ICC foi utilizado em $78,0 \%$ dos estudos.

O teste reteste possibilita a mensuração de um construto em dois momentos distintos assumindo que o seu estatuto é estável (CHWALOW, 1995). De acordo com Terwee et al. (2007) o intervalo de tempo apropriado para a realização do teste reteste deve ser entre uma e duas semanas após a primeira aplicação do instrumento.

Para a avaliação da validade de construto do CSPS-PB, utilizou-se a comparação dos escores de adesão obtidos entre grupos distintos e a análise fatorial.

Anteriormente à explanação da avaliação da validade de construto realizada neste estudo, torna-se indispensável a descrição acerca deste tipo de validade.

A validade de construto consiste em elemento fundamental na validade de 
instrumentos, tendo em vista que possibilita a verificação de forma direta da hipótese de legitimidade da representação comportamental do traço latente (PASQUALI, 2009).

Segundo Carmines e Zeller (1980), a validade de construto de um instrumento, não pode ser estabelecida em um único estudo, pois requer uma gama de pesquisas consistentes entre diferentes pesquisadores a fim de que possibilite estabelecer a validade de uma medida.

Para a avaliação da validade de construto da CSPS-PB entre grupos distintos, testou-se a hipótese da diferença dos escores de adesão com algumas variáveis individuais e relacionadas ao trabalho. Os resultados encontrados indicaram que, quanto maior a idade do enfermeiro, maior o escore de adesão às PP. No mesmo sentido, quanto maior a experiência clínica, maior os escores de adesão apresentados. Essa hipótese também foi confirmada na avaliação na validade de construto da versão original da CSPS, sendo que, o tempo de experiência clínica apresentou correlação positiva com a adesão às PP entre enfermeiros (LAM, 2014).

Em investigação realizada com enfermeiros na China, os profissionais com 41 anos ou mais e experiência clínica de mais de 11 anos, apresentaram maior adesão às PP (CHAN et al., 2002). Da mesma forma, profissionais de saúde com maior experiência clínica atuantes em salas de cirurgia, apresentaram melhor adesão e cumprimento com as PP (CHAN et al., 2008).

Para Kumakech, Achora e Berggren (2011), a pouca experiência clínica dos profissionais de saúde constituem um fator de risco para a exposição ocupacional. Em investigação realizada entre a equipe de enfermagem de duas instituições hospitalares, os profissionais mais jovens e com menos tempo de experiência clínica apresentaram maior associação aos acidentes ocupacionais (GARBACCIO et al., 2015).

Ainda, na comparação entre grupos, os enfermeiros que receberam treinamento acerca das PP apresentaram um escore mais elevado de adesão. Corroborando com esses achados, pesquisas têm encontrado resultados semelhantes (BREVIDELLI, CIANCIARULLO, 2009; CHAN et al., 2002; LUO et al., 2010).

De acordo com Brevidelli e Cianciarullo (2009), receber treinamento influencia positivamente no uso de EPI. Para Luo et al. (2010), os profissionais que recebem treinamento acerca das PP apresentam níveis melhores de conhecimento.

O segundo método utilizado para a avaliação da validade de construto da CSPS- 
PB foi a análise fatorial. Muitos autores têm discutido acerca do método mais apropriado para a realização da análise fatorial no processo de validação de um instrumento de medida já existente.

A análise fatorial é um procedimento estatístico utilizado com grande frequência na validação de instrumentos psicológicos (PASQUALI, 2012). Segundo Nunnally (1978), a análise fatorial constitui o eixo central da mensuração de construtos psicológicos, e é fundamental no processo de validação de instrumentos.

Para Carroll (1993), a decisão acerca do método de análise fatorial a ser utilizada, se exploratória ou confirmatória, depende de critérios que devem ser considerados. Quando as hipóteses a serem testadas têm embasamento forte de uma teoria psicológica ou análises consistentes realizadas anteriormente, utiliza-se a análise fatorial confirmatória. Se não há essas evidências, deve-se realizar análise fatorial exploratória, ou seja, permitir que a estrutura dos dados demonstrem o modelo fatorial mais adequado.

Considerando- se a existência de uma estrutura teórica já existente, optou-se primeiramente pela utilização da análise fatorial confirmatória da CSPS-PB para verificar se o modelo se adequava ao original proposto por Lam (2011). No entanto, o modelo não se adequou, ou seja, alguns itens e domínios não foram identificados.

Segundo Hair Jr. et al. (2005) e Schumacker e Momax (2004), é denominado de modelo subindentificado quando um ou mais parâmetros não podem ser identificados, ou seja, as informações não são suficientes. Então, esse modelo não está identificado e não poderá ser válido até que o pesquisador determine ou modifique alguns parâmetros (CAMPANA; TAVARES; SILVA, 2009).

Vale destacar que a versão original da CSPS não utilizou análise fatorial em sua construção. No entanto, os itens foram divididos em cinco domínios com base em seu agrupamento teórico descrito na literatura. Considerando esses pressupostos, foi realizada a análise fatorial exploratória para a verificação dos itens e de seus respectivos fatores.

Um critério essencial na realização da análise fatorial exploratória consiste no número de fatores a ser extraído (GLORFELD, 1995). Para Zwick e Velicer (1986), a determinação do número de fatores é a decisão mais importante a ser tomada pelo pesquisador. Alguns critérios têm sido adotados a fim de se garantir a extração correta 
desses fatores. Para este estudo, adotou-se a análise paralela e scree plot (autovalor $>1$ ).

A análise paralela utiliza a própria dimensionalidade do grupo real dos dados, ou seja, tem como objetivo determinar o número de fatores que, de fato, o instrumento apresenta (PASQUALI, 2012; REISE; WALLER; COMREY, 2000). Já para o scree plot e autovalor $>1$, cada fator retido exibe um autovalor que corresponde ao total da variância explicada (PATIL et al., 2008). Comparando-se as duas técnicas, a análise paralela demonstra ser mais confiável, pois, além de ser baseada em amostras e não na população, como no autovalor $>1$, não subestima fatores não existentes no instrumento (FRANKLIN et al., 1995).

A análise de componentes principais foi utilizada para verificar quantos fatores a matriz admitia. Adotou-se essa análise, pois esta permite analisar toda a variância das variáveis, e produz escores com os mesmos coeficientes de correlação que os fatores rotados (PASQUALI, 2012). Além disso, o método de componentes principais têm sido o mais utilizado para esse tipo de estudo (PALLANT, 2007). Segundo Velicer e Jackson (1990), o tipo de análise a ser utilizada não é relevante, uma vez que o número de fatores corretos são extraídos.

O teste KMO apresentou resultado satisfatório (0,63). Segundo Kaiser (1974), quanto mais afastada do " 1 " for o KMO, mais incerta se torna a matriz, ou seja, indica que as variáveis mensuradas não têm muito em comum. Assim, o KMO de 0,60 é classificado como modesto ou razoável (KAISER, 1974; PALANT, 2007). Já Hair Jr et al. (2006), descrevem 0,50 como valor aceitável.

Considerando-se os pressupostos teóricos apresentados e os resultados obtidos na extração dos fatores da CSPS-PB, a determinação de quatro fatores reproduz de fato, os domínios verdadeiros do instrumento.

Assim, após a realização da análise fatorial exploratória com quatro fatores, obteve-se variância explicada de $35,48 \%$. Todos os itens apresentaram cargas fatoriais maiores que 0,30. Para Pasquali (2003), cargas fatoriais maiores que 0,30 são adequadas para que o item faça parte do fator. No entanto, Tabachnick e Fidell (1996) indicam o valor mínimo de 0,32 para considerar o item representante útil do fator, correspondendo a $10 \%$ da variância explicada.

Todos os itens apresentaram cargas fatoriais satisfatórias, e nenhum item 
precisou ser excluído no processo de validação da CSPS-PB. Vale ressaltar que os itens foram agrupados aos domínios a que pertencem obedecendo aos critérios da análise fatorial exploratória realizada. É importante enfatizar que todos os itens apresentaram afinidades teóricas com seus respectivos domínios.

O modelo final da CSPS-PB foi composto por vinte itens alocados em quatro domínios, denominados Prevenção de infecção de pessoa para pessoa; Uso de EPI e descarte de materiais perfurocortantes; Limpeza e descontaminação da pele e equipamentos e Descarte e limpeza de materiais contaminados. 


\section{CONCLUSÃO}

O objetivo principal deste estudo foi realizar a adaptação cultural e validação da Compliance with Standard Precautions Scale (CSPS) para enfermeiros brasileiros. Considerando-se as etapas desse processo, foi possível concluir que:

- A tradução realizada por tradutores juramentados garantiu qualidade a esse processo, e possibilitou a utilização de termos e expressões pertinentes aos objetivos do trabalho;

- A validação de face e conteúdo realizadas pelo comitê de especialistas possibilitou a realização de modificações pertinentes e imperativas a fim de atender aos critérios de equivalências conceituais, idiomáticas, culturais e semânticas;

- A validação semântica realizada pela população alvo - enfermeiros - indicou que os itens da CSPS-PB foram compreensíveis e considerados relevantes para sua prática clínica;

- Os escore médios de adesão às PP apresentados pelos enfermeiros foi de 13,9 $(\mathrm{DP}=2,7)$, considerando-se uma escala de 0 a 20;

- A consistência interna apresentada foi adequada, ou seja, a confiabilidade da CSPS-PB foi considerada aceitável.

- O coeficiente de correlação intraclasse indicou uma correlação quase perfeita para o teste reteste na aplicação da CSPS-PB duas semanas após a primeira abordagem, conferindo estabilidade satisfatória;

- A validade de construto entre grupos distintos mostrou que a CSPS-PB foi capaz de discriminar as médias de adesão às PP entre os grupos de idade, tempo de experiência clínica e ter recebido treinamento;

- A validade de construto por meio da análise fatorial indicou que todos os itens apresentaram cargas fatoriais adequadas $(\geq 0,30)$, sendo que nenhum item precisou ser excluído. Foram identificados quatro domínios verdadeiros, e o modelo final da CSPS-PB composto por 20 itens, denominados: Prevenção de infecção de pessoa para pessoa; Uso de EPI e descarte de materiais perfurocortantes; Limpeza e descontaminação da pele e equipamentos e Descarte e limpeza de materiais contaminados. 


\section{CONSIDERAÇÕES FINAIS}

A utilização de medidas preventivas que visem à segurança do profissional e também do paciente constitui elemento imprescindível na assistência em saúde. Tendo em vista que as PP constituem um conjunto de medidas que têm como finalidade minimizar o risco de transmissão ocupacional, faz-se necessário que os profissionais, sobretudo os da enfermagem, utilizem em sua prática clínica diária.

A adesão às PP tem sido uma problemática amplamente discutida em todo o mundo, de modo mais particular entre os profissionais que atuam na assistência direta ao paciente.

Visando à existência de um instrumento válido e capaz de medir a adesão às PP, a Compliance with Stardard Precautions Scale (CSPS) foi traduzida e validada para enfermeiros brasileiros e denominada Versão para o Português do Brasil da CSPS (CSPS-PB).

Na execução deste trabalho, algumas adaptações foram necessárias para que o instrumento fosse compreensível e capaz de mensurar o objeto de estudo proposto. No entanto, sua característica principal de avaliação foi mantida, de modo que, após a realização do processo de adaptação, foi capaz de medir o mesmo construto do instrumento original.

Para o processo de validação, foram avaliadas as validades de face, de conteúdo e de construto, obtendo-se resultados satisfatórios. Vale ressaltar que, para a adaptação e validação da CSPS-PB, adotaram-se critérios metodológicos bem definidos, o que assegura a qualidade dos resultados apresentados. A avaliação da confiabilidade e da validade possibilitaram a obtenção de um instrumento válido e confiável para a mensuração deste construto.

Como limitação deste estudo, destacam-se as características da amostra, pois utilizaram-se somente profissionais enfermeiros de uma instituição hospitalar. No entanto, estudos futuros poderão fornecer dados adicionais importantes para a avaliação de outras propriedades psicométricas desse instrumento.

A utilização da CSPS-PB poderá proporcionar contribuições efetivas na avaliação da prática cínica do profissional de enfermagem com relação à adesão às PP, 
permitindo reflexões positivas que visem à segurança do profissional e do paciente.

Dados os resultados apresentados neste trabalho, referente ao processo de adaptação e validação da CSPS-PB, trata-se de um instrumento adequado, confiável e válido para medir a adesão às PP entre enfermeiros brasileiros, porém só poderá ser utilizada mediante autorização do autor. 


\section{REFERÊNCIAS}

AMIRA, C. O.; AWOBUSUYI, J. O. Needle-stick injury among health care workers in hemodialysis units in Nigeria: a multi-center study. International Journal of Occupational and Environmental Medicine, v. 5, n. 1, p. 1-8, 2014.

ARAÚJO, T. M. E.; COSTA E SILVA, N. Acidentes perfurocortantes e medidas preventivas para hepatite $B$ adotadas por profissionais de Enfermagem nos serviços de urgência e emergência de Teresina, Piauí. Revista Brasileira de Saúde Ocupacional, v. 39, n. 130, p. 175-183, 2014.

ASKARIAN, M.; MCLAWS, M. L.; MEYLAN, M. Knowledge, attitude, and practices related to standard precautions of surgeons and physicians in university- affiliated hospitals of Shiraz, Iran. International Journal of Infectious Disease, v. 11, p. 213-219, 2007.

BARTLETT, M. S. A note on the multiplying factors for various chi square approximations. Journal of the Royal Statistics Society, v.16, series B, p. 296-298, 1954.

BATHKE, J.; CUNICO, P. A.; MAZIERO, E. C. S.; CAUDURO, F. L. F.; SARQUIS, L. M. M.; CRUZ, E. D. A. Infraestrutura e adesão à higienização das mãos: desafios à segurança do paciente. Revista Gaúcha de Enfermagem, v. 34, n. 2, p. 78-85, 2013.

BEAM, E. L.; GIBBS, S. G.; BOULTER, K. C.; BECKERDITE, M. E.; SMITH, P. W. A method for evaluating health care workers' personal protective equipment technique. American Journal of Infection Control, v. 1, n. 6, p. 1-6, 2011.

BEATON, D. E; BOMBARDIER, C.; GUILLEMIN, F.; FERRAZ, M. B. Guidelines for the process of cross-cultural adaptation of self-report measures. Spine, v. 25, n. 24, p. 3186-3191, 2000.

BEATON, D. E; BOMBARDIER, C.; GUILLEMIN, F.; FERRAZ, M. B. Recommendations for the Cross-Cultural Adaptation of the DASH \& Quick DASH Outcome Measures. Institute for Work \& Health, 2002, 2007.

BENNETT, N. T.; HOWARD, R. J. Quantity of blood inoculated in a needlestick injury from suture needles. Journal of the American College of Surgeons, v. 178, n. 2, p. $107-110,1994$. 
BORSA, J. C.; DAMÁSIO, B. F.; BANDEIRA, D. R. Adaptação e Validação de Instrumentos Psicológicos entre Culturas: Algumas Considerações. Paidéia, v. 22, n. 53, p. 423-432, 2012.

BRAND, C. I.; FONTANA, R. T. Biossegurança na perspectiva da equipe de enfermagem de Unidades de Tratamento Intensivo. Revista Brasileira de Enfermagem, v. 67, n. 1, p. 78-84, 2014.

BRASIL. Agência Nacional de Vigilância Sanitária. Higienização das mãos em serviços de saúde/ Agência Nacional de Vigilância Sanitária. - Brasília: Anvisa, 2007.

Agência Nacional de Vigilância Sanitária. Guia Para Implementação: Um Guia para a implantação da estratégia multimodal da OMS para a melhoria da higienização das mãos a observadores: estratégia multimodal da OMS para a melhoria da higienização das mãos. Tradução de Sátia Marine - Brasília: Organização Pan-Americana da Saúde; Agência Nacional de Vigilância Sanitária. 2008, 63 p.

- Ministério da Saúde. Agência Nacional de Vigilância Sanitária. Manual de gerenciamento de resíduos de serviços de saúde / Ministério da Saúde, Agência Nacional de Vigilância Sanitária. - Brasília: Ministério da Saúde, 2006. 182 p.

. Ministério do Trabalho. Portaria n03.214, de 08 de junho de 1978. Aprova as Normas Regulamentadoras - NR - do Capítulo V, Título II, da Consolidação das Leis do Trabalho, relativas à Segurança e Medicina do Trabalho, 1978.

. Ministério do Trabalho e Emprego. Portaria n0485, de 11 de novembro de 2005. Aprova a Norma Regulamentadora n032. Segurança e Saúde no Trabalho em Estabelecimentos de Saúde. Diário Oficial da União, Brasília, 16 nov. 2005.

. Ministério do Trabalho e Emprego. Portaria n. ${ }^{2}$ 25, de 15 de outubro de 2001. Altera a Norma Regulamentadora que trata de Equipamento de Proteção Individual NR6 e dá outras providências. Diário Oficial da União, Brasília, 17 out. 2001.

. Ministério do Trabalho e Emprego. Portaria n. ${ }^{\circ}$ 107, de 25 de agosto de 2009 Altera o item 6.6.1 e o item A2 do Anexo I da Norma Regulamentadora n. ${ }^{\circ} 6$. Diário Oficial da União, Brasília, 27 ago. 2009. 
Ministério do Trabalho e Emprego. Portaria SIT n. ${ }^{0}$ 194, de 07 de dezembro de 2010. Altera a Norma Regulamentadora n. 6 (Equipamentos de Proteção Individual EPI). Diário Oficial da União, Brasília, 08 dez. 2010.

Ministério do Trabalho e Emprego. Portaria n.01.748, de 30 de agosto de 2011. Diário Oficial da União, Brasília, 31 ago. 2011.

BREVIDELLI, M. M.; CIANCIARULLO, T. I. Fatores psicossociais e organizacionais na adesão às precauções-padrão. Revista de Saúde Pública, v. 43, n. 6, p. 1-10, 2009.

CAMPANA A. N.; TAVARES, M. C.; SILVA, D. Modelagem de Equações Estruturais: Apresentação de uma abordagem estatística multivariada para pesquisas em Educação Física. Motricidade, v.5, n.4, p.59-80, 2009.

CARDOSO, A. C. M.; FIGUEIREDO, R. M. Situações de risco biológico presentes na assistência de enfermagem nas unidades de saúde da família (USF). Revista LatinoAmericana de Enfermagem, v. 18, n. 3, p. 368-372, 2010.

CARMINES, E.; ZELLER, R. A. Reliability and validity assessment. Beverly-Hills, CA Saga Publications, 1979.

CARROLL, J. B. Human Cognitive abilities: A survey of factor-analytic studies. New York: Cambridge University Press, 1993.

CENTERS FOR DISEASE CONTROL AND PREVENTION. Recommendations for prevention of HIV transmission in health care settings. Morbidity and Mortality Weekly Report, v. 36, n. SU02. 1987. Disponível em <http://www.cdc.gov/mmwr/preview/mmwrhtml/00023587.htm>. Acesso em: 28 mai. 2015.

CHAN, R.; MOLASSIOTIS, A.; CHAN, E.; CHAN, V.; HO, B.; LAI, C. Y.; LAM, P.; SHIT, F.; YIU, I. Nurses' knowledge of and compliance with universal precautions in an acute care hospital. International Journal of Nursing Studies, v. 39, p. 157-163, 2002.

CHAN, M. F., HO, A.; DAY, M.C. Investigating the knowledge, attitudes and practices patterns of operating room staff towards standard and transmission- based precautions; results of a cluster analysis. Journal of Clinical Nursing, v. 17, p. 1051-1062, 2008. 
CHIODI, M. B.; MARZIALE, M. H. P.; MONDADORI, R. M.; ROBAZZI, M. L. C. C. Acidentes registrados no Centro de Referência em Saúde do Trabalhador de Ribeirão Preto, São Paulo. Revista Gaúcha de Enfermagem, v. 31, n. 2, p. 211-217, 2010.

CHWALOW, A. J. Cross-cultural validation of existing quality of life scales. Patient Education and Counseling, v. 26, n. 1-3, p. 313-318, 1995.

CIRELLI, A. A.; FIGUEIREDO, R. M.; ZEM-MASCARENHAS, S. H. Adesão às precauções padrão no acesso vascular periférico. Revista Latino Americana de Enfermagem, v. 15, n. 3, p. 512-514, 2007.

COMREY, A. L.; LEE, H. B. A first course in factor analysis. Hillsdale, NJ: Erlbaum, 1992.

COZBY, P. C. Métodos de pesquisa em ciências do comportamento. São Paulo: Atlas, 2003.

CROCKER, L.; ALGINA, J. Introduction to classical and modern test theory. New York. Harcourt Brace Jovanovich College Publisher, 1996.

CRONBACH, L. J. Coefficient alpha and the internal structure of tests. Psychometrika, v.16, n.3, p. 297-334, 1951.

CRONBACH, L. J.; RAJARATNAM, N.; GLESER, G. C. Theory of generalizability: A liberalization of reliability theory. British Journal of Statistical Psychology, v. 16, n. 2, p. 137-163, 1963.

CUMINGS, S. R.; STWART, A.; RULLEY, S. B. Elaboração de questionários e instrumentos de coleta de dados. In: HULLEY, S. B. et al. Delineamento de pesquisa clínica. Uma abordagem epidemiológica. Porto Alegre: Artmed, 2003. 265-281 p.

CUTTER, J.; JORDAN, S. Inter-professional differences in compliance with standard precautions in operating theatres: A multi-site, mixed methods study. International Journal of Nursing Studies, v. 49, n. 8, p. 953-968, 2012.

DANTAS, R. A. S.; ROSSI, L. A. Tradução e adaptação transcultural de instrumentos na área da saúde: uma nova proposta. Escola de Enfermagem de Ribeirão Preto. 2004. In: 
ENCONTRO ÍBERO AMERICANO DE QUALIDADE DE VIDA, 20, 2004, Porto Alegre (Apresentação pôster)

DE CARVALHO NAGLiATE, P.C.; NOGUeIRA, P. C.; GODOY, S; MENDES, I. A. C. Measures of knowledge about standard precautions: A literature review in nursing. Nurse Education in Practice, v.13, n.4, p. 244-249, 2013.

DEJOY, D. M.; MURPHY, L. R.; GERSHON, R. R. M. The influence of employee, job task, and organizational factors on adherence to universal precautions among nurses. International Journal of Industrial Ergonomics, n.16, p. 43-55, 1995.

DEVELLIS, R.F. Scale Development: theory and applications. 2rd ed. Newbury Park, CA: Sage, 1991, $121 \mathrm{p}$.

EFSTATHIOU, G.; PAPASTAVROU, E.; RAFTOPOULOS, V.; MERKOURIS, A. Factors influencing nurses' compliance with Standard Precautions in order to avoid occupational exposure to microorganisms: A focus group study. BioMed Central, v. 10, n. 1, p. 1$12,2011$.

ENZMANN, D. RanEigen: a program to determine the parallel analysis criterion for the number of principal components. Applied Psychological Measurement, v.21, n.3, 232, 1997.

ERASMUS, V.; DAHA, T. J.; BRUG, H.; RICHARDUS, J. H.; BEHRENDT, M. D.; VOS, M. C.; VAN BEECK, E. F. Systematic review of studies on compliance with hand hygiene guidelines in hospital care. American Journal of Infection Control, v. 31, n. 3, p. 283-294, 2010.

FAYERS, P. M.; MACHIN, D. Scores and Measurements: Validity, Reliability and Sensitivy. Quality of Life. Assessment Analysis and Interpretation. Chi Chester, England. John Wiley \& Sons, 2007.

FERRER, M.; ALONSO, J.; PRIETO, L.; PLAZA, V.; MONSÓ, E.; MARRADES, R.; AGUAR, M. C.; KHALAF, A.; ANTÓ, J. M. Validity and reliability of the St George's Respiratory Questionnaire after adaptation to a different language and culture: the Spanish example. European Respiratory Journal, v. 9, n. 6, p. 1160-1166, 1996. 
FERREIRA L.; NEVES, A. N.; CAMPANA, M. B.; TAVARES, M. C. G. C. F. Guia da AAOS/IWH: sugestões para adaptação transcultural de escalas. Avaliação Psicológica, v. 13, n. 3, p. 457-461, 2014.

FRANKLIN, S. B.; GIBSON, D. J.; ROBERTSON, P. A.; POHLMANN, J. T.; FRALISH, J. S. Parallel Analysis: A method for determining significant principal components. Journal of Vegetation Science, v. 6, n. 1, p. 99-106,1995.

FREITAS, A. L. P.; RODRIGUES, S. G. A avaliação da confiabilidade de questionários: uma análise utilizando o coeficiente alfa de Cronbach. In: Simpósio de Engenharia de Produção, Unesp, 2005.

FROTA, O. P.; LOUREIRO, M. D. R.; FERREIRA, A. M. Aspiração endotraqueal por sistema aberto: práticas de profissionais de enfermagem em terapia intensiva. Escola Anna Nery, v. 18, n. 2, p. 296-302, 2014.

FROTA, O. P.; FERREIRA, A. M.; LOUREIRO, M. D. R.; CHEADE, M. F. M.; REIS, M. G. $O$ uso de equipamento de proteção individual por profissionais de enfermagem na aspiração endotraqueal. Revista de Enfermagem UERJ, v. 20, n. 1 (esp), p. 625630, 2012.

GAMMON J.; MORGAN-SAMUEL, H.; GOULD, D. A review of the evidence for suboptimal compliance of healthcare practitioners to standard/universal infection control precautions. Journal Clinical of Nursing, n. 17, v. 2, p. 157-167, 2008.

GARBACCIO, J. L.; REGIS, W. C. B.; SILVA, R. M. C.; ESTEVÃO, W. G. ACIDENTES OCUPACIONAIS COM A EQUIPE DE ENFERMAGEM DA ATENÇÃO HOSPITALAR. Cogitare Enfermagem, v. 20, n. 1, p. 146-152, 2015.

GARNER, J.S. Hospital infection control practices advisory committee. Guideline for isolation precautions in hospitals. Infection Control and Hospital Epidemiology, v. 17, n. 5, p. 53-80, 1996.

GERSHON, R. R.; VLAHOV, D.; FELKNOR, S. A.; VESLEY, D.; JOHNSON, P. C.; DELCLOS, G. L.; MURPHY, L. R. Compliance with universal precautions among health care workers at three regional hospitals. American Journal of Infection Control, v. 23, n. 4, p. 225-236, 1995. 
GLORFELD, L. W. An Improvement on Horn's Parallel Analysis Methodology for Selecting the Correct Number of Factors to Retain. Educational and Psychological Measurement, v. 55, n. 3, p. 377-393, 1995.

GREEN, L. W.; KREUTER, M. W.; DEEDS, S. G.; PARTRIDGE, K. B. Health education planning: a diagnostic approach. Palo Alto: Mayfield, 1980.

GUILLEMIN, F.; BOMBARDIER, C.; BEATON, D. Cross-Cultural Adaptation of HealthRelated Quality Of Life Measures: Literature Review and Proposed Guidelines. Journal of Clinical Epidemiology, v. 46, n. 12, p. 1417-1432, 1993.

GUTTMAN, L. Some necessary conditions for common factor analysis. Psvchometrika, v. 19, n. 2 , p. 149-161, 1954.

HAIR JR., J. F.; ANDERSON, R. E.; TATHAM, R. L.; BLACK, W. C. Análise multivariada de dados. 5 ed. Porto Alegre: Bookman, 2005.

HARRIS, S. A.; NICOLAI, L. A. Occupational exposures in emergency medical service providers and knowledge of and compliance with universal precautions. American Journal of Infection Control, v. 38, n. 2, p. 86-94, 2010.

$\mathrm{HO}$, R. Handbook of univariate and multivariate data analysis and interpretation with SPSS. London: Chapman \& Hall/CRC; 2006.

JULIO, R. S.; FILARDI, M. B. S.; MARZIALE, M. H. P. Acidentes de trabalho com material biológico ocorridos em municípios de Minas Gerais. Revista Brasileira de Enfermagem, v. 67, n. 1, p. 119-126, 2014.

KAISER, H. F. An index of factorial simplicity. Psychometrika, v.39, n.1, p. 31-36, 1974.

KAISER, H. F. The application of electronic computers to factor analysis. Educational and Psychological Measurement, v.20, p. 141-151, 1960.

KUMAKECH, E.; ACHORA, S.; BERGGREN, V.; BAJUNIRWE, F. Occupational exposure to HIV: a conflict situation for health workers. International Nursing Review, v. 58, n. 4, p. 454-462, 2011. 
KOTWAL, A.; TANEJA, D. Health Care Workers and Universal Precautions: Perceptions and Determinants of Non-compliance. Indian Journal of Community Medicine: Official Publication of Indian Association of Preventive \& Social Medicine, v. 35, n. 4, p. 526-528, 2010.

LAM, S.C. Universal to standard precautions in disease prevention: Preliminary development of compliance scale for clinical nursing. International Journal of Nursing Studies, v. 4, n. 12, p. 1533-1539, 2011.

LAM, S. C. Validation and cross-cultural pilot testing of compliance with standard precautions scale: self-administered instrument for clinical nurses. Infection Control and Hospital Epidemiology, v. 35, n. 5, p. 547-555, 2014.

LIU, X.; SUN, X.; GENUGTEN, L. V.; SHI, Y.; WANG, Y.; NIU, W.; RICHARDUS, J. H. Occupational exposure to blood and compliance with standard precautions among health care workers in Beijing, China. American Journal of Infection Control, v. 42, n. 3, 37-38, 2014a.

LIU, W. I.; LIANG, S. Y.; WU, S. F.; CHUANG, Y. H. Hand hygiene compliance among the nursing staff in freestanding nursing homes in Taiwan: a preliminary study. International Journal of Nursing Practice, v. 20, n. 1, p. 46-52, 2014b.

LOVEDAY, H. P.; LYNAM, S.; SINGLETON, J.; WILSON, J. J. Clinical glove use: healthcare workers' actions and perceptions. Journal of Hospital Infection, v. 86, n. 2, p. 110$116,2014$.

LUO, Y.; HE, G. P.; ZHOU, J. W.; LUO, Y. Factors impacting with standard precautions in nursing, China. International Journal of Infectious Disease, v. 14, n. 12 p. 1106$1114,2010$.

MCDOWELL, I.; NEWEEL, C. Measuring health: a guide to rating scales and questionnaires. 2 ed. New York: Oxford. University Press; 1996.

MALAGUTI, S.E.; HAYASHIDA, M.; CANINI, S.R.M.S.; GIR, E. Enfermeiros com cargos de chefia e medidas preventivas à exposição ocupacional: facilidades e barreiras. Revista Escola de Enfermagem USP, v. 42, n. 3, p. 496-503, 2008. 
MALAGUTI-TOFFANO, S. E.; CANINI, S. R. M. S.; GALVAO, M. T. G.; BREVIDELL, M. M.; Gir, E. Adesão às precauções-padrão de profissionais de enfermagem de um hospital universitário. Acta Paulista de Enfermagem (UNIFESP. Impresso), v. 25, n. 3, p. 401-407, 2012.

MAROCO, J.; GARCIA-MARQUES, T. Qual a fiabilidade do alfa de Cronbach? Questões antigas e soluções modernas? Laboratório de Psicologia, v. 4, n. 1, p. 65-90, 2006.

MOHAMMADI, N.; ALLAMI, A.; MALEK MOHAMADI, R. Percutaneous exposure incidents in nurses: Knowledge, practice and exposure to hepatitis $B$ infection: Percutaneous exposure incidents in nurses. Hepatitis Monthly, v. 11, n. 3, p. 186-190, 2011.

NADERI, H.; SHEYBANI, F.; MOSTAFAVI, I.; KHOSRAVI, N. Compliance with hand hygiene and glove change in a general hospital, Mashhad, Iran: an observational study. American Journal of Infection Control, v. 40, n. 6, p. 221-223. 2012.

NEVES, H. C. C.; SOUZA, A. C. S.; MEDEIROS, M.; MUNARI, D. B.; RIBEIRO, L. C. M.; TIPPLE, A. F. V. Segurança dos trabalhadores de enfermagem e fatores determinantes para adesão aos equipamentos de proteção individual, Revista Latino Americana de Enfermagem, v. 19, n. 2, p. 1-8, 2011.

NUNNALLY, J. L. Psychometric theory. 2rd ed. New York: McGraw-Hill, 1978.

NUNNALLY, J. L. Psychometric theory. New York: McGraw-Hill, 1979.

OLIVEIRA, A. C.; CARDOSO, C. S.; MASCARENHAS, D. Precauções de contato em Unidade de Terapia Intensiva: fatores facilitadores e dificultadores para adesão dos profissionais. Revista de Escola de Enfermagem da USP, v. 44, n. 1, p. 161-165, 2010.

OLIVEIRA, A. C.; PAIVA, M. H. R. S. Analysis of occupational accidents with biological material among professionals in pre-hospital services. Revista Latino Americana de Enfermagem, v. 21, n. 1, p. 309-315, 2013.

PALLANT, J. SPSS Survival Manual. Open University Press, 2007. 
PARK, S.; JEONG, I.; HUH, J.; YOON, Y.; LEE, S.; CHOI, C. Needlestick and sharps injuries in a tertiary hospital in the Republic of Korea. American Journal of Infection Control, v. 36, n. 6, p. 439-443, 2008.

PETERSON, R. A. A meta-analysis of Cronbach's coefficient alpha. Journal of Consumer Research, v. 21, n. 2, p. 381-391, 1994.

PASQUALI, L. Análise Fatorial para Pesquisadores. Brasília: LabPAM, 2012. 281 p.

. Parâmetros psicométricos dos testes psicológicos. In:

Técnicas de exames psicológicos-TEP. São Paulo: Casa do Psicólogo, 2001. 111-36 p.

- Princípios de elaboração de escalas psicológicas. Revista de Psiquiatria Clínica, v. 25, n. 5, p. 27-36, 1998. 992-999, 2009.

Psicometria. Revista da Escola de Enfermagem da USP, v. 43, n. spe, p. Psicometria: teoria dos testes na psicologia e na educação. Petrópolis: Vozes, 2003.

. Instrumentos psicológicos: manual prático de elaboração. Brasília: LabPAM/BAPP, 1999. 37-71 p.

PATIL, V. H.; SINGH, S. N.; MISHRA, S.; DONAVAN, D. T. Efficient theory development and factor retention criteria: Abandon the eigenvalue greater than one criterion. Journal of Business Research, v. 61, n. 2, p. 162-170, 2008.

PEREIRA, F. M. V.; MALAGUTI, S. E. ; SILVA, A. M. ; CANINI, S. R. M. S. ; GIR, E. . Adesão às precauções-padrão por profissionais de enfermagem que atuam em terapia intensiva em um hospital universitário do interior paulista. Revista da Escola de Enfermagem da USP (Impresso), v. 47, n. 3, p. 686-693, 2013.

PEREIRA, F. M.; LAM, S. C.; CHAN, J. H.; MALAGUTI-TOFFANO, S. E.; GIR, E. Difference in compliance with Standard Precautions by nursing staff in Brazil versus Hong Kong. American Journal of Infection Control, v. 45, p. 1-4, 2015. 
PETER, J. P. Reliability: A Review of Psychometric Basics and Recent Marketing Practices. Journal of Marketing Research, v. 16, n.1, p. 6-17, 1979.

PILATTI, L. A.; PEDROSO, B.; GUTIERREZ, G. L. Propriedades Psicométricas de Instrumentos de Avaliação: Um debate necessário. Revista Brasileira de Ensino de Ciência e Tecnologia, v. 3, n. 1, p. 81-91, 2010.

PRADO, M. F.; HARTMANN, T. P. S.; TEIXEIRA FILHO, L. A. Acessibilidade da estrutura física hospitalar para a prática da higienização das mãos. Escola Anna Nery Revista de Enfermagem, v. 17, n. 2, p. 220-226, 2013.

PRIMO, M. G. B.; RIBEIRO, L. C. M.; FIGUEIREDO, L. F. S.; SIRICO, S. C. A.; SOUZA, M. A. Adesão à prática de higienização das mãos por profissionais de saúde de um Hospital Universitário. Revista Eletrônica de Enfermagem, v. 12, n. 2, p. 266-271, 2010.

RAMOS DE CARVALHO, T. R.; LIMA, M. G.; AZEVEDO, R. C. S.; CAETANO, D. Tradução do inglês para o português do Questionário de Auto avaliação da Escala de Hamilton de Depressão. Jornal Brasileiro de Psiquiatria, v. 42, n. 5, p. 255-260, 1993.

RAPPARINI, C. Manual de implementação: programa de prevenção de acidentes com materiais perfurocortantes em serviços de saúde. São Paulo: Fundacentro, 2010. $161 \mathrm{p}$.

RATTRAY, J., JONES, M.C. Essential elements of questionnaire design and development. Journal of Clinical Nursing, v. 16, n. 2, p. 234-243, 2007.

REISE, S. P.; WALLER, N. G.; COMREY, A. L. Factor analysis and Scale Revision. Psychological Assessment, v.12, n.3, 287-297, 2000.

REZENDE, K. C. A. D.; TIPPLE, A. F. V.; SIQUEIRA, K. M.; ALVES, S. B.; SALGADO, T. A.; PEREIRA, M. S. Adesão à higienização das mãos e ao uso de equipamentos de proteção pessoal por profissionais de enfermagem na atenção básica em saúde. Ciência, Cuidado e Saúde, v. 11, n. 2, p. 343-351, 2012.

RODRIGUES, F. I. M.; TELES, N. S. B.; ALMEIDA, P. C. Uso de equipamentos de proteção individual em uma emergência traumatológica. Journal of Nursing UFPE on line [JNUOL], v. 8, n. 7, p. 2082-2088, 2014. 
SAKIHAMA, T.; HONDA, H.; SAINT, S.; FOWLER, K. E.; SHIMIZU, T.; KAMIYA, T.; SATO, Y.; ARAKAWA, S.; LEE, J. J.; IWATA, K.; MIHASHI, M.; TOKUDA, Y. Hand Hygiene Adherence Among Health Care Workers at Japanese Hospitals: A Multicenter Observational Study in Japan. Journal of Patient Safety, v.4, 2014.

SANTOS, T. C. R.; ROSEIRA, C. E.; PIAI-MORAIS, T. H.; FIGUEIREDO, R. M. Higienização das mãos em ambiente hospitalar: uso de indicadores de conformidade. Revista Gaúcha de Enfermagem, v.35, n.1, p. 70-77, 2014.

SAWILOWSKY, S. S. Reability as psychometrics versus datametrics. In B. Thompson (Ed.), Score reliability: Contemporary thinking on reliability issue. Thousand Oaks, CA: Sage Publication, 2003. 103-121 p.

SCHUMACKER, R. E.; LOMAX, R. G. su New Jersey: Lawrence Erlbaum Associates, 2001.

SIEGEL, J. D.; RHINEHART, E.; JACKSON, M.; CHIARELO, L. Guideline for isolation precautions: preventing transmission of infectious agents in healthcare settings 2007. Atlanta, Jun. 2007. Disponível em: <http://www.cdc.gov/ ncidod/dhqp/pdf/isolation2007.pdf>. Acesso em: 22 nov. 2014.

SILVA, G. S.; ALMEIDA, A. J.; PAULA, V. S.; VILLAR, L. M. Conhecimento e utilização de medidas de precaução padrão por profissionais de saúde. Escola Anna Nery Revista de Enfermagem, v. 16, n. 1, p. 103-110, 2012.

SILVA, J. A.; PAULA, V. S.; ALMEIDA, A. J.; VILLAR, L. M. Investigação de acidentes biológicos entre profissionais de saúde. Escola Anna Nery Revista de Enfermagem, v. 13, n. 3, p. 508-516, 2009.

SHROUT, P. E.; FLEISS, J. L. Intraclass correlations: uses in assessing rater reliability. Psychological Bulletin, v. 86, n. 2, n. p. 420-8, 1979.

STREINER, D. L; NORMAN, G. R. Health measurement scales. A practical guide to their development and use. 4th ed. New York: Oxford University Press; 2008.

TABACHNICK, B. G.; FIDELL, L. S. Using multivariate statistics. 3rd ed. New York: HarperCollins, 1996. 
TERWEE, C. B.; BOT, S. D. M.; BOER, M. R.; VAN DER WINDT, D. A. W. M.; KNOL D. L.; DEKKER, J.; BOUTER, L. M.; DE VET, H. C. Quality criteria were proposed for measurement properties of health status questionnaires. Journal of Clinical Epidemiology, v. 60, n. 1, p. 34-42, 2007.

TERWEE, C. B.; SCHELLINGERHOUT, J. M.; VERHAGEN, A. P.; KOES, B. W.; DE VET, H. C. Methodological quality of studies on the measurement properties of neck pain and disability questionnaires: a systematic review. Journal of Manipulative and Physiological Therapeutics, v. 34, n. 4, p. 261-272, 2011.

TIPPLE, A. F. V.; SILVA, E. A. C.; TELES, S. A.; MENDONÇA, K. M.; SILVA E SOUZA, A. C.; MELO, D. S. Acidente com materiais biológico sem atendimento pré-hospitalar Móvel: Realidade para Trabalhadores da Saúde e Não Saúde. Revista Brasileira de Enfermagem, v. 66, n. 3, p. 378-384, 2013.

URBINA, S. Fundamentos da testagem moderna. Porto Alegre: Artmed, 2007.

VALIM, M. D.; MARZIALE, M. H. P. Adaptação cultural do "Questionnaires for knowledge and Compliance with Standard Precautions" para o português brasileiro. Revista Gaúcha de Enfermagem, v.34, n.4, p. 28-36, 2013.

VALIM M. D.; MARZIALE, M. H.; RICHART-MARTÍNEZ, M.; SANJUAN-QUILES, Á. Instruments for evaluating compliance with infection control practices and factors that affect it: an integrative review. Journal Clinical of Nursing, v. 23, n. 11-12, p. 15021519, 2014.

VELICER, W. F.; JACKSON, D. N. Component Analysis Versus Common Factor-Analysis - Some Further Observations. Multivariate Behavioral Research, v. 25, n. 1, p. 97$114,1990$.

YUAN, K. H.; BENTLER, P. M. Structural equation modeling. In: Rao CR, Sinharay S. Handbook of Statistics 26: psychometrics. Netherlands: Elsevier; 2007.

WARLEY, E.; PEREYRA, N.; DESSE, J.; CETANI S.; DE LUCA, A.; ANTABAK N.T.; SZYLD, E. Estudio sobre la exposición ocupacional a sangre y fluidos corporales en el personal de enfermería de un hospital de referencia de Buenos Aires, Argentina. Revista Panamericana de Salud Publica, v.25, n.6, p. 524-529, 2009. 
WORLD HEALTH ORGANIZATION. Infection control standard precautions in health care. Health-care facility recommendations for standard precautions. Geneva, Switzerland: World Health Organization, 2006.

World Alliance for Patient Safety. Global Patient Safety Challenge: 20052006 / World Alliance for Patient Safety, 2005, 2006. 35 p.

. WHO Guidelines on Hand Hygiene in Health Care. First Global Patient Safety Challenge Clean Care is Safer Care, 2009. 270 p.

. World Alliance for Patient Safety who Guidelines on Hand Hygiene in Health Care (Advanced Draft): A Summary. WHO Guidelines on Hand Hygiene in Health Care. 2004. 31 p.

ZHANG, P.; WANG, L.; BAO, H.; GAO, Z.; CHEN, X.; ZHANG, D.; JIANG, N. Incidence of needlestick and other sharp object injuries in a Chinese hospital. American Journal of Infection Control, v. 42, n. 2, p. 213-224, 2014.

ZHANG, M.; WANG, H.; MIAO, J.; DU, X.; LI, T.; WU, Z. Occupational exposure to blood and body fluids among health care workers in a general hospital, China. American Journal of Industrial Medicine, v. 52, n. 2, p. 89-98, 2009.

ZWICK, W. R.; VELICER, W. F. Comparison of five roles for determining the number of components to retain. Psychological Bulletin. n. 99, v. 3, p.432-442, 1986. 
A pêndices $\mid \mathbf{1 2 2}$

Apêndices 


\section{APÊNDICE 1 \\ TERMO DE CONSENTIMENTO LIVRE E ESCLARECIDO Para os Juízes}

Vimos por meio deste convidá-lo a participar da pesquisa intitulada "Adaptação Cultural e Validação da Compliance with Standard Precautions Scale (CSPS) para profissionais de enfermagem brasileiros" do Programa Interunidades de Doutoramento em Enfermagem da Escola de Enfermagem de Ribeirão Preto, cujo propósito é validar o instrumento. Caso concorde em participar, solicitaremos a sua colaboração na validação de face e de conteúdo visando analisar as equivalências presentes no mesmo (semântica, idiomática, conceitual e experimental). Após a validação de face e conteúdo, a versão final da CSPS será aplicada em um grupo de enfermeiros que atuam na assistência à pacientes em dois hospitais localizados no Estado de São Paulo, para análises das propriedades psicométricas de confiabilidade (consistência interna e reprodutibilidade) e de validade (construto). Estima-se que a reunião para a validação terá duração de duas horas. Qualquer dúvida poderá ser esclarecida com os pesquisadores e sua resposta será respeitosamente utilizada em eventos científicos da área da saúde, sem restrições de prazos e citações, desde a presente data. Caso concorde em participar, é preciso assinar esse termo, que está em duas vias originais assinadas pelos pesquisadores, sendo uma delas sua e a outra do pesquisador responsável. A sua participação é voluntária, este estudo não oferece qualquer custo, risco ou desconforto para você e asseguramos que você não será identificado. Embora você não receba benefícios diretos por sua participação nesta pesquisa, sua colaboração trará contribuições importantes para a validação da CSPS. Caso decida participar do estudo, você poderá interromper sua participação na pesquisa em qualquer momento da sua execução sem gerar-lhe prejuízos. A qualquer momento, você poderá solicitar esclarecimentos adicionais sobre sua participação na pesquisa. Em caso de dúvidas, durante ou após sua participação você poderá entrar em contato com as pesquisadoras Profa. Elucir Gir ou Fernanda Maria Vieira Pereira no endereço - Escola de Enfermagem de Ribeirão Preto: Av. Bandeirantes, 3900, Ribeirão Preto - SP, CEP: 14040-900, no telefone (016) 3602-3414 ou (016) 81014800, ou ainda através dos emails: egir@eerp.usp.br e fernanddamaria@hotmail.com. Se você ainda tiver dúvidas com relação aos aspectos éticos desta pesquisa, poderá entrar em contato com o Comitê de Ética em Pesquisa da Escola de Enfermagem de Ribeirão Preto pelo telefone (16)3202-3386. Caso se sinta prejudicado por ter participado da pesquisa, você deverá buscar indenização de acordo com a lei vigente no Brasil.

Fernanda Maria Vieira Pereira

Pesquisador responsável
Prof $^{\mathrm{a}}$.Dr. ${ }^{\mathrm{a}}$ Elucir Gir

Orientadora

\section{Consentimento de participação:}

$\mathrm{Eu}$, abaixo assinado, concordo em participar do estudo: "Adaptação Cultural e Validação da Compliance with Standard Precautions Scale (CSPS) para profissionais de enfermagem brasileiros", como sujeito voluntário e com a garantia de que o estudo está em concordância com a Resolução 196/96 que regulamenta a pesquisa envolvendo seres humanos. 


\section{APÊNDICE 2}

No.

Data:

1

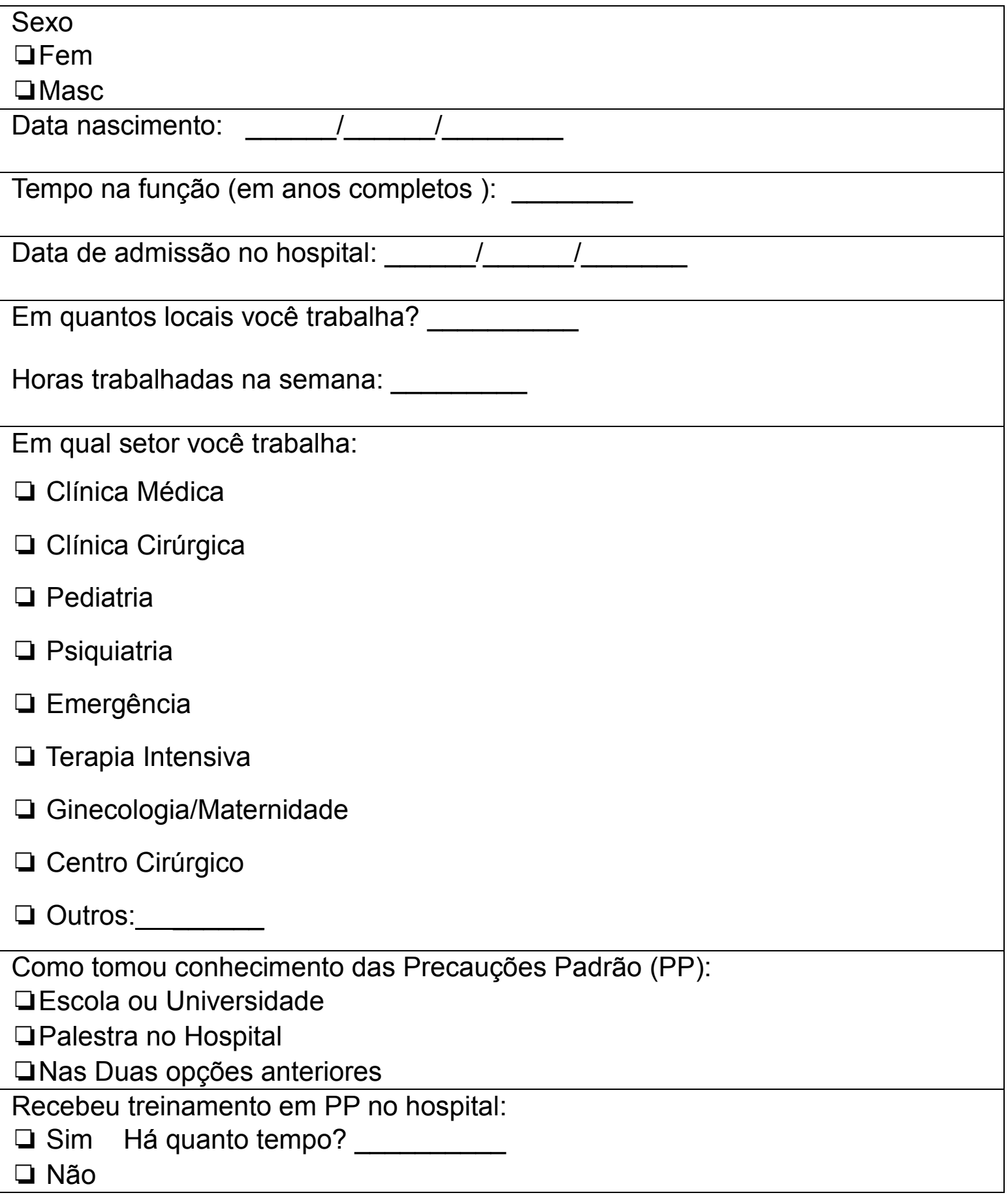




\section{APÊNDICE 3 \\ TERMO DE CONSENTIMENTO LIVRE E ESCLARECIDO}

Gostaríamos de convidá-lo (a) para participar da pesquisa "Adaptação Cultural e Validação da Compliance with Standard Precautions Scale (CSPS). Esta pesquisa tem como objetivo adaptar culturalmente para o Brasil uma escala que avalia a adesão dos enfermeiros ás precauções padrão. Acreditamos que a validação deste instrumento será de grande importância, pois além de ser uma escala recente e atualizada, pode ser utilizada para verificar a adesão às precauções-padrão pelos profissionais de enfermagem. Para sua realização será aplicado um questionário com informações demográficas/ profissionais e uma escala contendo 20 itens. Sua participação constará de responder estes instrumentos de forma individual conforme sua disponibilidade e no momento oportuno. Estima-se que a coleta de dados terá duração de 15 a 20 minutos. Embora você não receba benefícios diretos por sua participação nesta pesquisa, os resultados obtidos poderão direcionar estratégias para garantir a segurança do profissional e também do paciente no ambiente hospitalar. Você tem garantido o seu direito de não aceitar participar ou de retirar sua permissão, a qualquer momento, sem nenhum tipo de prejuízo ou retaliação, pela sua decisão. As informações desta pesquisa serão confidencias, e serão divulgadas apenas em eventos ou publicações científicas, não havendo identificação dos voluntários, a não ser entre os responsáveis pelo estudo, sendo assegurado o sigilo sobre sua participação. É importante ressaltar, que este estudo não oferece qualquer risco ou desconforto, e asseguramos que você não terá nenhum gasto para a sua participação. Caso concorde em participar, é preciso assinar esse termo, que está em duas vias originais assinadas pelos pesquisadores, sendo uma delas sua e a outra do pesquisador responsável. A qualquer momento, você poderá solicitar esclarecimentos adicionais sobre sua participação na pesquisa. Em caso de dúvidas, durante ou após sua participação você poderá entrar em contato com as pesquisadoras Profa. Elucir Gir ou Fernanda Maria Vieira Pereira no endereço Escola de Enfermagem de Ribeirão Preto: Av. Bandeirantes, 3900, Ribeirão Preto - SP, CEP: 14040900, no telefone (016) 3602-3414 ou (016) 81014800, ou ainda através dos e-mails: egir@eerp.usp.br e fernanddamaria@hotmail.com. Se você ainda tiver dúvidas com relação aos aspectos éticos desta pesquisa, poderá entrar em contato com o Comitê de Ética em Pesquisa da Escola de Enfermagem de Ribeirão Preto pelo telefone (16)3202-3386.

$\mathrm{Eu}$, após a leitura deste documento e ter tido a oportunidade de conversar com o pesquisador responsável, para esclarecer todas as minhas dúvidas, acredito estar suficientemente informado, ficando claro para mim que minha participação é voluntária e que posso retirar este consentimento a qualquer momento sem penalidades ou perda de qualquer benefício. Estou ciente também dos objetivos da pesquisa, dos procedimentos aos quais serei submetido, dos possíveis danos ou riscos deles provenientes e da garantia de confidencialidade e esclarecimentos sempre que desejar. Diante do exposto expresso minha concordância de espontânea vontade em participar deste estudo.

Profa. Dra. Elucir Gir - Orientadora

Fernanda Maria Vieira Pereira - Pesquisadora responsável 
Anexos $\mathbf{1 2 6}$

Anexos 


\section{ANEXO 1}

\section{Compliance with Standard Precautions Scale (CSPS)}

Please mark a $\boldsymbol{V}$ in the box that best reflects your current clinical practice.

Please answer all 20 questions.

Never Seldom Sometimes Always

Q1. I wash my hands between patient contacts.

Q2. I only use water for hand washing.

Q3. I use alcoholic hand rubs as an alternative if my hands are not visibly soiled.

Q4. I recap used needles after giving an injection.

Q5. I put used sharp articles into sharps boxes.

Q6. The sharps box is disposed only when it is full.

Q7. I remove Personal Protective Equipment (PPE) in a designated area.

Q8. I take a shower in case of extensive splashing even after I have put on Personal Protective Equipment(PPE).

Q9. I cover my wound(s) or lesion(s) with waterproof dressing before patient contacts.

Q10. I wear gloves when I am exposed to body fluids, blood products, and any excretion of patients.

Q11. I change gloves between patient contacts.

Q12. I decontaminate my hands immediately after removal of gloves.

Q13. I wear a surgical mask alone or in combination with goggles, face shield and apron whenever there is a possibility of a splash or splatter.

Q14. My mouth and nose are covered when I wear a mask.

Q15. I reuse a surgical mask or disposable Personal Protective Equipment (PPE).

Q16. I wear a gown or apron when exposed to blood, body fluids or any patient excretions.

Q17. Waste contaminated with blood, body fluids, secretion and excretion is placed in red plastic bags irrespective of the patient's infection status.

Q18. I decontaminate surfaces and equipment after use.

Q19. I wear gloves to decontaminate used equipment with visible soils.

Q20. I clean up spillage of blood or other body fluids immediately with disinfectants.

$\square \square \square \square$




\section{ANEXO 2}

Versão Português 1 - Compliance with Standard Precautions Scale (CSPS)

Assinale com um X na alternativa que melhor reflete a sua prática clínica atual

Q1. Eu lavo minhas mãos entre contatos com cada paciente.
Q2. Eu uso somente água para lavar as mãos.
Q3. Uso desinfetante alcoólico alternativamente, se minhas mãos não
estão visivelmente sujas.
Q4. Eu recubro as agulhas de injeção após o uso.
Q5. Eu coloco artigos afiados em usados em caixas próprias.
Q6. A caixa de artigos afiados é descartada somente quando está cheia.
Q7. Eu removo Equipamento de Proteção Pessoal (EPP) em um local
especial.

Nunca Raramente Ás vezes Sempre

Q8. Eu tomo banho quando acontece de me molhar muito no atendimento mesmo que eu tenha usado Equipamento de Proteção Pessoal (EPP).

Q9. Eu cubro meus ferimentos ou machucados com curativo à prova d’água antes de entrar em contato com pacientes.

Q10. Eu uso luvas quando estou exposto a secreções, sangue, ou qualquer excreção de pacientes.

Q11. Eu troco de luvas cada vez que atendo um novo paciente.

Q12. Eu faço a descontaminação de minhas mãos imediatamente após a remoção de luvas.

Q13. Eu uso máscara cirúrgica somente, ou em combinação com os óculos de proteção de rosto, e avental, sempre que tem a possibilidade de respingos ou espirros.

Q14. Minha boca e meu nariz ficam cobertos quando eu uso a máscara.

Q15. Eu uso mais de uma vez a mesma máscara, ou Equipamento Protetor Pessoal descartável.

Q16. Eu uso uma vestimenta ou avental quando estou exposto a sangue, secreções corporais, ou excreções de pacientes.

Q17. Lixo contaminado com sangue, líquidos do corpo, secreções e excreções são colocados em sacolas plásticas vermelhas independente do estado do paciente.

Q18. Eu faço a descontaminação de superfícies e do equipamento após o uso.

Q19. Eu uso luvas para descontaminar o equipamento usado com manchas visíveis.

Q20. Eu limpo imediatamente derramamento de sangue ou outros liquidos corporais com desinfetante.

Você acaba de completar o questionário. Guarde-o no envelope e lacre com o adesivo. Obrigado por participar da pesquisa. Lembre-se, todas as informações serão mantidas em completo sigilo. Certifique-se que respondeu a TODAS as questões. 


\section{ANEXO 3}

Versão Português 2 - Compliance with Standard Precautions Scale (CSPS)

Assinale com um $X$ na alternativa que melhor reflete a sua prática clínica atual

Q1. Lavo as mãos após contato com cada paciente.
Q2. Uso apenas água para lavar as mãos.
Q3. Uso produto a base de álcool para esfregar as mãos como
alternativa se minhas mãos não estiverem visivelmente sujas.
Q4. Cubro as agulhas com uma tampa após aplicar uma injeção.
Q5. Coloco os materiais cortantes usados em caixas especificas
para itens perfurocortantes.

Q6. A caixa de materiais perfurocortantes só é descartada quando estiver cheia.

Q7. Removo os EPI (Equipamento de Proteção Individual) em uma área apropriada.

Q8. Tomo banho em caso de respingos extensos, mesmo após ter colocado os EPI (Equipamento de Proteção Individual.

Q9. Cubro meus machucados ou lesões com curativos a prova d’água antes de ter contato com os pacientes.

Q10. Uso luvas quando fico exposto a líquidos corporais, produtos de sangue e qualquer excreção de pacientes.

Q11. Troco luvas entre um paciente e outro.

Q12. Descontamino as mãos imediatamente após remover as luvas.

Q13. Uso apenas uma máscara cirúrgica ou junto com óculos de proteção, máscara facial e avental sempre que houver possibilidade de respingos ou derramamentos.

Q14. Minha boca e nariz ficam cobertos quando uso uma máscara.

Q15. Eu reutilizo uma máscara cirúrgica ou EPI (Equipamento de Proteção Individual) descartável.

Q16. Uso uma bata ou avental quando estou exposto a sangue, líquidos corporais ou quaisquer excreções do paciente.

Q17. O lixo contaminado com sangue, líquidos corporais, secreção e excreção é colocado dentro de sacos plásticos vermelhos, independente do estado de infeção do paciente.

Q18. Descontamino as superfícies e equipamentos antes do uso.

Q19. Uso luvas para descontaminar equipamentos usados com sujeira visível.

Q20. Limpo os derramamentos de sangue ou outros líquidos corporais imediatamente com desinfetantes.

Nunca Raramente Ás vezes Sempre

$\square \square \square \square$

$\square \quad \square \quad \square \quad \square$

$\square \quad \square \quad \square$
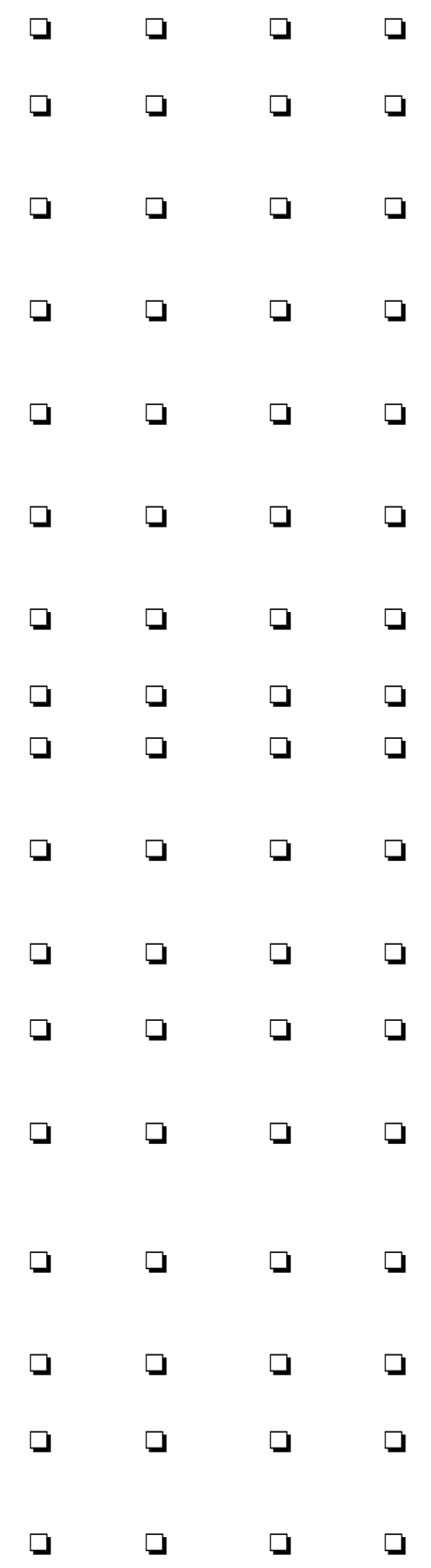

Você acaba de completar o questionário. Guarde-o no envelope e lacre com o adesivo. Obrigado por participar da pesquisa. Lembre-se, todas as informações serão mantidas em completo sigilo. Certifique-se que respondeu a TODAS as questões. 


\section{ANEXO 4}

Versão Português Consensual 1 - Compliance with Standard Precautions Scale (CSPS)

Q1.Eu lavo minhas mãos entre contatos com pacientes.
Q2. Eu uso somente água para lavar as mãos.
Q3. Eu uso produto a base de álcool para esfregar as mãos como
alternativa se não estiverem visivelmente sujas.

Q4. Eu reencapo agulhas usadas após aplicar uma injeção.

Q5. Eu descarto materiais perfurocortantes em caixas próprias.

Q6. A caixa de materiais perfurocortantes é descartada somente quando está cheia.

Q7. Eu retiro os Equipamentos de Proteção Individual (EPI) em um local designado.

Q8. Eu tomo banho em caso de respingos extensos mesmo que eu tenha usado EPI.

Q9. Eu cubro meus ferimentos ou lesões com curativos a prova d'agua antes do contato com pacientes.

Q10. Eu uso luvas quando estou exposto a fluidos corporais, sangue ou derivados e qualquer excreção de pacientes.

Q11. Eu troco de luvas entre contato com pacientes.

Q12. Eu higienizo as minhas mãos imediatamente após remover as luvas.

Q13. Eu uso apenas máscara cirúrgica ou em combinação com óculos de proteção e avental sempre que houver a possibilidade de respingos ou derramamentos.

Q14. Minha boca e meu nariz ficam cobertos quando uso máscara.

Q15. Eu reutilizo uma máscara cirúrgica ou EPI descartável.

Q16. Eu uso avental/capote quando estou exposto a sangue, fluídos corporais ou qualquer excreção de pacientes.

Q17. Material contaminado com sangue, fluídos corporais, secreções e excreções de pacientes é descartado em sacos plásticos brancos independente do estado infeccioso do paciente.

Q18. Eu descontamino superficies e equipamentos após o uso.

Q19. Eu uso luvas para descontaminar equipamentos que apresentam sujeira visível.

Q20. Eu limpo imediatamente com desinfetante superfícies após derramamento de sangue ou outros fluídos corporais.

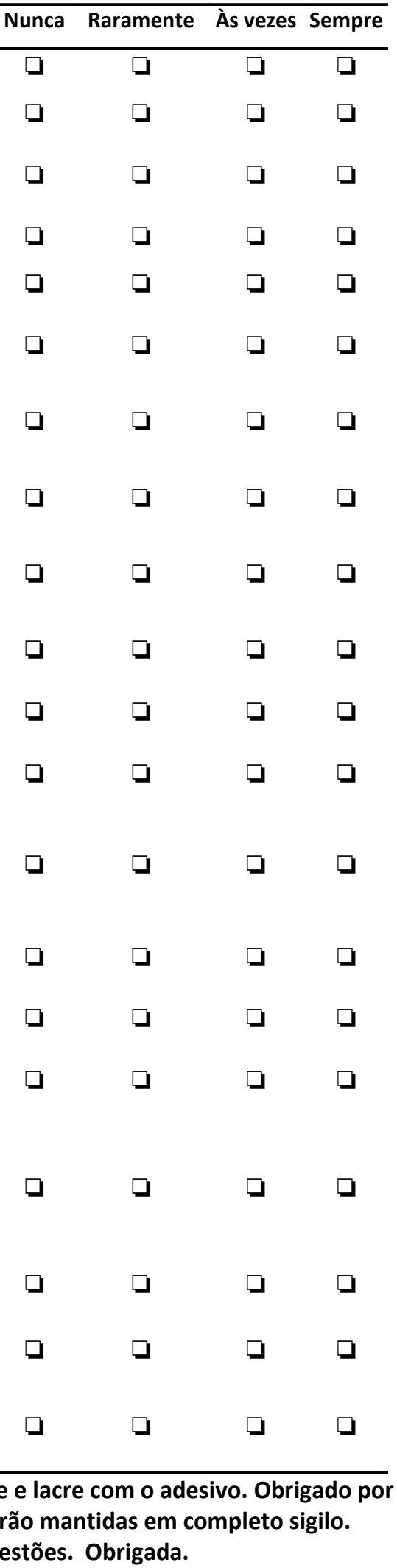

Você acaba de completar o questionário. Guarde-o no envelope e lacre com o adesivo. Obrigado por participar da pesquisa. Lembre-se, todas as informações serão mantidas em completo sigilo. Certifique-se que respondeu a TODAS as questões. Obrigada. 


\section{ANEXO 5}

\section{Versão Inglês 1}

Please mark a $\mathbf{X}$ in the box that best reflects your current clinical practice.

\begin{tabular}{|c|c|c|c|c|}
\hline & Never & Rarely & sometimes & always \\
\hline Q1. I wash my hands between contact with patients. & 口 & ם & ב & ב \\
\hline Q2. I only use water to wash my hands. & 口 & ב & 口 & ב \\
\hline $\begin{array}{l}\text { Q3. I use an alcohol-based product to scrub my hands as an } \\
\text { alternative if they are not visibly dirty. }\end{array}$ & $\square$ & घ & $\square$ & 口 \\
\hline Q4. I recap needles after applying an injection. & $\square$ & ם & $\square$ & ב \\
\hline Q5. I throw away sharp materials in the appropriate boxes. & $\square$ & د & $\square$ & 口 \\
\hline $\begin{array}{l}\text { Q6. The box of sharp materials is thrown away only when it } \\
\text { is full. }\end{array}$ & $\square$ & $\square$ & $\square$ & घ \\
\hline $\begin{array}{l}\text { Q7. I take the personal protection equipment (PPE) from its } \\
\text { designated place. }\end{array}$ & $\square$ & ב & ב & च \\
\hline $\begin{array}{l}\text { Q8. I bathe after cases of extensive splashing even if I have } \\
\text { been using PPE. }\end{array}$ & 口 & $\square$ & ב & च \\
\hline $\begin{array}{l}\text { Q9. I cover my wounds or lesions with waterproof bandages } \\
\text { before any patient contact. }\end{array}$ & $\square$ & $\square$ & $\square$ & च \\
\hline $\begin{array}{l}\text { Q10. I use gloves when I am exposed to bodily fluids, blood } \\
\text { or derivatives and any excretion from patients. }\end{array}$ & $\square$ & $\square$ & $\square$ & $\square$ \\
\hline Q11. I change my gloves between patient contact. & $\square$ & 口 & $\square$ & घ \\
\hline Q12. I clean my hands immediately after removing gloves. & $\square$ & ב & $\square$ & 口 \\
\hline $\begin{array}{l}\text { Q13. I use just a surgical mask or with protective goggles } \\
\text { and apron whenever there is the possibility of splashes or } \\
\text { spillage. }\end{array}$ & 口 & ב & $\square$ & ஏ \\
\hline $\begin{array}{l}\text { Q14. My mouth and my nose are covered when I use a } \\
\text { mask. }\end{array}$ & $\square$ & $\square$ & $\square$ & $\square$ \\
\hline Q15. I re-use a surgical mask or disposable PPE. & $\square$ & 口 & $\square$ & $\square$ \\
\hline $\begin{array}{l}\text { Q16. I use an apron/overalls when I am exposed to blood, } \\
\text { bodily fluids or any excretion from patients. }\end{array}$ & $\square$ & $\square$ & $\square$ & $\square$ \\
\hline $\begin{array}{l}\text { Q17. Material that is contaminated with blood, bodily fluids } \\
\text { secretions and excretions from patients is disposed of in } \\
\text { white plastic bags no matter the infectious state of the } \\
\text { patient. }\end{array}$ & $\square$ & ב & ש & $\square$ \\
\hline Q18. I decontaminate equipment and surfaces after use. & $\square$ & 口 & $\square$ & $\square$ \\
\hline $\begin{array}{l}\text { Q19. I use gloves to decontaminate equipment that shows } \\
\text { visible dirt. }\end{array}$ & $\square$ & ב & $\square$ & $\square$ \\
\hline $\begin{array}{l}\text { Q20. I immediately clean surfaces with disinfectant after } \\
\text { spillage of blood or other bodily fluids. }\end{array}$ & $\square$ & 口 & $\square$ & פ \\
\hline
\end{tabular}

You have now completed the questionnaire. Store it in the envelope and seal with adhesive. Thank you for participating in the survey. Remember, all information will be kept strictly confidentiality. Make sure that responded to all questions. 


\section{ANEXO 6}

\section{Versão Inglês 2}

Please mark a $\mathbf{X}$ in the box that best reflects your current clinical practice

\begin{tabular}{|c|c|c|c|c|}
\hline & Never & Rarely & sometimes & always \\
\hline Q1. I wash my hands between contacts with patients. & $\square$ & $\square$ & $\square$ & $\square$ \\
\hline Q2. I only use water for hand washing. & פ & ב & ב & ב \\
\hline $\begin{array}{l}\text { Q3. I use an alcohol-based product to scrub my hands as an } \\
\text { alternative if my hands are not visibly soiled. }\end{array}$ & $\square$ & פ & $\square$ & $\square$ \\
\hline Q4. I recap used needles after applying an injection. & $\square$ & $\square$ & $\square$ & $\square$ \\
\hline Q5. I put away sharp materials in the appropriate boxes. & $\square$ & $\square$ & $\square$ & $\square$ \\
\hline $\begin{array}{l}\text { Q6. The box of sharp materials is disposed away only when } \\
\text { it is full. }\end{array}$ & ב & פ & $\square$ & 口 \\
\hline
\end{tabular}

Q7. I remove Personal Protection Equipment (PPE) from its designated place.

Q8. I take a shower after cases of extensive splashing even if I have been using PPE

Q9. I cover my wounds or lesions with waterproof bandages before any patient contact.

Q10. I use gloves when I am exposed to bodily fluids, blood or derivatives and any excretion from patients.

Q11. I change my gloves between patient contact.

Q12. I clean my hands immediately after removing gloves.

Q13. I only use a surgical mask or with protective goggles and apron whenever there is the possibility of splashes or spillage.

Q14. My mouth and my nose are covered when I use a mask.

Q15. I re-use a surgical mask or disposable PPE

Q16. I use an apron/overalls when I am exposed to blood, bodily fluids or any excretion from patients.

Q17. Material that is contaminated with blood, bodily fluids secretions and excretions from patients is disposed of in white plastic bags no matter the infectious state of the patient.

Q18. I decontaminate equipment and surfaces after use.

Q19. I use gloves to decontaminate equipment that shows visible dirt.

Q20. I immediately clean surfaces with disinfectant after spillage of blood or other bodily fluids.
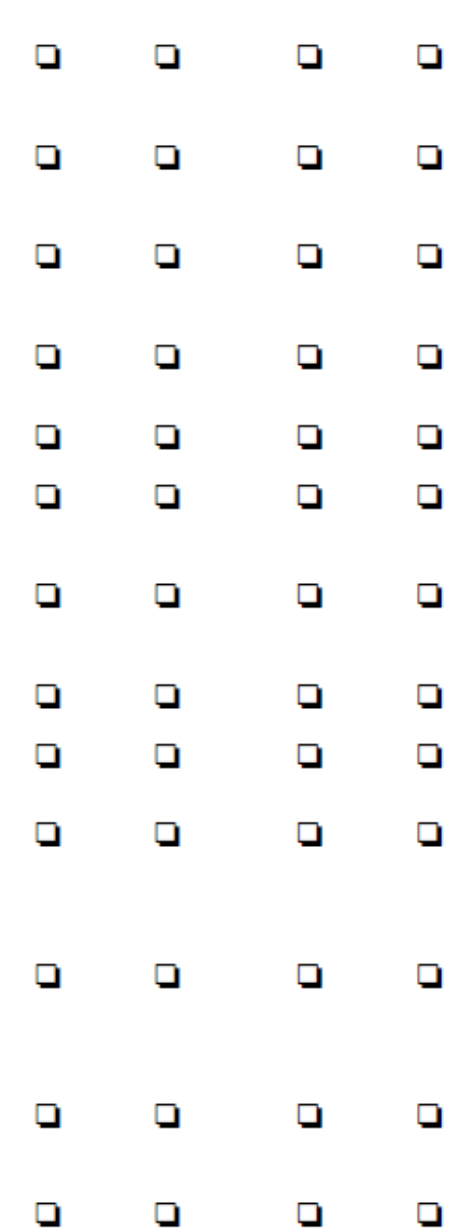

• $\square \square \square$

You have now completed the questionnaire. Store it in the envelope and seal with adhesive. Thank you for participating in the survey. Remember, all information will be kept strictly confidential. Make sure that responded to all questions. 


\section{ANEXO 7}

\section{Versão Inglês Final}

Please mark a $\mathbf{X}$ in the box that best reflects your current clinical practice

Never Rarely Sometimes Always

Q1. I wash my hands between contacts with patients.

Q2. I only use water for hand washing.

Q3. I use an alcohol-based product to scrub my hands as an alternative if my hands are not visibly soiled.

Q4. I recap used needles after giving an injection.

Q5. I put away sharp materials in the appropriate boxes.

Q6. The box of sharp materials is disposed away only when it is full.

Q7. I remove Personal Protection Equipment (PPE) from its designated place.

Q8. I take a shower after cases of extensive splashing even if I have been using PPE.

Q9. I cover my wounds or lesions with waterproof bandages before any patient contact.

Q10. I use gloves when I am exposed to bodily fluids, blood or derivatives and any excretion from patients.

Q11. I change my gloves between patient contact.

Q12. I clean my hands immediately after removing gloves.

Q13. I only use a surgical mask or with protective goggles and apron whenever there is the possibility of splashes or spillage.

Q14. My mouth and my nose are covered when I use a mask.

Q15. I re-use a surgical mask or disposable PPE

Q16. I use an apron/overalls when I am exposed to blood, bodily fluids or any excretion from patients.

Q17. Material that is contaminated with blood, bodily fluids secretions and excretions from patients is disposed of in white plastic bags no matter the infectious state of the patient.

Q18. I decontaminate equipment and surfaces after use.

Q19. I wear gloves to decontaminate used equipment with visible soils.

Q20. I immediately clean surfaces with disinfectant after spillage of blood or other bodily fluids.

$\square \square \square \square$
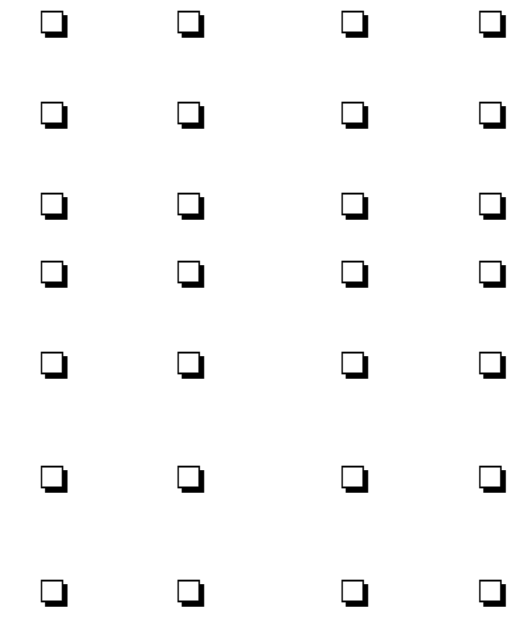


\section{ANEXO 8}

Versão Português Consensual 2

Assinale com um $\mathrm{X}$ na alternativa que melhor reflete a sua prática clínica atual

\begin{tabular}{|c|c|c|c|c|}
\hline & Nunca & Raramente & Ás vezes & Sempre \\
\hline Q1.Eu lavo minhas mãos entre contatos com pacientes. & ב & $\square$ & ב & $\square$ \\
\hline Q2. Eu uso somente água para lavar as mãos. & פ & $\square$ & פ & פ \\
\hline $\begin{array}{l}\text { Q3. Eu uso produto à base de álcool para higienizar as minhas mãos } \\
\text { como alternativa se não estiverem visivelmente sujas. }\end{array}$ & $\square$ & $\square$ & פ & $\square$ \\
\hline Q4. Eu reencapo agulhas usadas após aplicar uma injeção. & $\square$ & $\square$ & & ב \\
\hline Q5. Eu descarto materiais perfurocortantes em caixas próprias. & ב & ב & ב & ב \\
\hline $\begin{array}{l}\text { Q6. A caixa de materiais perfurocortantes é descartada somente } \\
\text { quando está cheia. }\end{array}$ & 口 & $\square$ & & $\square$ \\
\hline $\begin{array}{l}\text { Q7. Eu retiro os Equipamentos de Proteção Individual (EPI) em um } \\
\text { local designado. }\end{array}$ & ב & ב & פ & פ \\
\hline $\begin{array}{l}\text { Q8. Eu tomo banho em caso de respingos extensos mesmo que eu } \\
\text { tenha usado EPI. }\end{array}$ & a & $\square$ & פ & פ \\
\hline $\begin{array}{l}\text { Q9. Eu cubro meus ferimentos ou lesões com curativos à prova d'água } \\
\text { antes do contato com pacientes. }\end{array}$ & פ & $\square$ & פ & 口 \\
\hline $\begin{array}{l}\text { Q10. Eu uso luvas quando estou exposto a fluidos corporais, sangue } \\
\text { ou derivados e qualquer excreção de pacientes. }\end{array}$ & פ & $\square$ & & $\square$ \\
\hline Q11. Eu troco de luvas entre contato com pacientes. & פ & $\square$ & $\square$ & פ \\
\hline $\begin{array}{l}\text { Q12. Eu higienizo as minhas mãos imediatamente após remover as } \\
\text { luvas. }\end{array}$ & פ & $\square$ & פ & $\square$ \\
\hline $\begin{array}{l}\text { Q13. Eu uso máscara cirúrgica ou em combinação com óculos de } \\
\text { proteção e avental sempre que houver a possibilidade de } \\
\text { respingos ou derramamentos. }\end{array}$ & ם & $\square$ & פ & פ \\
\hline Q14. Minha boca e meu nariz ficam cobertos quando uso máscara. & פ & $\square$ & $\square$ & פ \\
\hline Q15. Eu reutilizo uma máscara cirúrgica ou EPI descartável. & ב & $\square$ & $\square$ & ב \\
\hline $\begin{array}{l}\text { Q16. Eu uso avental/capote quando estou exposto a sangue, fluidos } \\
\text { corporais ou qualquer excreção de pacientes. }\end{array}$ & ב & $\square$ & פ & $\square$ \\
\hline $\begin{array}{l}\text { Q17. Eu descarto material contaminado com sangue, fluidos corporais, } \\
\text { secreções e excreções de pacientes é descartado em sacos } \\
\text { plásticos brancos independentemente do estado infeccioso do } \\
\text { paciente. }\end{array}$ & פ & $\square$ & פ & $\square$ \\
\hline Q18. Eu descontamino superficies e equipamentos após o uso. & פ & פ & פ & פ \\
\hline $\begin{array}{l}\text { Q19. Eu uso luvas para descontaminar equipamentos que apresentam } \\
\text { sujeira visível. }\end{array}$ & פ & ב & פ & פ \\
\hline $\begin{array}{l}\text { Q20. Eu limpo imediatamente com desinfetante superfícies após } \\
\text { derramamento de sangue ou outros fluídos corporais. }\end{array}$ & ם & 口 & פ & ص \\
\hline
\end{tabular}

Você acaba de completar o questionário. Guarde-o no envelope e lacre com o adesivo. Obrigado por participar da pesquisa. Lembre-se, todas as informações serão mantidas em completo sigilo. Certifique-se que respondeu a TODAS as questões. Obrigada. 


\section{ANEXO 9}

\section{Versão Português Consensual 3}

Assinale com um $\mathrm{X}$ na alternativa que melhor reflete a sua prática clínica atual

\begin{tabular}{|c|c|c|c|c|}
\hline & Nunca & Raramente & Às vezes & Sempre \\
\hline Q1.Eu lavo minhas mãos entre contatos com pacientes. & $\square$ & $\square$ & $\square$ & $\square$ \\
\hline Q2. Eu uso somente água para lavar as mãos. & $\square$ & $\square$ & $\square$ & $\square$ \\
\hline $\begin{array}{l}\text { Q3. Eu uso produto à base de álcool para higienizar as mãos como } \\
\text { alternativa se não estiverem visivelmente sujas. }\end{array}$ & $\square$ & $\square$ & $\square$ & $\square$ \\
\hline Q4. Eu reencapo agulhas usadas após aplicar uma injeção. & $\square$ & $\square$ & $\square$ & $\square$ \\
\hline Q5. Eu descarto materiais perfurocortantes em caixas próprias. & $\square$ & $\square$ & $\square$ & $\square$ \\
\hline $\begin{array}{l}\text { Q6. A caixa de materiais perfurocortantes é descartada somente } \\
\text { quando está cheia. }\end{array}$ & $\square$ & $\square$ & $\square$ & $\square$ \\
\hline $\begin{array}{l}\text { Q7. Eu retiro os Equipamentos de Proteção Individual (EPI) em um } \\
\text { local designado. }\end{array}$ & $\square$ & $\square$ & $\square$ & $\square$ \\
\hline $\begin{array}{l}\text { Q8. Eu tomo banho em caso de respingos extensos mesmo que eu } \\
\text { tenha usado EPI. }\end{array}$ & $\square$ & $\square$ & $\square$ & $\square$ \\
\hline $\begin{array}{l}\text { Q9. Eu cubro meus ferimentos ou lesões com curativos à prova d' água } \\
\text { antes do contato com pacientes. }\end{array}$ & $\square$ & $\square$ & $\square$ & $\square$ \\
\hline $\begin{array}{l}\text { Q10. Eu uso luvas quando estou exposto a fluidos corporais, sangue } \\
\text { ou derivados e qualquer excreção de pacientes. }\end{array}$ & $\square$ & $\square$ & $\square$ & $\square$ \\
\hline Q11. Eu troco de luvas entre contato com pacientes. & $\square$ & $\square$ & $\square$ & $\square$ \\
\hline $\begin{array}{l}\text { Q12. Eu higienizo as minhas mãos imediatamente após remover as } \\
\text { luvas. }\end{array}$ & $\square$ & $\square$ & $\square$ & $\square$ \\
\hline $\begin{array}{l}\text { Q13. Eu uso máscara cirúrgica ou em combinação com óculos de } \\
\text { proteção e avental sempre que houver a possibilidade de } \\
\text { respingos ou derramamentos. }\end{array}$ & $\square$ & $\square$ & $\square$ & $\square$ \\
\hline Q14. Minha boca e meu nariz ficam cobertos quando uso máscara. & $\square$ & $\square$ & $\square$ & $\square$ \\
\hline Q15. Eu reutilizo uma máscara cirúrgica ou EPI descartável. & ב & $\square$ & $\square$ & $\square$ \\
\hline $\begin{array}{l}\text { Q16. Eu uso avental/capote quando estou exposto a sangue, fluidos } \\
\text { corporais ou qualquer excreção de pacientes. }\end{array}$ & $\square$ & $\square$ & $\square$ & $\square$ \\
\hline $\begin{array}{l}\text { Q17. Eu descarto material contaminado com sangue, fluidos corporais, } \\
\text { secreções e excreções de pacientes é descartado em sacos } \\
\text { plásticos brancos independentemente do estado infeccioso do } \\
\text { paciente. }\end{array}$ & $\square$ & $\square$ & $\square$ & $\square$ \\
\hline Q18. Eu descontamino superficies e equipamentos após o uso. & ב & $\square$ & $\square$ & $\square$ \\
\hline $\begin{array}{l}\text { Q19. Eu uso luvas para descontaminar equipamentos que apresentam } \\
\text { sujeira visível. }\end{array}$ & $\square$ & $\square$ & $\square$ & $\square$ \\
\hline $\begin{array}{l}\text { Q20. Eu limpo imediatamente com desinfetante (álcool) superfícies } \\
\text { após derramamento de sangue ou outros fluídos corporais. }\end{array}$ & $\square$ & $\square$ & $\square$ & $\square$ \\
\hline
\end{tabular}

Você acaba de completar o questionário. Guarde-o no envelope e lacre com o adesivo.

Obrigado por participar da pesquisa. Lembre-se, todas as informações serão mantidas em completo sigilo. Certifique-se que respondeu a TODAS as questões. Obrigada. 


\section{ANEXO 10}

Versão para o Português do Brasil da CSPS (CSPS-PB)

Assinale com um $\mathrm{X}$ na alternativa que melhor reflete a sua prática clínica atual

\begin{tabular}{|c|c|c|c|c|}
\hline & Nunca & Raramente & Às vezes & Sempre \\
\hline 1.Eu lavo minhas mãos entre contatos com pacientes. & $\square$ & $\square$ & 口 & 口 \\
\hline 2. Eu uso somente água para lavar as mãos. & $\square$ & $\square$ & $\square$ & $\square$ \\
\hline $\begin{array}{l}\text { 3. Eu uso produto à base de álcool para higienizar as mãos } \\
\text { como alternativa se não estiverem visivelmente sujas. }\end{array}$ & $\square$ & $\square$ & $\square$ & $\square$ \\
\hline 4. Eu reencapo agulhas usadas após aplicar uma injeção. & $\square$ & $\square$ & 口 & $\square$ \\
\hline 5. Eu descarto materiais perfurocortantes em caixas próprias. & $\square$ & $\square$ & $\square$ & $\square$ \\
\hline $\begin{array}{l}\text { 6. A caixa de materiais perfurocortantes é descartada somente } \\
\text { quando está cheia. }\end{array}$ & $\square$ & $\square$ & $\square$ & $\square$ \\
\hline $\begin{array}{l}\text { 7. Eu retiro os Equipamentos de Proteção Individual (EPI) em } \\
\text { um local designado. }\end{array}$ & $\square$ & $\square$ & $\square$ & 口 \\
\hline $\begin{array}{l}\text { 8. Eu tomo banho em caso de respingos extensos mesmo que } \\
\text { eu tenha usado EPI. }\end{array}$ & 口 & $\square$ & • & • \\
\hline $\begin{array}{l}\text { 9. Eu cubro meus ferimentos ou lesões com curativos à prova } \\
\text { d'água antes do contato com pacientes. }\end{array}$ & $\square$ & 口 & $\square$ & 口 \\
\hline $\begin{array}{l}\text { 10. Eu uso luvas quando estou exposto a fluidos corporais, a } \\
\text { sangue ou a derivados e qualquer excreção de pacientes. }\end{array}$ & $\square$ & $\square$ & 口 & 口 \\
\hline 11. Eu troco de luvas entre contato com pacientes. & $\square$ & $\square$ & 口 & 口 \\
\hline $\begin{array}{l}\text { 12. Eu higienizo as minhas mãos imediatamente após } \\
\text { remover as luvas. }\end{array}$ & 口 & ב & • & 口 \\
\hline $\begin{array}{l}\text { 13. Eu uso máscara cirúrgica ou em combinação com óculos } \\
\text { de proteção e avental sempre que houver a possibilidade de } \\
\text { respingos ou derramamentos. }\end{array}$ & $\square$ & ב & • & • \\
\hline $\begin{array}{l}\text { 14. Minha boca e meu nariz ficam cobertos quando uso } \\
\text { máscara. }\end{array}$ & a & ב & • & • \\
\hline 15. Eu reutilizo uma máscara cirúrgica ou EPI descartável. & $\square$ & $\square$ & 口 & $\square$ \\
\hline $\begin{array}{l}\text { 16. Eu uso avental/capote quando estou exposto a sangue, a } \\
\text { fluidos corporais ou a qualquer excreção de pacientes. }\end{array}$ & 口 & ב & ロ & • \\
\hline $\begin{array}{l}\text { 17. Eu descarto material contaminado com sangue, fluidos } \\
\text { corporais, secreções e excreções de pacientes em sacos } \\
\text { plásticos brancos independentemente do estado infeccioso do } \\
\text { paciente. }\end{array}$ & 口 & ב & ロ & • \\
\hline 18. Eu descontamino superfícies e equipamentos após o uso. & $\square$ & $\square$ & 口 & $\square$ \\
\hline $\begin{array}{l}\text { 19. Eu uso luvas para descontaminar equipamentos que } \\
\text { apresentam sujeira visível. }\end{array}$ & $\square$ & ב & 口 & • \\
\hline $\begin{array}{l}\text { 20. Eu limpo imediatamente com desinfetante (álcool) } \\
\text { superfícies após derramamento de sangue ou outros fluidos } \\
\text { corporais. }\end{array}$ & $\square$ & ב & • & ロ \\
\hline
\end{tabular}

Você acaba de completar o questionário. Guarde-o no envelope e lacre com o adesivo.

Obrigado por participar da pesquisa. Lembre-se, todas as informações serão mantidas em completo sigilo. Certifique-se que respondeu a TODAS as questões. 


\section{ANEXO 11}

CSPS Reproduction Approval Letter

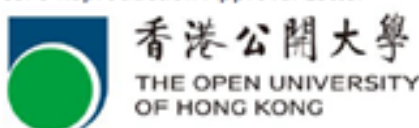

Nursing

Compliance with Standard Precautions Scale (CSPS) Reproduction Approval Letter

10 October 2012

Ms. Femanda Maria Vieira Pereira

Escola de Enfermagem de Ribeirào Preto da Universidade de Săo Paulo - EERP/USP

Rua Castro Alves. 766 - AP 45 - Vila Tibério - CEP:14050-370 - Ribeirão Preto-SP - Brasil

Dear Ms. Pereira,

I write to inform you that CSPS reproduction approval has been given for you to engage in the project named below:

\begin{tabular}{|c|c|}
\hline Project title: & $\begin{array}{l}\text { Cultural Adaptation and Validation of Compliance with Standard Precautions Scale } \\
\text { (CSPS) to Brazilian nursing professionals }\end{array}$ \\
\hline Approval code: & B500D36-201206 \\
\hline Imvestigator(s): & $\begin{array}{l}\text { Fernanda Maria Vieira Pereira } \\
\text { Elucir Gir }\end{array}$ \\
\hline Duration: & 36 months (June 2012 to July 2015) \\
\hline Location of Study: & Brasil \\
\hline Options of offer: & $\begin{array}{l}\text { Option B- Free of charge with the provision of collected data: } \\
\approx \text { The maximum number of coples of the CSPS is restricted to } 500 \text {. } \\
\text { citations are required. } \\
\text { - Authorization of reproducing the CSPS is granted with the provision of at least } 300 \text { collected } \\
\text { data in Microsoft Excel file or SPSS format. The data should include age, gender, title, total } \\
\text { clinical experience in year(s), types of working unit, and the raw data of the } 20 \text {-items CSPS. }\end{array}$ \\
\hline
\end{tabular}

It will be much appreciated if the completion of the project will be reported to the CSPS developer.

Yours sincerely,

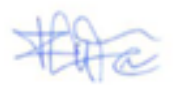

Simon C. LAM

Developer of CSPS

Assistant Professor

Nursing Division, Open University of Hong Kong

chlam@ouhk.edu.hk 
ANEXO 12

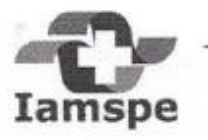
Instituto de Assistência Médica ao Servidor Público Estadual
HSPE - Hospital do Servidor Público Estadual Avenida Ibirapuera, 981 - Vila Clementino - Cep: 04029-000

SECRETARIA DE GESTÃo PÚBLICA

Iamspe

Săo Paulo, 09 de abril de 2013

Autorizo a pesquisadora Fernanda Maria Vieira Pereira a realizar a pesquisa intitulada: "Adaptação Cultural e Validaçāo da Compliance with Standard Precautions Scale (CSPS) para profissionais de enfermagem brasileiros", nas dependências do HSPE.

Atenciosamente,

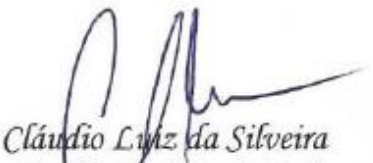

Diretor Téc. \e Divisão de Enfermagem

Diretoria- HSSPE- IAMSPE

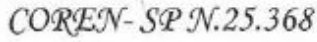


ANEXO 13

\section{ESCOLA DE ENFERMAGEM DE Platoforma RIBEIRÃO PRETO - USP}

\section{PARECER CONSUBSTANCIADO DO CEP}

\section{DADOS DO PROJETO DE PESQUISA}

Título da Pesquisa: Adaptação Cultural e Validação da Compliance with Standard Precautions Scale (CSPS) para profissionais de enfermagem brasileiros

Pesquisador: Fernanda Maria Vieira Pereira

Área Temática:

Versão: 2

CAAE: 13906813.6 .0000 .5393

Instituição Proponente: Escola de Enfermagem de Ribeirão Preto - USP

Patrocinador Principal: Financiamento Próprio

DADOS DO PARECER

Número do Parecer: 343.473

Data da Relatoria: 03/07/2013

Apresentação do Projeto:

Trata-se de um projeto em pendência.

Objetivo da Pesquisa:

sem alterações.

Avaliação dos Riscos e Benefícios:

sem alterações.

Comentários e Consideraçōes sobre a Pesquisa:

sem alterações.

Consideraçöes sobre os Termos de apresentação obrigatória:

As pesquisadoras apresentaram resposta às pendências, a saber:

1- No TCLE para os juízes, citaram os benefícios e o tempo estimado para a coleta de dados(validação do instrumento); explicitaram que as duas vias são originais e estão assinadas pelos pesquisadores; garantiram o anonimato do sujeito e a liberdade

de retirar o consentimento a qualquer momento;

2- No TCLE para os enfermeiros, garantiram que a via original está assinada pelos pesquisadores, citaram o tempo previsto para a coleta de dados e ausência de gastos;

3- Esclareceram que o comitê de Juízes será composto por seis profissionais, sendo 03

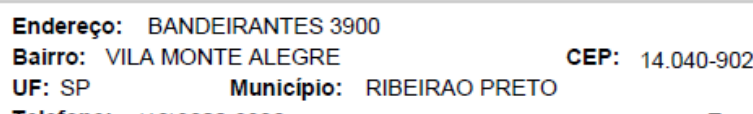

Telefone: (16)3602-3386

E-mail: cep@eerp.usp.br 


\section{ESCOLA DE ENFERMAGEM DE RIBEIRÃO PRETO - USP}

Continuação do Parecer: 343.473

enfermeiros especialistas na temática, 01 pessoa com domínio na língua inglesa e 02 pessoas que conheçam a metodologia do estudo;

4- Incluiram o número de juízes (06) no número 450 relativo aos enfermeiros e corrigiram a folha de rosto.

\section{Recomendaçōes:}

Não há.

Conclusōes ou Pendências e Lista de Inadequaçōes:

As pendências foram corrigidas adequadamente.

Situação do Parecer:

Aprovado

Necessita Apreciação da CONEP:

Não

Consideraçōes Finais a critério do CEP:

Parecer aprovado "ad referendum".

RIBEIRAO PRETO, 29 de Julho de 2013

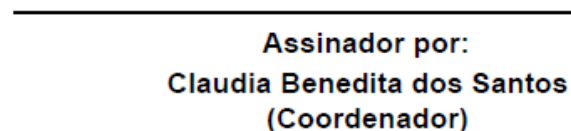

(Coordenador)

Endereço: BANDEIRANTES 3900

Bairro: VILA MONTE ALEGRE CEP: $14.040-902$

UF: SP Município: RIBEIRAO PRETO

Telefone: (16)3602-3386

E-mail: cep@eerp.usp.br 
ANEXO 14

\section{INSTITUTO DE ASSISTÊNCIA MÉDICA AO SERVIDOR PÚBLICO ESTADUAL - IAMSPE}

\section{PARECER CONSUBSTANCIADO DO CEP}

\section{Elaborado pela Instituição Coparticipante}

\section{DADOS DO PROJETO DE PESQUISA}

Título da Pesquisa: Adaptação Cultural e Validação da Compliance with Standard Precautions Scale (CSPS) para profissionais de enfermagem brasileiros

Pesquisador: Fernanda Maria Vieira Pereira

Área Temática:

Versão: 2

CAAE: 13906813.6 .0000 .5393

Instituição Proponente: Escola de Enfermagem de Ribeirão Preto - USP

Patrocinador Principal: Financiamento Próprio

\section{DADOS DO PARECER}

Número do Parecer: 405.247

Data da Relatoria: 24/09/2013

\section{Apresentação do Projeto:}

O presente estudo abordará todos os enfermeiros que presta assistência a qualquer paciente e que adere a medidas preventivas, a fim de diminuir o risco de exposição ocupacional e garantir também a segurança do paciente.Com objetivos claros e factíveis.

\section{Objetivo da Pesquisa:}

Realizar a adaptação cultural da Compliance with Standard Precautions Scale (CSPS) para profissionais de enfermagem brasileiros.

\section{Avaliação dos Riscos e Benefícios:}

A pesquisa apresenta risco mínimo aos participantes, considerando que no momento da coleta de dados haja constrangimento ao responder se adere ou não às precauções-padrão em seu ambiente de trabalho.Os beneficios estão relacionados a estudar a adesão às precauções-padrão e se os profissionais de enfermagem aderem a medidas preventivas na assistência a pacientes.

\section{Comentários e Consideraçōes sobre a Pesquisa:}

Trata-se de um estudo metodológico quantitativo do processo de adaptação cultural que utilizará o método proposto Ferrer et al (1996) que consiste em: Tradução; Consenso da versão em português; Avaliação por Comitê de Juízes; Retrotradução (Back-translation); Consenso da versão em português e comparação com a original; Avaliação Semântica dos itens; Pré-teste; Avaliação

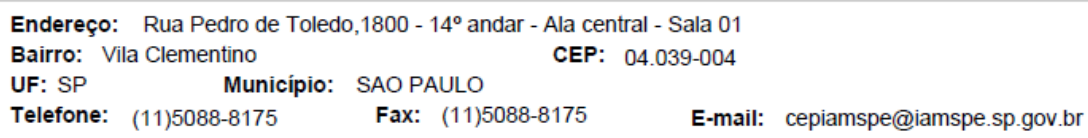




\section{INSTITUTO DE ASSISTÊNCIA \\ MÉDICA AO SERVIDOR \\ PÚBLICO ESTADUAL - IAMSPE}

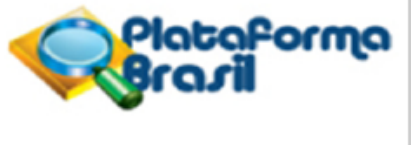

Continuação do Parecer: 405.247

das propriedades psicométricas do instrumento.A coleta será por meio de entrevistas individuais com todos enfermeiros com duração de 10 a 15 minutos realizada pela pesquisadora, no próprio local de trabalho durante todos os dias da semana, nos turnos manhã, tarde e noite.

\section{Consideraçōes sobre os Termos de apresentação obrigatória:}

Foram apresentados a folha de rosto,o projeto de pesquisa,o TCLE para os enfermeiros e juizes e a autorização da pesquisa pelo Diretot tecnico da Divisão de enfermagem.

Recomendaçōes:

Nenhuma

Conclusōes ou Pendências e Lista de Inadequações:

Nenhuma

Situação do Parecer:

Aprovado

Necessita Apreciação da CONEP:

Não

Consideraçōes Finais a critério do CEP:

O Colegiado acatou o parecer do relator. Projeto Aprovado.

SAO PAULO, 25 de Setembro de 2013

Assinador por:
Gizelda Monteiro da Silva
(Coordenador)

Endereço: Rua Pedro de Toledo, $1800-14^{\circ}$ andar - Ala central - Sala 01 Bairro: Vila Clementino CEP: $04.039-004$

UF: SP Município: SAO PAULO

Telefone: (11)5088-8175 Fax: (11)5088-8175 E-mail: cepiamspe@iamspe.sp.gov.br 


\section{ANEXO 15}

\section{INSTITUTO DE ASSISTÊNCIA MÉDICA AO SERVIDOR PÚBLICO ESTADUAL - IAMSPE}

\section{PARECER CONSUBSTANCIADO DO CEP}

Elaborado pela Instituição Coparticipante

\section{DADOS DO PROJETO DE PESQUISA}

Título da Pesquisa: Adaptação Cultural e Validação da Compliance with Standard Precautions Scale (CSPS) para profissionais de enfermagem brasileiros

Pesquisador: Fernanda Maria Vieira Pereira

Área Temática:

Versão: 2

CAAE: 13906813.6 .3001 .5463

Instituição Proponente: Escola de Enfermagem de Ribeirão Preto - USP

Patrocinador Principal: Financiamento Próprio

\section{DADOS DO PARECER}

Número do Parecer: $599.965-0$

Data da Relatoria: 24/09/2013

\section{Apresentação do Projeto:}

O presente estudo abordará todos os enfermeiros que presta assistência a qualquer paciente e que adere a medidas preventivas, a fim de diminuir o risco de exposição ocupacional e garantir também a segurança do paciente.Com objetivos claros e factíveis.

\section{Objetivo da Pesquisa:}

Realizar a adaptação cultural da Compliance with Standard Precautions Scale (CSPS) para profissionais de enfermagem brasileiros.

\section{Avaliação dos Riscos e Benefícios:}

A pesquisa apresenta risco mínimo aos participantes, considerando que no momento da coleta de dados haja constrangimento ao responder se adere ou não às precauções-padrão em seu ambiente de trabalho.Os beneficios estão relacionados a estudar a adesão às precauções-padrão e se os profissionais de enfermagem aderem a medidas preventivas na assistência a pacientes.

\section{Comentários e Considerações sobre a Pesquisa:}

Trata-se de um estudo metodológico quantitativo do processo de adaptação cultural que utilizará o método proposto Ferrer et al (1996) que consiste em: Tradução; Consenso da versão em português; Avaliação por Comitê de Juízes; Retrotradução (Back-translation); Consenso da versão em português e comparação com a original; Avaliação Semântica dos itens; Pré-teste; Avaliação

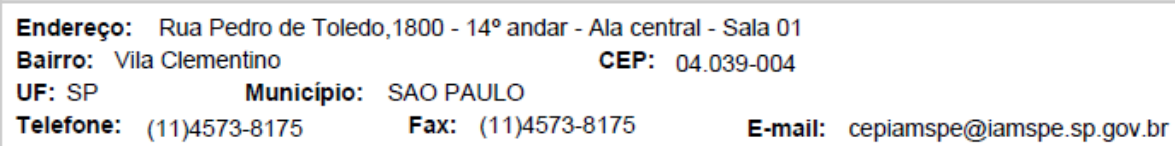




\section{INSTITUTO DE ASSISTÊNCIA MÉDICA AO SERVIDOR PÚBLICO ESTADUAL - IAMSPE}

Continuação do Parecer: 599.965-0

das propriedades psicométricas do instrumento.A coleta será por meio de entrevistas individuais com todos enfermeiros com duração de 10 a 15 minutos realizada pela pesquisadora, no próprio local de trabalho durante todos os dias da semana, nos turnos manhã, tarde e noite.

\section{Consideraçōes sobre os Termos de apresentação obrigatória:}

Foram apresentados a folha de rosto,o projeto de pesquisa,o TCLE para os enfermeiros e juizes e a autorização da pesquisa pelo Diretot tecnico da Divisão de enfermagem.

Recomendaçöes:

Nenhuma

Conclusões ou Pendências e Lista de Inadequações:

Nenhuma

Situação do Parecer:

Aprovado

Necessita Apreciação da CONEP:

Não

Consideraçōes Finais a critério do CEP:

O Colegiado acatou o parecer do relator. Projeto Aprovado.

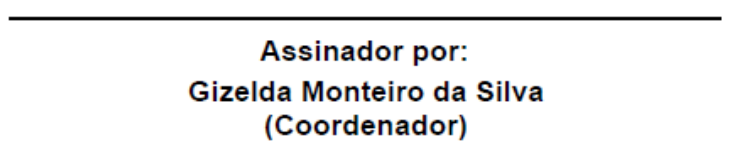

Este parecer reemitido substitui o parecer número 599965 gerado na data 25/09/2013 12:31:53, onde o número CAAE foi alterado de 13906813.6.0000.5393 para 13906813.6.3001.5463.

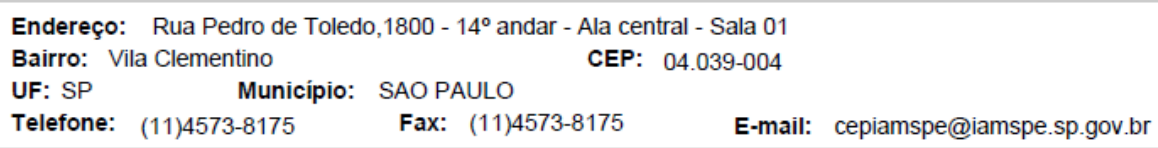

